University of San Diego

Digital USD

1998-07-01

\title{
The Relationship of Self-Esteem, Learned Resourcefulness and Social Support to Health-Related Quality of Life in Long-Term Cancer Survivors
}

Leli W. Pedro DNSc, MS, RNC, OCN

University of San Diego

Follow this and additional works at: https://digital.sandiego.edu/dissertations

Part of the Nursing Commons

\section{Digital USD Citation}

Pedro, Leli W. DNSc, MS, RNC, OCN, "The Relationship of Self-Esteem, Learned Resourcefulness and Social Support to Health-Related Quality of Life in Long-Term Cancer Survivors" (1998). Dissertations. 279.

https://digital.sandiego.edu/dissertations/279

This Dissertation: Open Access is brought to you for free and open access by the Theses and Dissertations at Digital USD. It has been accepted for inclusion in Dissertations by an authorized administrator of Digital USD. For more information, please contact digital@sandiego.edu. 


\title{
UNIVERSITY OF SAN DIEGO
}

Philip Y. Hahn School of Nursing

DOCTOR OF NURSING SCIENCE

THE RELATIONSHIP OF SELF-ESTEEM, LEARNED RESOURCEFULNESS AND SOCIAL SUPPORT TO HEALTH-RELATED QUALITY OF LIFE IN LONG-TERM CANCER SURVIVORS

by

Leli W. Pedro, MS, RNC, OCN

A dissertation presented to the

FACULTY OF THE PHILIP Y. HAHN SCHOOL OF NURSING

UNIVERSITY OF SAN DIEGO

\author{
In partial fulfillment of the \\ requirements for the degree \\ DOCTOR OF NURSING SCIENCE \\ July 1998 \\ Dissertation Committee \\ Louise M. Rauckhorst, EdD, RN, Chair \\ Mary Jo Clark, PhD, RN \\ Geraldine V. Padilla, PhD
}




\begin{abstract}
Increased survival and advances in oncology research demand that health professionals attend to the gap in knowledge regarding health-related quality of life (HRQL) variables associated with the unique sequelae of cancer in the long-term (LT) cancer survivor. Research in this area may direct the development of effective interventions to increase the HRQL of LT cancer survivors. The study's purpose was to describe the relationships between self-esteem, leamed resourcefulness, and social support to $H R Q L$ as well as their predictive value to $H R Q L$ for $L T$ cancer survivors.

A quantitative, descriptive, correlational, and noninterventional design was used to describe the relationship of self-esteem, leamed resourcefulness, social support, and HRQL for LT cancer survivors. Data from six mail-back, self-report instruments were collected from a purposive sample of 456 eligible cancer survivors from two cancer data bases (24.3\% response rate). Descriptive, correlational, and regression statistics were computed.

Study findings revealed: (a) a strongly positive relationship between self-esteem and HRQL ( $r=.69$, p value .00 ), (b) a moderately strong inverse relationship between learned resourcefulness and HRQL $(r=-.32, p$ value .01$)$, and (c) only the total loss component of social support had a statistically significant inverse relationship with HRQL $(r=-.38 ; p$ value .00$)$. Together self-esteem, learned resourcefulness, and the loss component of social support explained over half the variance $\left(R^{2}=.53\right)$ of HRQL with self-esteem accounting for $52 \%$ of the predictive value.

Study findings have implications for nursing research, education and practice. A major implication is the need for assessment and research designed to test interventions aimed at supporting and improving self-esteem for LT cancer survivors. Anticipating and buffering losses of social support may increase HRQL. A survivorship age- and stageappropriate (acute vs. long-term) knowledge base is needed for quality care of LT cancer survivors. Further research in this area may include: (a) study replication with a more diverse sample, (b) testing to refine the study's conceptual model, and (c) path analysis to test the study's conceptual framework or other frameworks related to the process of living as survivors. Lastly, a need exists for broader education about the unique, ongoing concerns of LT cancer survivors.
\end{abstract}




\section{ACKNOWLEDGMENTS}

I wish to acknowledge the members of my dissertation committee, Louise Rauckhorst, EdD, Chair, Mary Jo Clark, Ph.D., and Geraldine Padilla, Ph.D., for their patience and encouraging, consistent input during this important academic and professional process.

My graduate experience germinated and became reality as a result of my treasured relationships with faculty, staff, students and administration of Loma Linda University School of Nursing. Their scholarly, emotional and financial support were daily reminders that no one ever makes it alone. Thanks also goes to the National Institute on Aging for their financial assistance and encouragement in the final stages of the dissertation process and to Wendell Hom who encouraged and assisted me in acquiring this significant funding. In addition Jim Enders of the Desert Sierra Cancer Surveillance Program (Region 5) and Jimmie Loder of Loma Linda University Cancer Institute Cancer Data Center provided invaluable support in the recruitment of study participants.

Finally, my deepest appreciation goes to friends and colleagues whose faithful nurturance were a source of energy and inspiration during the pursuit of this goal. In particular, this degree is a reality for me as a result of the consistent, encouraging presence, and devotion from my family and lifetime partner, Michael Galbraith, RN, PhD. 


\section{TABLE OF CONTENTS}

Acknowledgments $\ldots \ldots \ldots \ldots \ldots \ldots \ldots \ldots \ldots \ldots \ldots \ldots \ldots \ldots \ldots \ldots \ldots$ ii

Chapter 1. Introduction $\ldots \ldots \ldots \ldots \ldots \ldots \ldots \ldots \ldots \ldots \ldots \ldots \ldots \ldots$

Background and Significance $\ldots \ldots \ldots \ldots \ldots \ldots \ldots \ldots \ldots \ldots \ldots \ldots$

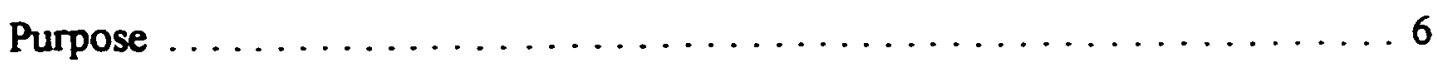

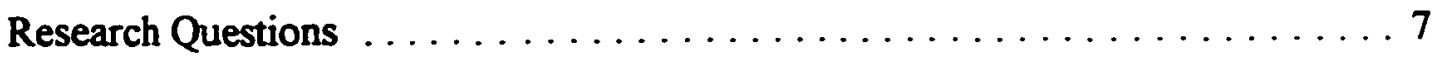

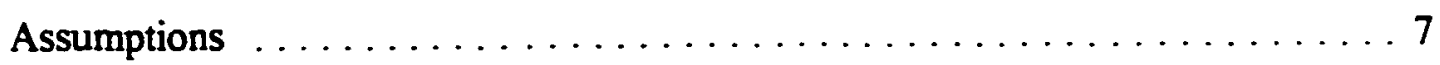

Conceptual Framework $\ldots \ldots \ldots \ldots \ldots \ldots \ldots \ldots \ldots \ldots \ldots \ldots$

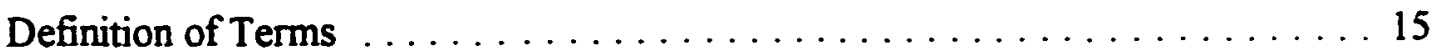

Long-Term Cancer Survivor .................... 15

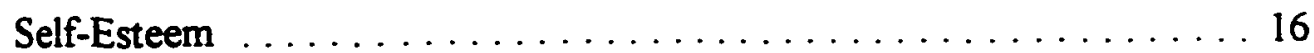

Learned Resourcefulness $\ldots \ldots \ldots \ldots \ldots \ldots \ldots \ldots \ldots$

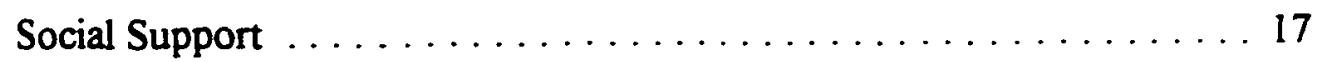

Health-Related Quality of Life $\ldots \ldots \ldots \ldots \ldots \ldots \ldots \ldots \ldots$

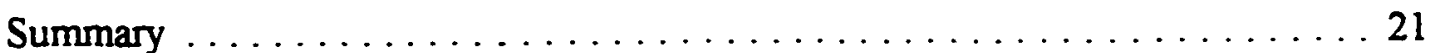

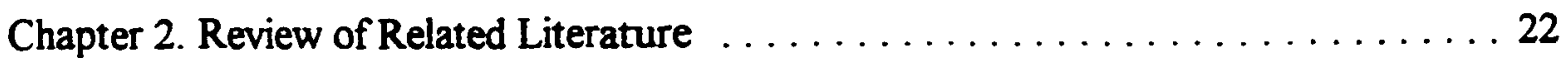

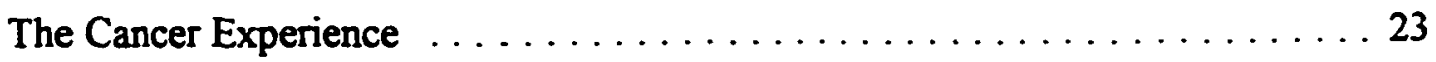

Cancer Survivorship . . . . . . . . . . . . . . . . . . 24

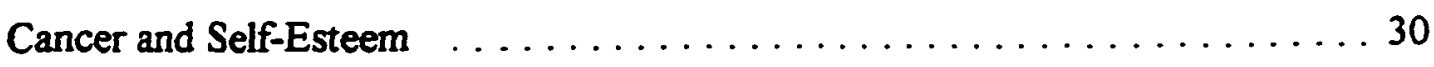

Cancer and Learned Resourcefulness . . . . . . . . . . . . . . 37

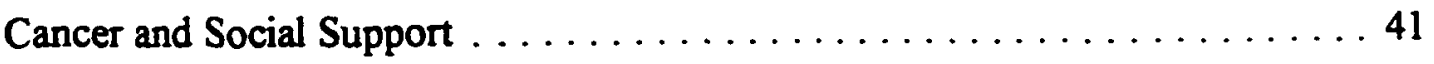

Cancer Survivorship and Health-Related Quality of Life .......... 48

iii 
Critique of Related Research Studies . . . . . . . . . . . . . 63

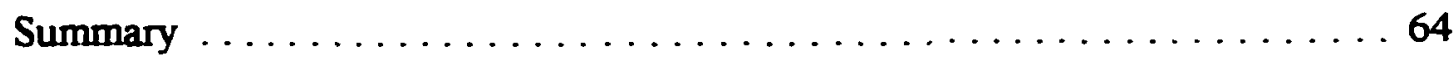

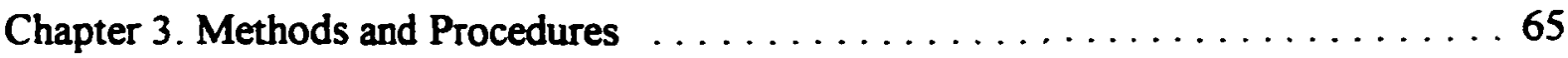

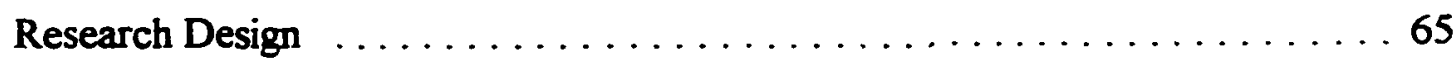

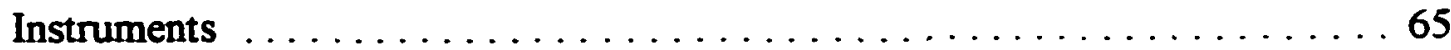

Demographic Profile Sheet $\ldots \ldots \ldots \ldots \ldots \ldots \ldots \ldots \ldots$

Rosenberg Self-Esteem Scale $\ldots \ldots \ldots \ldots \ldots \ldots \ldots \ldots 67$

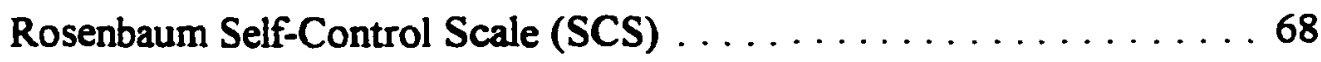

Norbeck Social Support Questionnaire (NSSQ) . . . . . . . . . . 69

Ferrans and Powers Quality of Life Index-Cancer Version (QLI-CV) . 71

Long-Term Cancer Survivor's Quality of Life Inventory (LTCSQLI) . 73

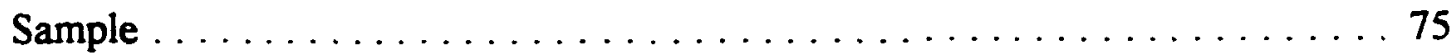

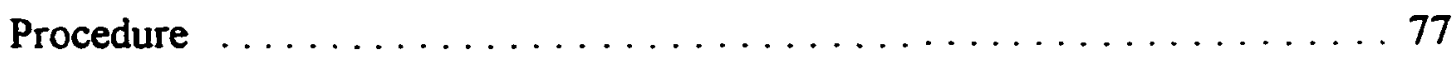

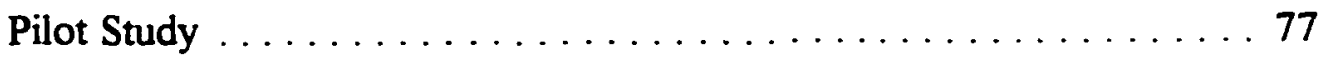

Main Study . . . . . . . . . . . . . . 77

Ethical Considerations $\ldots \ldots \ldots \ldots \ldots \ldots \ldots \ldots \ldots \ldots \ldots \ldots$

Data Analysis . . . . . . . . . . . . . . . . . . . 80

Limitations . . . . . . . . . . . . . . . . . . . . 82

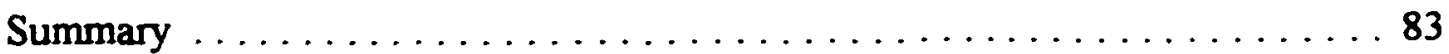

Chapter 4. Results and Discussion of Findings $\ldots \ldots \ldots \ldots \ldots \ldots \ldots \ldots$. $\ldots 4$

Description of the Study Sample $\ldots \ldots \ldots \ldots \ldots \ldots \ldots \ldots . \ldots . \ldots 4$

Age $\ldots \ldots \ldots \ldots \ldots \ldots \ldots \ldots \ldots \ldots \ldots \ldots \ldots \ldots .64$ 
Gender

General Demographics ...................... 86

Cancer Demographics ....................... 87

Presentation of the Findings $\ldots \ldots \ldots \ldots \ldots \ldots \ldots \ldots \ldots \ldots . \ldots 9$

Descriptive Findings . . . . . . . . . . . . . . . . . 89

Findings Related to Research Questions . . . . . . . . . . 91

Relationship Between Self-Esteem and HRQL $\ldots \ldots \ldots \ldots 91$

Relationship Between Learned Resourcefulness and HRQL . . . 92

Relationship Between Social Support and HRQL . . . . . . 93

Self-Esteem, Learned Resourcefulness and Social Support as

Predictors of HRQL . . . . . . . . . . . . . . . 96

Supplementary Analysis $\ldots \ldots \ldots \ldots \ldots \ldots \ldots \ldots \ldots . \ldots 9$

Relationship Between Significant Demographic Variables and HRQL . . . . . . . . . . . . . . . . . 97

Findings Related to LTCSQLI $\ldots \ldots \ldots \ldots \ldots \ldots \ldots .98$

Qualitative Findings $\ldots \ldots \ldots \ldots \ldots \ldots \ldots \ldots . \ldots 9$

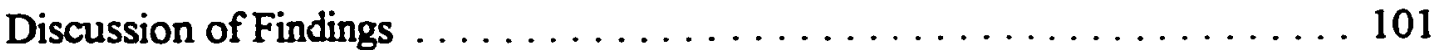

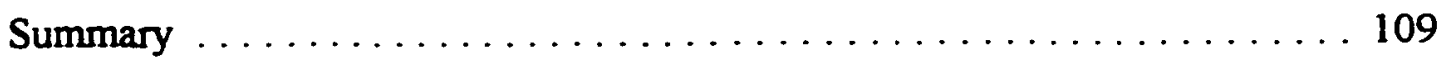

Chapter 5. Summary, Conclusions, and Recommendations $\ldots \ldots \ldots \ldots \ldots \ldots 110$

Summary of Study and Findings $\ldots \ldots \ldots \ldots \ldots \ldots \ldots \ldots \ldots \ldots \ldots \ldots$

Conclusions $\ldots \ldots \ldots \ldots \ldots \ldots \ldots \ldots \ldots \ldots \ldots \ldots \ldots \ldots \ldots \ldots \ldots \ldots \ldots \ldots$

Recommendations for Nursing Practice $\ldots \ldots \ldots \ldots \ldots \ldots \ldots \ldots \ldots$

Recommendations for Nursing Education . . . . . . . . . . . 114 
List of Appendices

Appendix A: Approval Documents for Use of Copyrighted Materials . . . 132

Appendix B: Demographic Profile Sheet $\ldots \ldots \ldots \ldots \ldots \ldots \ldots \ldots \ldots$

Appendix C: Rosenberg Self-Esteem Scale (SES) $\ldots \ldots \ldots \ldots \ldots \ldots$

Appendix D: Rosenbaum's Self-Control Schedule (SCS) . . . . . . . 137

Appendix E: Norbeck's Social Support Questionnaire (NSSQ) . . . . . . 139

Appendix F: Ferrans and Powers Quality of Life Index - Cancer Version (QLICV ............................ 145

Appendix G: Long-Term Cancer Survivor's Quality of Life Inventory (LTCSQLI) .

Appendix H: Approval from University of San Diego Committee on the Protection of Human Subjects . . . . . . . . . . 151

Appendix T. Instinutional Review Board Approval for Loma Linda University Cancer Institute and Desert Sierra Cancer Surveillance Program (Region 5)

Appendix J: Letter to Physicians, Loma Linda University Cancer Institute . 153

Appendix K: Letter to Physicians, Desert Sierra Cancer Surveillance Program (Region 5) ......................... 155

Appendix L: Letter to Potential Participants, Loma Linda University Cancer

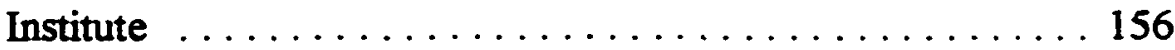

Appendix M: Letter to Potential Participants, Desert Sierra Cancer Surveillance Program (Region 5) ................. 157

Appendix $\mathbf{N}$ : Informed Consent Form $\ldots \ldots \ldots \ldots \ldots \ldots \ldots \ldots \ldots$

Appendix 0: Cover Letter $\ldots \ldots \ldots \ldots \ldots \ldots \ldots \ldots \ldots \ldots \ldots$ 
List of Tables

Table 1: $\quad$ Summary of Characteristics of Instruments Used to Measure the Independent and Dependent Study Variables . . . . . . . . 66

Table 2: $\quad$ Summary of Data Bases, Characteristics, and Participant Selection Process . . . . . . . . . . . . . . . . . . . . . . 76

Table 3: Number of Cases Available, Cases Deleted by Physicians, Packets Mailed, Response Rate, and Usable Data . . . . . . . . . . 79

Table 4: Summary of Statistical Tests Used to Answer Each Research Question ...................... 81

Table 5: $\quad$ Age of the Sample by Category $\ldots \ldots \ldots . \ldots . \ldots 8$

Table 6: General Demographics of the Sample ............ 89

Table 7: Cancer Demographics of the Sample $\ldots \ldots \ldots . \ldots 8$

Table 8: Descriptive Statistics for the Study Variables Self-Esteem, Learned Resourcefulness, and HRQL . . . . . . . . . . . . 90

Table 9: Descriptive Statistics for the Study Variable Social Support . . $\quad 91$

Table 10: Reliability Estimates from Study Sample for HRQL instruments 92

Table 11: Correlation Coefficients for Social Support (NSSQ) and HRQL Using QLI-CV . . . . . . . . . . . . . . 95

Table 12: Correlation Coefficients for Social Support (NSSQ) and HRQL Using LTCSQLI . . . . . . . . . . . . . . 96

Table 13: Forward Stepwise Multiple Regression Statistics for Independent Variables and HRQL Using the QLI-CV . . . . . . . . 97

List of Figures

Figure 1 Diagram of Conceptual Framework for This Study . . . . . . . . 8 Figure 2 Diagram of Modified Conceptual Framework for This Study . . . . 108 


\section{Chapter 1}

Introduction

This chapter provides an overview of the research study reported in this document. It begins with a presentation of the background and significance of the study, followed by the purpose, research questions, assumptions, conceptual framework, and definitions of terms.

\section{Backround and Significance}

The diagnosis of cancer changes one's life forever. Each step of the experience makes a profound impact on the lives and health of those diagnosed with this disease. Change at each step is a movement to a new place which adds another dimension to the experience of cancer. Schag, Ganz, Wing, Sim, and Lee (1994) stated that clients who "survive cancer do not return to a state of normal health similar to that of their healthy peers" (p. 139). They further asserted that cancer survivors have a variety of ongoing concerns that affect quality of life (QOL). It is also well documented that one never "gets over" cancer (Muzzin, Anderson, Figueredo, \& Gudelis, 1994). Although the client may appear normal in everyday life, tensions and anxieties resulting from the diagnosis of cancer and its treatment linger. For survivors, the work of "normalizing", or learning to live with and beyond cancer, is a lifelong career. The lasting repercussions of cancer can take their toll on QOL and health for cancer survivors.

Leaming that one has cancer used to be tantamount to hearing a death sentence. 
With scientific progress and advances in health care, the diagnosis of cancer does not necessarily equal death. According to the American Cancer Society (1995), over eight million Americans alive today have a history of cancer, five million of them having been diagnosed five or more years ago. Most of these five million people can be considered cured, while others still have evidence of cancer. Furthermore, about four in ten clients diagnosed with cancer will be alive five years after diagnosis. Although cancer statistics report decreased or stabilized death rates, the number of deaths from cancer have increased. This is because the over 65 population with cancer has become larger and older (American Cancer Society, 1995). With the reduction of new cancers, decreasing cancer death rates, and rising 5 year survival rates (Anderson \& Lutgendorf, 1997), cancer is a survivable disease for many.

One approach to describing the stages of the cancer experience for the individual is Mullen's (1985) conceptualization of the "Seasons of Survival." The three seasons delineated by Mullen (1985) are "acute survival," "extended survival," and "permanent survival". The first season, acute survival, begins with the diagnosis of cancer. This stage is dominated by medical efforts to prolong life, with individuals being forced to confront their own mortality. Of the three seasons, this stage is most widely documented in empirical and theoretical literature both in nursing and in other disciplines (Bertero \& Ek, 1993; Hassey-Dow, 1990; Richardson, Zamegar, Bisno, \& Levine, 1990).

During the second season, extended survival, the cancer is in abeyance, yet there is constant worry about recurrence. This is usually a period of managing physical limitations resulting from treatment. This phase has more recently been documented in the oncology 
literature with the focus on identifying those at high risk for recurrence and the development of groups and publications to address the needs of persons passing through this difficult "season" (Evans, Thompson, Browne, Barr \& Barton, 1993; Northouse, 1981; Whedon \& Ferrell, 1994).

The third season, that of permanent survival, is more commonly associated with the phenomenon called "cure". Yet it has several dimensions beyond victory over disease. These dimensions are related to the myths about cancer and the stigma surrounding it which persist even with "cure," as well as to the physical sequelae which affect employment and insurability, personal relationships, and one's sense of self. Further empirical examination of the experience characteristic of this phase of cancer survival is needed. Personal and social factors identified in the acute and extended seasons have been described in the literature. Anecdotal literature and qualitative studies of permanent survival also describe these factors. More research is needed which specifically describes the long-term survivor. Furthermore, research concerning the influence of personal and social factors previously identified in research concerning the acute and extended season of survivorship would increase knowledge of the permanent survival phase of life after cancer (Halstead \& Fernsler, 1994; Muzzin et al., 1994).

The diagnosis of cancer, and the person's subsequent confrontation with possible death, is one of life's most intense and powerful stressors. As is characteristic of human responses to most stressors, the cancer client is at once forced to rally physiological and psychological energy to cope with this life-threatening event. The need to cope with a new stressor places additional demands on established living patterns. Facing death suddenly 
changes one's appraisal of and satisfaction with his or her current level of physical, emotional and social functioning. When these aspects change, QOL can be expected to change.

As a concept, QOL encompasses the ideas of having (finance, employment), loving (social relationships, love, and care), and being (individual in society, leisure, and ability to be active) (Allardt, 1980). It is that which makes life and survival valuable (Padilla et al., 1983). QOL has also been described as the difference between actual and perceived goals measured at a particular time (Calman, 1989). The experiences that accompany the diagnosis and treatment of cancer have the potential to alter all domains (physical, psychological, sociological, and spiritual) of QOL (Loescher, Clark, Atwood, Leigh, \& Lamb, 1990; Wyatt \& Friedman, 1996). For example, Wyatt, Kurtz and Liken (1993) explored long-term survivorship through focus group discussions with women who had experienced breast cancer. They found that themes emerged related to each of the domains in their conceptual framework: physical, social, psychological and spiritual well-being.

Quality of life is the umbrella concept under which health-related quality of life (HRQL) falls. The more specific concept of HRQL focuses on the health aspects of an individual's overall QOL. In other words, HRQL is a subset of the more general concept QOL. Often the terms QOL and HRQL are used interchangably in the literature. Although QOL can include HRQL aspects, it is useful for research studies to be explicit about the aspect of QOL under investigation. Further discussion of this important differentiation of the concept QOL is presented in the literature review.

Interest in the relationships between psychosocial factors and disease outcomes 
continues to increase in the fields of psychology and health care. QOL issues and rehabilitation concerns are now salient issues in managing disease and assessing treatment outcomes (Cella \& Tulsky, 1990). According to psychological reviews, approximately $20 \%$ of cancer survivors experience significant psychologic adjustment difficulties (Dobkin \& Morrow, 1986). Schag et al. (1994), in a study on a disease-free sample of lung, colon, and prostate cancer survivors, found psychological distress to be present in all three survivor groups. Thus, it is important to be able to identify survivors at greatest risk for psychological or behavioral problems and, ultimately, increased health problems, as well as those in greatest need of preventive or rehabilitative services. Furthermore, the study of specific variables associated with risk for psychosocial morbidity in long-term survivors is needed.

The ability to prolong life loses some of its value without the knowledge and ability to enhance, not only biological survival, but the psychosocial and physical quality of that survival. Since cancer survivors are expected to live for a considerable period of time, empirically-based knowledge about the consequences of cancer and its treatment on their QOL is of paramount importance (Schag et al., 1994). The knowledge gained from this study can be used by members of the health care team to address two concerns: (a) how to assist long-term survivors during the transition to life after cancer, and (b) how to enhance psychosocial factors leading to high level HRQL for long-term cancer survivors. This knowledge may further be utilized to develop a screening process to identify cancer survivors at risk for psychosocial maladaptation and decreased HRQL. Additionally, the knowledge gained from this study may provide direction for the design of centers whose 
focus will be to provide resources and support (physiological and psychosocial, as well as spiritual) related to the ongoing needs of long-term cancer survivors in the variety of settings in which they reside.

The study's significance relates to the American Nurses Association's (1980) definition of nursing as the "diagnosis and treatment of client responses to actual and potential health problems" (p. 9). Knowledge of the cancer survivor's unique actual and potential health responses during permanent survival will promote greater competence in individualizing nursing care for this specific client group. Studies to date of the variables of self-esteem, social support, and sociodemographic status of cancer survivors and the relationship of these variables to HRQL have primarily focused on the acute and extended seasons of survival. With increased numbers of survivors facing the experience of permanent or long-term survival, questions remain as to the extent to which these variables are present and continue to affect HRQL in this season.

\section{Purpose}

The purpose of this study was to describe the relationships between selected psychosocial variables and HRQL in cancer survivors in the permanent season of survival. The independent variables studied have been identified in the literature as influencing the acute and extended seasons of cancer survival. More specifically, this study describes the relationship between the client variables of self-esteem, learned resourcefulness, and social support and HRQL among cancer survivors in permanent survival. 


\section{Research Questions}

This study sought answers to the following research questions:

1. What is the relationship of self-esteem to HRQL for long-term cancer survivors?

2. What is the relationship of learned resourcefulness to HRQL for long-term cancer survivors?

3. What is the relationship of social support to HRQL for long-term cancer survivors?

4. To what extent are self-esteem, learned resourcefulness, and social suppor. predictive of HRQL for long-term cancer survivors?

\section{Assumptions}

This study was based on the following assumptions about cancer and HRQL for long-term cancer survivors:

1. The cancer experience "permanently" or "significantly" alters one's philosophy of life.

2. Having faced death and survived, HRQL takes on new dimensions for the long-term cancer survivor.

3. Changes and events occurring during the acute and extended seasons of survival influence the experiences of a cancer survivor in permanent survival.

4. When faced with a life-threatening experience, individuals try to find ways to preserve the quality of their life.

\section{Conceptual Framework}

The conceptual framework for this study was derived from a combination of elements from both Mullen's (1985) "seasons of survival" and Ferrell, Grant, and Padilla's (1991) Quality of Life Model Applied to Cancer Survivors as illustrated in Figure 1. 
Figure 1. Diagram of Conceptual Framework for this study.

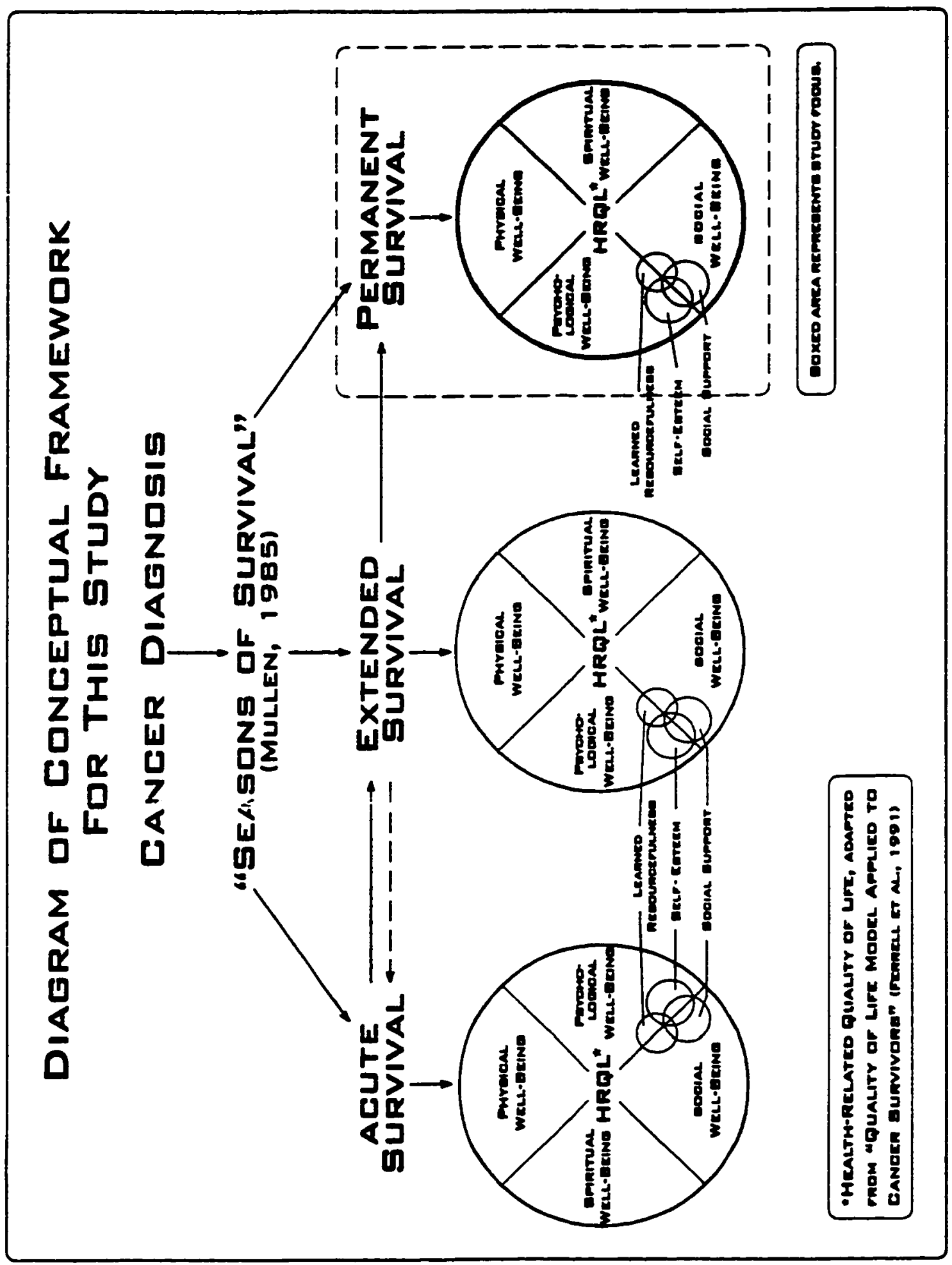


Mullen described the phase or season of cancer survival to be studied, and Ferrell et al.'s model provided the HRQL perspective for this study. The ideas leading to the construction of the study's conceptual framework are discussed below.

Mullen's seasons of survival provide a framework to assist health care providers, as well as clients, to make sense of the individual's complex experiences following a diagnosis of cancer. These three seasons of survival are labeled: (a) acute survival, (b) extended survival, and (c) permanent survival. The first season, acute survival, finds the cancer survivor struggling with the immediacy of mortality that accompanies a diagnosis of cancer. In extended survival, the cancer survivor must deal with the uncertainty that accompanies the effects of treatment and the possibility of recurrence. The possibility of recurrence in the extended season of survival is illustrated in Figure 1 by the dotted line returning to the season of acute survival. This movement back to the previous season is less likely for survivors in the permanent season of survival. Permanent survival describes the cancer survivor who faces issues related to the stigma and myths surrounding cancer plus the physical sequelae which affect self-esteem, and interpersonal and social relationships. The boxed area in Figure 1 identifies the third season, permanent survival, which was the focus of this study in which permanent cancer survivors comprised the targeted sample.

The study's conceptual framework combines the "seasons of survival" with the HRQL model designed by Ferrell et al. (1991), and adapted for cancer survivors. This model originated in previous research on QOL in cancer patients with pain and in bone marrow transplant survivors (Ferrell, Wisdom \& Wenzl, 1989; Ferrell, Grant, Padilla, Vemuri, \& Rhiner, 1991). This model portrays HRQL as multidimensional, a key aspect of 
Ferrell et al.'s conceptualization of HRQL. Drawing on the work of many others, Ferrell et al. (1991) conceptualized four domains of HRQL for patients with cancer. These domains are: (a) physical well-being, (b) psychological well-being, (c) social well-being, and (d) spiritual well-being. Although there are different points of view among scholars regarding the dimensions (attributes of the construct) of HRQL, there is general agreement on the major HRQL domains (sphere or field of concern) as conceptualized by Ferrell et al. (1991).

While stressful life events have been shown to take their toll on HRQL (Cella, 1994; Cobb, 1976; Najman \& Levine, 1981), a number of resources potentially available to the individual have been shown to buffer the effect of negative events such as the diagnosis of cancer (Adler \& Matthews, 1994; Ell, Mantell, Hamovitch, \& Nishimoto, 1989; Heidrich \& Ward, 1992; Schaefer, Coyne, \& Lazarus, 1981; Wills, 1985). Principal among these buffering resources have been personal attributes and the characteristics of the social network. These buffering phenomena have been studied in a variety of circumstances related primarily to the experience of cancer survival during the acute and extended seasons (Bertero \& Ek, 1993; Evans, Thompson, et al., 1993). Studies of these phenomena need to be extended to long-term cancer survivors or those in permanent survival.

Variables associated with HRQL may be found within each of the four domains described in Ferrell et al.'s model (1991). Both quantitative and qualitative studies reporting on the HRQL of cancer survivors in acute and extended survival document the stress and challenge of coping and adaptation in these seasons of survival. The literature also documents the presence of psychological and social variables related to the well-being 
of cancer survivors in both seasons. These include, but are not limited to, mental attitudes toward life, interpersonal relationships, cognitive restructuring of the experience, and the meaning of life as it relates to one's roles and relationships (Cella \& Tulksy, 1990; de Haes \& van Knippenberg, 1985; Padilla, 1992).

There is both quantitative and qualitative evidence to support the proposition that, for the long-term cancer survivor, concerns arise primarily in the psychological and social domains of HRQL (Fredette, 1995; Wyatt \& Friedman, 1996). Therefore, this study was guided by the conceptual framework described above and focused on independent variables in both the psychological (self-esteem, learned resourcefulness) and social (social support) domains of HRQL. Each of these three variables is illustrated by circles within the appropriate HRQL domains in Figure 1. Alterations in the specific variables of self-esteem and social support have been found to be associated with risk for psychosocial morbidity during the earlier survivor period (Curbow \& Somerfield, 1991; Braden, 1990). This study was designed to explore whether this is also true for the long-term cancer survivor. Studies to date have not examined the variable learned resourcefulness in the context of long-term cancer survivorship. Background for the study's focus on these independent variables follows.

Investigators of the first independent study variable, self-esteem, found support for the idea that self-esteem may play a central role in managing the stress of the diagnosis of cancer (Curbow \& Somerfield, 1991). An underlying assumption in these studies is that cancer and cancer treatment are powerful stressors that can have adverse effects on selfesteem. For example, Quigley (1989) reported the importance of self-esteem and body 
image for cancer patients. From another perspective, Heidrich and Ward's (1992) research indicated that positive adjustment of women with cancer may be the result of the ability to manipulate their self-esteem to prevent psychological distress. Other authors described self-esteem as a resource variable that helps individuals withstand the negative effects of cancer (Hobfoll \& Walfisch, 1984). Since self-esteem seems to play a central role in the experience of cancer, its specific influence on HRQL in long-term cancer survival was further explored in this study.

The second independent variable, learned resourcefulness, is a complex concept and is described briefly to identify its place in the conceptual framework for this study. The concept of learned resourcefulness is useful for describing processes occurring in the psychological dimension of QOL (Braden, 1990). Rosenbaum $(1983,1990)$ defined learned resourcefulness as a collection of skills, mostly cognitive, used to control the undesirable effects of certain thoughts, feelings, or sensations so that performance of daily activities will continue without difficulty. The dynamic nature of society creates highly demanding and ever-changing situations which challenge competencies and well-established behavioral repertoires. These challenges, in turn, produce intense physiological and emotional reactions that often have adverse effects on physical and psychological wellbeing. Self-regulation and self-management are learned and maintained mental and psychological self-control processes which allow people to engage in health-related behaviors (Rosenbaum, 1990).

There are four basic assumptions underlying the conceptual model of self-control which is the basis for learned resourcefulness: (a) human behavior is goal-directed; (b) self- 
control behavior is called for when individuals encounter obstacles in the smooth execution of goal-directed behavior; (c) self-control is always associated with certain processregulating cognitions (e.g. assigning meanings to events, attributing causality to what has happened, or developing expectancies for the future); and (d) there are multiple and interactive factors that influence the process-regulating cognitions and the self-control behavior (Rosenbaum, 1990). From these assumptions, three dimensions of learned resourcefulness consistently emerge in nursing and related literature (Zauszniewski, 1995a, 1995b). The first dimension is self-control or self-monitoring of internal events, including thoughts, feelings, and sensations, to prevent interference with task performance (Rosenbaum, 1980). The second dimension is self-direction or taking the initiative to employ problem-solving when faced with stressful situations or conditions (Elkins, 1985). The third dimension is self-efficacy or belief in one's ability to cope effectively when faced with adversity (Rosenbaum, 1983).

These three dimensions of learned resourcefulness, (self-control, self-direction, and self-efficacy) are illustrated in a study of dialysis patients by Rosenbaum \& Ben-Ari Smira (1986). These researchers found a very strong association between the patients' level of learned resourcefulness and their ability to restrict their fluid intake. High resourcefulness dialysis patients adhered more closely to fluid-intake restrictions than did low resourcefulness patients. Path analysis performed on the data revealed that subjects' expectations that they could resist drinking even on a hot day were a function of how they evaluated their own skills as well as their past success in fluid restrictions. Those who were successful attributed their past success to their own efforts and were highly resourceful. 
Thus, high resourcefulness, positive self-evaluations of past performance, and efficacy expectations enhanced self-control, which contributed to the subjects' adherence.

Applying these concepts to the long-term cancer survivor, one might hypothesize that a sense of learned resourcefulness, with the skills of self-monitoring, self-direction and self-efficacy acquired through cancer survivorship, is positively associated with HRQL. Furthermore, a component of learned resourcefulness, cognitive reframing (the notion of PRC's in Rosenbaum's model), has QOL as one of its consequences (Braden, 1990; Braden, McGlone, \& Pennington, 1993). Therefore, the potential influence of learned resourcefulness on HRQL for the long-term cancer survivor needs to be explored.

Psychosocial studies involving cancer patients have examined the influence of the third independent variable, social support, on adjustment to disease and health outcomes (Ell, Nishimoto, Mediansky, Mantell, \& Hamovitch, 1992; Lackner, Goldenberg, Arrizza, \& Tjosvold, 1994; Tempelarr, de Haes, de Ruiter, Bakker, van den Heuvel, \& van Nieuwenhuijzen, 1989; Waxler-Morrison, Hislop, Mears, \& Kan, 1991). This support is provided to the individual through assistance with tasks, provision of material needs, and emotional support from significant others (Caplan, 1974). Studies continue to investigate social support as a variable associated with adaptation to the stress of cancer and its treatment and relationships between support and survival. Study results, although often inconclusive, suggest that an appreciation of the complexity of the construct social support is needed to understand one of the strongest potential resources people have in coping with cancer - the social relationship (Blanchard, Albrecht, Ruckdeschel, Grant, \& Hemmick, 1995; Krishnasamy, 1996). The findings from the studies reviewed lends support to the 
study of the relationship between social support and HRQL, specifically in the long-term cancer survivor. Specific analysis of studies of social support as it relates to HRQL are discussed and critiqued in Chapter 2, Review of Related Literature.

A final concept illustrated in the conceptual framework diagram is the overlap among the independent study variables. The literature supports the influence of social support on self-esteem (Evans, Thompson, et al.1993; Dirksen, 1989; Tempelarr et al., 1989; Wills, 1985). Self-esteem, in turn, has been found to influence learned resourcefulness, a personal characteristic acquired from interactions with athers (Zauszniewski, 1995 b). These ideas will be discussed in further depth in Chapter 2.

\section{Definition of Terms}

Key terms are defined conceptually and operationally as follows. Detailed information regarding each instrument is included in Chapter 3, Methods and Procedures. Long-Term Cancer Survivor

Conceptual definition. This is a person in permanent survival, the third season of survival described by Mullen (1985). This person's focus is on integrating the lasting effects of cancer with entry or transition into a new phase of life. Distinctions are made in the literature between short, intermediate, and long-term survivors because they represent somewhat different phases of the disease, its biology and treatment, and, consequently, the individual's experience.

Operational definition. The long-term cancer survivor in this study was an individual who was living recurrence-free at least 5 years beyond the initial diagnosis of cancer on self-report or as indicated by their physician. 


\section{Self-Esteem}

Conceptual definition. Self-esteem is the affect associated with cognitive selfassessment (Kelman \& Minkler, 1989). Most research on self-esteem in cancer patients identifies self-esteem as a valuable attribute worth preserving. This emerges from the underlying assumption that cancer and its treatment are powerful stressors that can have adverse effects on one's self-esteem.

Research studies on self-esteem in cancer populations have investigated it as an outcome variable (Watson, 1983; Cella \& Tross, 1986) and as a causal agent (Lewis, 1989). Another focus of self-esteem research in cancer literature has been its relationship to QOL (Foltz, 1987; Evans , Pellizzari, Culbert, \& Metzen, 1993). Regardless of the cancer research perspective, the variable self-esteem seems to be an important, central variable in studies of the phenomena accompanying the experiences of cancer clients. In this study, self-esteem is viewed as a determinant of the outcome variable HRQL for longterm cancer survivors. Further discussion on QOL determinants and dimensions is included in Chapter 2, Review of Related Literature.

Operational definition. Self-esteem for this study was operationally defined as the scores on the Rosenberg Self-Esteem Scale (Rosenberg \& Kaplan, 1982). This global measure of self-esteem was developed to assess general feelings of self-acceptance and self-respect. The use of this instrument encompassed the ideas of feelings (affect) and selfassessment included in the conceptual definition chosen for this study.

\section{Leamed Resourcefulness}

Conceptual definition. Learned resourcefulness for this study is a cognitive- 
behavioral repertoire of specific coping skills coupled with belief in one's ability to cope effectively with adversity (Rosenbaum, 1990). The concept of leamed resourcefulness may assist in understanding HRQL for the long-term cancer survivor. There are no studies to date which specifically identify the influence of learned resourcefulness on HRQL in longterm cancer survivors.

Operational definition. Learned resourcefulness for this study was operationally defined as scores on Rosenbaum's (1980) self-control schedule (SCS), a measure of learned resourcefulness. The SCS is a self-report instrument directed at assessing individual tendencies to apply self-control methods to the solution of behavioral problems. The instrument measures enabling skill, one's perceived level of ability to manage adversity.

Three dimensions of resourcefulness have consistently emerged in nursing and related literature: self-control, self-direction and self-efficacy (Zauszniewski, 1995a, 1995b). The SCS was designed to measure four content areas: (a) use of cognitions and positive self-statements, (b) use of problem-solving strategies, (c) ability to postpone immediate gratification of needs, and (d) belief in one's coping effectiveness. Three of the four content areas closely parallel the three conceptual dimensions of resourcefulness identified in the literature: the use of cognition and self-instruction reflects self-control; the application of problem-solving strategies reflects self-direction; and the belief in one's coping effectiveness represents self-efficacy (Zauszniewski, 1995a).

\section{Social Support}

Conceptual definition. Social support is defined as the provision of nurturing interpersonal transactions that involve the expression of positive affect, the affirmation or 
endorsement of the person's beliefs or values, and/or the provision of aid or assistance (Kahn \& Antonucci, 1980; Norbeck, 1981). Many researchers of the concept social support have not defined it explicitly. However, a reasonable consensus exists regarding the concepts' essential components (Lugton, 1997; Blanchard et al., 1995). For this study, social support was defined using the work of Norbeck, Lindsey, and Carrieri (1983) who identified three major components of support: functional aspects (affect, affirmation, and aid), network (number of people, duration and frequency of contact), and loss (number of people and perceived amount of support lost).

Social support has both subjective and functional components. Subjectively, social support is the information that a person acquires which leads him/her to feel loved, valued, and cared for (Cobb, 1976). Affect, affirmation, and aid are the functional components of social support (Kahn \& Antonucci 1980). Affect refers to positive interpersonal transactions; affirmation refers to the endorsement of the person's beliefs or values; and aid is the provision of assistance to the individual. The concept of convoy, an additional aspect of social support, refers to the mechanisms by which interpersonal relationships protect people from the harmful effects of stress (Kahn \& Antonucci, 1980). It is the vehicle through which social support is provided and is measured through three properties of the social network: number of people in the network, the duration of relationships, and the frequency of contact with network members. A variable of secondary interest in this conceptualization of social support is recent losses in the network as the individual's convoy, or primary group providing support, changes over time.

Social support has come to be regarded as a central psychosocial factor positively 
influencing a variety of outcomes, including physical health, mental well-being, and social functioning. Although social support studies, taken as a whole, provide little insight into the precise mechanisms through which social support may influence health outcomes, they do suggest the presence of a powerful variable (Wortman, 1984). Thus, the variable of social support merits serious attention among investigators interested in facilitating positive outcomes, such as increased HRQL, among cancer survivors.

Wortman's (1984) critique of the literature related to social support and clients with cancer suggested that, in selecting a definition of social support for research on cancer, investigators should attempt to be as specific and precise as possible, avoiding definitions that are combinations of diverse assets or phenomena that might protect people, such as self-esteem or locus of control. The social support relevant to the person with cancer facilitates dealing with the multiple uncertainties and fears created by the diagnosis and treatment of cancer. There is an enhanced need for social support as the person with cancer contends with anxieties about treatment, prognosis, pain, recurrence, physical changes and cancer myths and stigma. This can, ironically, undermine social relationships, one of the strongest potential resources for people with cancer.

Qperational definition. Social support for this study was operationally defined as scores on the Norbeck Social Support Questionnaire (NSSQ) (Norbeck et al., 1983) which measures three major components of social support: (a) functional aspects (affect, affirmation, and aid); (b) network (number of people, duration and frequency of contact); and (c) loss (number of people and perceived amount of support lost). This instrument, which measures both subjective and functional components of social support, is congruent 
with the theoretical definition of social support chosen for the study.

Health-Related Ouality of Life

Conceptual definition. In general, HRQL refers to the positive or negative value people place on the health aspects of their lives (Guyatt et al., 1997). HRQL is a personal statement of the positive and negative life attributes of a survivor of a disease such as cancer (Padilla, Ferrell, Grant, \& Rhiner, 1990). For the cancer survivor, HRQL focuses on that which makes life and survival valuable for the individual (Padilla et al., 1983). HRQL includes personal well-being (physical, psychological, social and/or spiritual) in areas important to the individual (Ferrans, 1990). Health-related quality of life for survivors has a temporal component and is viewed as multidimensional, dynamic, and personal. Multidimensionality refers to the various aspects to be considered in the concept such as physical, psychological, social, and spiritual well-being (Ferrell, 1995). HRQL is dynamic and personal in that it evolves and changes according to experiences of the individual. Lastly, there is a temporal component to HRQL. For example, what is described as HRQL by an individual at a given point in time will vary as a function of passing through various conditions and experiences such as cancer.

This study focuses on the more specific concept HRQL, as opposed to the more general QOL concept. Since health care professionals, and nurses in particular, are concerned with the health of individuals, they are most interested in the aspects of life quality that are more directly related to health (such as physical comfort and psychological well-being), rather than aspects such as quality of the environment, finances or employment. This differentiation is discussed further in Chapter 2, Review of Related 
Literature.

Qperational definition. HRQL for this study was operationally defined as scores on Ferrans and Power's Quality of Life Index-Cancer Version (1985). This instrument measures both the importance of and satisfaction with life in the physical, psychological, sociological, and spiritual domains. Secondarily, HRQL was operationally defined as scores on the Long-Term Cancer Survivor's Quality of Life Inventory (LTCSQLI) (Pedro, 1995). At the time of the study there were no validated instruments which specifically measured HRQL for the long-term cancer survivor. The investigator constructed a new instrument specifically to measure the long-term cancer survivor's HRQL: The Long-term Cancer Survivor's Quality of Life Inventory (LTCSQLI) (Pedro, 1995). It was included with the battery of data collection instruments used in this study.

\section{Summary}

This chapter highlighted the significance of studying selected psychosocial factors associated with HRQL for long-term cancer survivors. The conceptual framework for this study is a combination of Mullen's (1985) seasons of survival and the Ferrell et al. (1991) Quality of Life Model Applied to Cancer Survivors. An overview of the independent variables of self-esteem, learned resourcefulness and social support, and the dependent variable HRQL was presented. A description of the strength of association and predictive value of the study variables in relationship to $H R Q L$ is needed to increase the knowledge base concerning HRQL for long-term cancer survivors. With this knowledge, nurses can begin to assess and plan specific approaches to the care and support of long-term cancer survivors that will more effectively facilitate their successful living beyond cancer. 


\section{Chapter 2}

\section{Review of Related Literature}

This chapter provides a review of the literature beginning with an overview of the experience of cancer and cancer survivorship followed by a review of the literature relevant to each of the study variables. Theoretical and empirical literature regarding both the independent variables (self-esteem, leamed resourcefulness and social support) and dependent variable (HRQL) is reviewed and critiqued. Since the body of literature relevant to cancer and each study variable is extremely vast, a representative, rather than exhaustive, review of the literature is presented. Selection criteria included: (a) theoretical and empirical writing frequently cited in nursing, medical and psychosocial literature regarding each study variable, (b) literature described and explored the study variables within the context of HRQL as opposed to global QOL, and (c) literature focused on individual adults in permanent survival rather than on their families or on survivors in the acute or extended "seasons" of survival. Lastly, in the review the independent study variables were viewed as determinants of HRQL (factors that affect HRQL) rather than as dimensions of HRQL (attributes of the construct itself).

In recent decades, professionals in the field of oncology nursing and related disciplines have broadened their approach to include psychosocial, as well as physical, factors involved in the experience of cancer and HRQL (de Haes \& Knippenberg, 1985; Padilla \& Grant, 1985). It is a widely accepted fact that the diagnosis of cancer has far 
reaching and lasting effects on individual lives, including the quality of those lives (Muzzin et al., 1994; Thorne, 1989; Shanfield, 1980). Mullen's (1985) "seasons of survival" paradigm, which identifies acute, extended, and permanent seasons, has been utilized by investigators in oncology (Fredette, 1995; Wyatt et al., 1993) to describe the career of cancer survivors. Survivorship in acute and extended seasons of survival and the effect of variables associated with HRQL during these periods have been studied in both qualitative and quantitative research (Belec, 1992; Evans et al., 1993; Ferrans, 1994; Richardson et al., 1990; Rieker et al., 1989; Schag et al., 1994; Whedon \& Ferrell, 1994). The influence of cancer client variables such as self-esteem, leamed resourcefulness and social support on HRQL and acute and extended survivorship are reported in the cancer literature (Dirksen, 1989; Waxler-Morrison et al., 1991). Empirical study of the variables which influence permanent survival and their relationship to HRQL in that season is needed.

\section{The Cancer Experience}

Cancer as a disease is filled with existential dilemmas, as well as dramatic subjective components of illness, which influence HRQL. Nothing can change an individual's major concerns quite as dramatically or uniquely as the experience of cancer (Anderson \& Lutgendorf, 1997). Recent estimates of the annual number of new cancer cases in the United States (excluding carcinoma in situ of any site and basal and squamous cell skin cancers) have ranged from 1.4 million $(1,359,150)$ in 1996 to 1.2 million $(1,228,600)$ for 1998. The expected numbers of cancer deaths in 1998 in the United States is 564,800 , an average of between 1,000 and 2,000 per day (Landis, Murray, Bolden, \& Wingo, 1998). Although the incidence and prevalence of cancer remain high, a favorable trend has been 
reported for the first time by the American Cancer Society's Department of Epidemiology and Surveillance (Landis et al., 1998). A reduction in the total number of new cancer cases, declining cancer death rates, and improved 5-year survival rates for most cancers (with the exception of lung and bronchus) is reported. In addition, Surveillance, Epidemiology, and End Results (SEER) data confirm a national decrease of $2.6 \%$ in the cancer death rate between 1991 and 1995 - the first sustained decline since record-keeping began in the 1930's (Rosenthal, 1998).

Genetic engineering, diagnostic imaging, and new cancer therapies have allowed health professionals to gain better control over the growth and spread of cancer cells that can result in death. As a result of longer survival periods, clinical concerns have expanded to include, not only patients' physical well-being, but also their psychosocial needs (Loescher, Welch-McCaffrey, Leigh, Hoffman, \& Meyskens, 1989; Welch-McCaffrey, Hoffman, Leigh, Loescher, \& Meyskens, 1989). These needs have become important areas of focus for both research and clinical care. Fernsler, Holcombe, and Pulliam's survey (1984) and Smith and Stullenbarger's meta-analysis (1995) of oncology nursing research cited the need for rigorous nursing research regarding the unique physical and psychosocial needs of cancer clients. These scientific advances and improved methods for cancer screening, diagnosis, and treatment have enabled scientists to begin to challenge the idea of cancer as a metaphor for death.

\section{Cancer Survivorship}

Muzzin et al. (1994, p. 1201) described the experience of cancer as a "career" that one "never really gets over". Additionally, anecdotal work written for lay persons and 
health professionals alike, by both lay and professional writers and survivors of cancer, describes the sense of tremendous lasting impact that accompanies the diagnosis of cancer and the experience of living with cancer (Nessim \& Ellis, 1991; Seligman, 1996).

Studies reviewed illustrated the lasting effects of cancer on QOL. One example is Thome's (1989) phenomenological study of fifteen volunteer informants in the "Life after Cancer" project. The study was designed to explore and describe the experience of adjusting to life without cancer in an effort to understand this phenomenon to facilitate wellness in cancer survivors. The ten female and five male participants in the convenience sample ranged in age from thirty to seventy-four years, and averaged five years since diagnosis with a variety of types of cancer. They had all undergone medical treatment by surgery, radiation, and/or chemotherapy.

Findings revealed that there were lasting physical, psychological and social repercussions from cancer even in the post-treatment absence of disease. Participants spoke of experiencing periodic anxiety, especially when time for the annual check-up approached, and wondering about recurrence or contracting a second cancer. They described lasting social life changes, most often the loss of friends who feared cancer or who disapproved of the patient's management choices. Other types of lasting repercussions mentioned were the residual cosmetic and functional deficiencies resulting from cancer treatments. Although the type and severity of such lasting effects differed, none of those interviewed was entirely free of them. These "cured" cancer patients described a subjective sense of cure that was uniquely defined. These survivors believed that their own approaches and attitudes, as well as those of their professional and personal health care resources, determined their QOL after 
cancer.

The researchers concluded from the findings that: (a) wellness is not an automatic sequel to being cured of cancer, (b) active involvement and personal control are central to QOL in all stages of survivorship, and (c) health care providers have an important role in facilitating survivorship. In addition, the study findings supported the argument that health care professionals can be more effective if they modify their anti-cancer imagery and attitudes. Lastly, the accounts from survivors indicated that they believe health care providers have some responsibility for the QOL patients experience during and after cancer. The validity of these qualitative findings is limited by the sampling method. This sample of volunteer informants recruited through word of mouth may not be representative of all long-term cancer survivors. On the other hand, the process of simultaneous data collection and analysis provided continuous affirmation, revision or deletion of assumptions. Interrelationships between themes were subjected to ongoing validation by the informants. This ensured that abstractions remained grounded in the data.

Another descriptive study illustrating the lasting effects of cancer (Polinsky, 1994) included a purposive sample of 223 breast cancer survivors who were Reach to Recovery volunteers and 16 months to 32 years beyond their original surgery for breast cancer. Selfreport questionnaire booklets were used for data collection and included a demographic profile, general functional assessment using the profile of mood states and the 200-item Short Form Health Survey from the RAND corporation's Medical Outcomes Study, and an author-generated instrument, the Breast Cancer-Specific Measure adapted from the Cancer Rehabilitation Evaluation System. 
The findings document the chronic nature and ongoing impact of the illness, including continued physical symptoms (such as pain and numbness), continued thoughts about the possibility of recurrence, insecurity about medical follow-up, and the willingness or unwillingness of others to discuss cancer and its long-term effects. Although the general measures of functioning indicated high levels of physical, psychological, and social functioning in breast cancer survivors, the findings specific to breast cancer diagnosis and treatment indicated multiple problems and concerns. Polinsky (1994) concluded that, although breast cancer survivors do well in general, long-term survivorship involves many physical, psychological, and social effects and that normalization of commonly occurring effects could greatly enhance the QOL of a breast cancer survivor who needs to know she is not alone.

Limitations of the study included that the sample consisted of a special group of breast cancer survivors who were more knowledgeable than the average woman as a result of their training by the American Cancer Society as role models for newly-diagnosed breast cancer patients. Therefore, the results are not generalizable to breast cancer survivors without this special training.

Guillory's (1992) study sought to answer the question, What comprises survivorship?, by testing a theoretical causal model that postulated cancer survivorship as a function of selected age, marital status, life satisfaction (quality of life, social support, self concept, and spirituality), and physiological status (immune status, stage of disease, and treatment modality). A non-experimental research design with structural equation modeling and latent variables was used with a purposive sample of 135 women diagnosed with breast 
cancer. The study utilized the following valid and reliable measures: Ferran's Quality of Life Index - Cancer Version, Brandt and Weinert's PRQ-85, Rosenberg's Self-Esteem Scale, Reed's Spiritual Perspective Scale, and Dow's Adaptation After Cancer Profile.

The main findings from the study revealed life satisfaction to be the only latent variable to merge, or overlap, with other variables, and that further study was needed to construct and test the theoretical model underlying survivorship. Other findings indicated that: (a) social support, and not quality of life, contributed most to variance in the life satisfaction score, (b) uncertainty over the future was a major factor of survivorship, (c) social support was an enhancer of mastery over cancer, and (d) there were no differences in the IgM levels between women diagnosed less than five years versus those diagnosed over five years ago. Limitations of the study included a probable sample bias towards African American women with breast cancer who were socioeconomically disadvantaged and the use of instruments found to be somewhat culturally insensitive (Guillory, 1992).

A review of the literature addressing the needs of survivors indicated that they have a multitude of unique and unmet needs (Gambosi \& Ulreich, 1990; Rose, 1989). Stalker, Johnson, and Cimma (1989) conducted a needs assessment telephone interview survey for the development of a support program for cancer survivors among 200 former cancer patients who had completed treatment at a cancer center. Data were collected using a Likert-type scale on which subjects indicated their degree of concern about 12 aspects of life, including job or work situation, changes in relationships with family, changes in relationships with friends, finances, general physical health, general frame of mind, appearance, health or life insurance status, personal or intimate physical relations, ability to 
have children, ability to discuss past illness with friends, colleagues and family, and planning for the future.

Statistical analysis compared concerns of individuals who had completed treatment within the previous 24 months with concerns of those who had completed it more than 24 months earlier. No significant differences were found between the two groups $(p<.05)$ regarding the degree of their concerns. Respondents in the group that had completed treatment more than 24 months before the survey indicated that their concerns had failed to diminish. In fact, in some areas their concerns had increased.

Stalker et al. (1989) reported that sixty-seven percent of the survivors had received some kind of support or information that had helped them to return to normal life after treatment. Resources used included family, friends, hospital physician, hospital nurse, patient's own physician, hospital social worker, other hospital staff, group services from agencies, and community-based organizations. However, almost one third (32\%) of the sample indicated they had received no help or information from any source. The results of the study indicated that former patients desire and need additional services and that their projected use of such services was high. However, respondents' predictions of use would not necessarily match actual use.

The results of the study cannot be generalized beyond the study sample who were primarily married, employed individuals between the ages of 40 and 60 . The study did not compare the sample with the general population, yet provided a comparison of concern for each potential problem area. Studies such as this support the need to study comprehensively the unique needs of the long-term cancer survivor, as well as the type of resources which are 
most useful in meeting their unique needs at different stages of survivorship.

The cancer survivorship studies cited above all had different research questions. Their findings all indicate that multiple factors are associated with survivorship. The findings of each of these studies also indicate that survivorship is unique for each individual and that care must be taken when generalizing results to groups of survivors who differ in relation to cancer site, age, gender, ethnicity and stage of survival.

No concept analysis for survivorship or survival, which are necessary for the delineation of a theory of survival, was found in the theoretical literature. A dilemma facing researchers who are interested in studying cancer survivors is the way terms such as survivor, survivorship and related concepts and constructs are defined. Early survivor studies dealt with the concept of survivor as victim (as in survivor of stroke) as compared to the concept of survivor as victor in later studies. There seems to be difficulty in conceptualizing a clear and more positive definition for cancer survivorship. Thus, the literature is more helpful in defining associated concepts such as resilience (Wagnild \& Young, 1993), hardiness (Pollock, 1986; 1989), rehabilitation (Watson, 1992) and quality of life (Aaronson, 1988; Padilla \& Grant, 1985). Despite this lack of clarity, the literature challenges researchers to apply what is known about these concepts and the process of survival in the acute and extended seasons to the care of the growing population of survivors in the permanent season of survival.

\section{Cancer and Self-Esteem}

The term "self-esteem" is frequently used interchangeably with "self-concept" in the literature. It is important to be aware of the differences in meaning that exist between these 
two concepts. George (1980) differentiated between them by describing self-concept as the cognitive aspect of self-perception, that is, what one thinks about oneself in an objective fashion, or "how I see myself." In contrast, self-esteem refers to the affect associated with cognitive self-assessment, or "How I feel about how I see myself". Within the context of QOL, the concept self-esteem seems more predominant. Perhaps this is related to the emotional nature of self-esteem which is conceptually congruent with QOL, a personal or subjective statement of the attributes of one's life.

Research data indicate that self-esteem is dynamic and serves as a mediator in the process of adjustment to cancer via affirmation from either family, friends or health care providers (Polinsky, 1994; Thorne, 1989). Wills (1985) further documented that interpersonal relationships serve a supportive function by strengthening a person's selfesteem through the experience of feeling accepted and valued by significant others. The following sampling of self-esteem studies provide a background for the inclusion of this important variable in the present study of long-term cancer survivors.

The purpose of a study by Dirksen (1989) was to test and expand a theoretical model which predicts subjective well-being, specifically the influence of locus of control, social support, and self-esteem on well-being in individuals diagnosed with cancer. The independent variables locus of control (internal, external, chance and powerful others), social support, and self-esteem were causally ordered in a theoretical model with well-being as the dependent variable. Data from self-administered questionnaires were collected from a convenience sample of 75 primarily male, Caucasian, married and well-educated subjects diagnosed with malignant melanoma. Months since diagnosis ranged from under 12 to over 
108 months. The mean age of the subjects was 55.2 years with a range of 25 to 83 years. The subjects spoke and wrote English. Valid and reliable study instruments included: the Cancer Health Locus of Control Scale, the Norbeck Social Support Questionnaire, the SelfEsteem Inventory, and the Index of Well-Being. Findings on mean scores revealed that a moderately high level of internal locus of control and self-esteem, a low level of social support and a high level of well-being were reported by this sample. Self-esteem was found to have a significant positive relationship with well-being. In addition, social support was found to be a significant predictor of the level of self-esteem in the study population. Stepwise multiple regression analysis and graphic residual analysis, a type of exploratory data analysis, were used to ascertain any violation of causal and statistical model assumptions.

The study findings supported prior research in which self-esteem was found to be an important determinant of subjective well-being (Dirksen, 1989). The lack of a significant relationship between social support and well-being were explained by the researcher using averages of NSSQ scores. This strategy was intended to avoid problems in multicollinearity, yet it may not have been completely resolved the problem. The lack of support for the predicted relationships between internal locus of control and self-esteem or well-being were attributed, in part, to inability of the Cancer Health Locus of Control scale to tap the full domain of internal control for this sample of cancer survivors.

Dirksen (1990) proposed further research on: (a) specific additional model variables to explain the remaining variance in well-being using a larger sample with different cancer diagnoses to reduce the risk of a Type II error, and (b) the missing variable(s) influencing 
self-esteem, particularly since it has such a significant impact on well-being.

The study's strength lies in the fit between the conceptual framework and the chosen study design. The small convenience sample limits the generalizability of the findings. Since the sample was primarily male, married, Caucasian, and well educated, the findings are not generalizable to melanoma patients who are female, unmarried, of different ethnic backgrounds, and/or less educated.

As part of a larger study on quality of life, Tempelarr et al. (1989) set out to find answers to the following research questions: (a) what are the positive and negative experiences of cancer patients in their social interactions in comparison to the experiences of the 'normal population'?, and (b) can the prevalence of positive and negative social experiences among cancer patients be predicted on the basis of sociodemographic factors, medical factors, the possibility of continuing role activities, and personality characteristics? The investigators compared the positive and negative social interaction experiences of 109 cancer surgery patients and 108 chemotherapy patients from the Netherlands to those of a "normal" control group without cancer $(\mathrm{n}=200)$.

Participants were approached by their physicians once they had begun treatment. A questionnaire, cover letter and return postage envelope was sent to each participant. The control group was randomly selected from the telephone directories for the same residential areas as those of the patients. Ages of participants ranged from 16 to 86 years. To measure the dependent variables of positive and negative social experiences, a tool was constructed by the investigators to measure negative experiences and an existing tool measuring positive experiences was adapted and expanded. Sociodemographic and medical factors were 
collected from patient records. Role activities were taken from a validated Dutch ADL (Activities of Daily Living) list. Personality characteristics (neuroticism and self-esteem) were measured by a subscale from the Dutch Personality Questionnaire and Rosenberg's self-esteem scale respectively (Tempelaar et al., 1989).

Using the Students' t-test to compare mean scores on the positive and negative experience-scale revealed that the patients undergoing surgical treatment for cancer had more positive and fewer negative social experiences than the controls. The same was true for chemotherapy patients, with the exception of scores on positive item 5 which indicated that they experienced having received the same amount of useful information as the control group. Correlations of positive and negative experiences with sociodemographic variables revealed that for the surgical treatment patients: (a) age and sex were related to positive and negative experiences, (b) older patients had fewer positive and negative social experiences than younger patients, and (c) women reported more positive and more negative experiences than men. Results from an analysis of variance and multiple comparison using the Scheffe test revealed that the worse an individual's medical condition, the more help and support the individual perceived to be available. Personality characteristics, particularly selfesteem and neuroticism, were found to be significantly related to the positive and negative outcomes of social interaction. Positive social experiences were associated with a greater feeling of self-esteem, and negative social experiences with neuroticism or low levels of self-esteem (Tempelaar et al., 1989).

A study limitation was the variation in sociodemographics (age and gender) between the study and control groups. Thus, one cannot explain the differences in positive and 
negative social experiences by differences in age and gender. The study design was appropriate for the research questions and the sample size was adequate. Validity and reliability data for the study instruments were not provided, which limits the ability to interpret the findings.

Heidrich and Ward (1992) took a different approach to the study of self-esteem by proposing that people may adjust to their illness through a redefinition of the ideal self which, in turn, enhances self-esteem. The sample for their descriptive study consisted of older women ranging in age from 66-93 years. These community-dwelling elderly women had participated in a prior study and were recruited through various religious, civic and social organizations. They were mostly widowed, retired and lived alone. The seventeen women with cancer were compared with a randomly selected group of women without cancer $(n=30)$. The women with cancer were more educated and slightly better off financially than elderly women in the comparison group. This was possibly due to the specific type of women at community, church, and civic organizations from which they were recruited. The women completed survey materials that were distributed at these meetings at home and returned them to the researchers in prepaid envelopes. A multivariate analysis of variance compared the 2 groups of women on health variables (mean scores on the Older Americans Research Services - Schedule of Illnesses), self concept (mean scores on the actual, ideal, and self-discrepancy scales), psychological distress (mean scores on Center for Epidemiological Studies-Depression Scale) and well-being (mean scores on Neugarten's Life Satisfaction Index-A).

Secondary analysis of data compared the study group and the comparison group on 
measures of psychological distress and well-being, actual self, ideal self and the discrepancy between actual and ideal selves. The women with cancer scored significantly lower $(F=3.13, p<0.05)$ than the comparison group only on ideal self-ratings. The proposed explanation for the difference was that women with cancer adjust positively as a result of their ability to lower their ideal-self expectations, thus reducing discrepancies regarding the self that can result in psychological distress. The use of two comparison groups of women and statistical analyses performed were appropriate for the conceptual model outlined for this study. The unusually high response rate $(93 \%)$ may be related to the monetary incentive offered to the participants ( $\$ 10$ to the participants, or the organization of their choice). Heidrich and Ward (1992) proposed using larger samples, longitudinal study designs, and focusing on other disease experiences to strengthen further research in this area.

The findings in this sampling of self-esteem studies support the importance of the role of self-esteem in the cancer experience, as well as the value of its continued study. This complex, dynamic concept has been examined using different approaches. It has been examined both as an independent variable (Dirksen, 1990) and as a dependent variable (Heidrich \& Ward, 1992). Self-esteem is reported to be a mediator in the process of adjusting to cancer (Polinsky, 1994). This review provides support for further study of this variable as it applies to the experience of cancer in general and its inclusion as an independent variable in the current HRQL study with long-term cancer survivors. 


\section{Cancer and Leamed Resourcefulness}

Learned resourcefulness is a personal characteristic acquired through interactions with others and demonstrated in one's abilities to independently manage daily activities (Rosenbaum, 1990). It's utility may include the promotion of adaptive, healthy lifestyles (Zauszniewski, 1995a).

The experience of cancer not only takes a toll on an individual physically, but also psychologically and emotionally. Anecdotal reports from individuals with cancer often include a description of the powerful effect the disease has on their psyches, which then leads them to try and make sense of the experience via multiple cognitive strategies.

Therefore, learned resourcefulness is a concept that may have relevance in the exploration of the human experience of cancer survivors.

Cowan, Graham, and Cochrane (1992) hypothesized that cognitive adaptation (a skill encompassed within learned resourcefulness) is directly related to perceived quality of life. The concept has received increasing attention in the theoretical literature (Zauszniewski, 1995b; Mishel, 1990) and has been included as a variable in a number of nursing studies focused on clients with chronic illnesses (Braden, 1990; Braden et al., 1993; Hinds, 1990; White, Tata, \& Burns, 1996). However, studies exploring this variable's influence on life quality - and, more specifically, the life quality of cancer survivors - are limited. The following section includes a review of the studies of learned resourcefulness which provided a background for the inclusion of this variable in the current study.

Hinds (1990) conducted a retrospective cross-sectional study which included the variable learned resourcefulness, among 6 others, in a QOL study of patients with lung 
Survivors HRQL 38

cancer. The study's main purpose was to determine whether relationships existed between patients' preferences for illness-related information, their satisfaction with family functioning, their level of learned resourcefulness, and their reported QOL.

The sample consisted of 87 patients with lung cancer who ranged in age from 38-82 years. The majority were high school- educated, married males ( $72 \%$ males, $28 \%$ female). Length of time since diagnosis ranged from less than 3 months to more than 24 months. Information about stages of diagnosis and types of treatment was not available in the report. Data were collected using self-administered structured questionnaires. The specific instruments used to measure the study variables were not described in the report.

Stepwise multiple regression analysis revealed $30 \%$ of the variance in QOL for this population to be explained, in decreasing order of magnitude, by prognosis $\left(R^{2}=0.07\right)$, surgery $\left(R^{2}=0.07\right)$, current radiotherapy $\left(R^{2}=0.04\right)$, performance status $\left(R^{2}=0.03\right)$, selfcontrol skills (learned resourcefulness) $\left(R^{2}=0.03\right)$, the amount of information patients preferred $\left(R^{2}=0.03\right)$, and the patients' age-group $\left(R^{2}=0.03\right)$. Learned resourcefulness was found to contribute only $3 \%$ of the variance in QOL explained by the combination of 7 predictor variables in this population of lung cancer clients. Hinds (1990) concluded that: (a) since no single factor contributed a substantial amount of the variance in this sample, individuals differed in their perception of the importance of these factors on their QOL, and (b) QOL is subjective, dynamic and depends on the circumstances an individual faces. The research report did not relate the findings to those reported in published studies with similar variables, which limits the context in which to interpret the findings. Description of the specific instruments used in this study and data concerning their validity and reliability were 
not reported. The findings can only be generalized to similar samples (i.e., primarily married males with hung cancer). However, the results are a step towards the identification of factors which influence well-being and QOL for lung cancer patients.

Braden (1990) also conducted a study of the relationship between learned resourcefulness and life quality. This study was the second test of Braden's Self-Help Model and was implemented to gain understanding of the essential dynamics of the learned response to the chronic illness experience. This five-stage Self-Help Model includes a description of factors that decrease self-help and life quality and factors that increase learning a self-help response that leads to an increased life quality. The model recognizes that individuals need to use a repertoire of enabling skills to meet both the situational and cognitive challenges of an illness. The model is parallel to Rosenbaum's (1990) conceptualization of learned resourcefulness which describes enabling skills as a mediator between the direct interference of disruptive forces and learning a self-help response that contributes to increased QOL.

The convenience sample consisted of 396 adults, diagnosed with rheumatoid arthritis $(43 \%)$ or arthritis-related conditions (57\%). The ages of subjects ranged from 18 to 88 years $(\bar{x}=57$ years) Eighty-six percent of the sample were women. Most subjects were married (59\%), white (85\%), college educated (58\%), had attended some type of self-help class within the past 3 years $(58 \%)$, and had an average household income of $\$ 20,000$. The mean number of years ill was 15 years.

A correlation matrix of model variables was used in the multiple regression equation to answer the research questions. The following independent variables were included in this 
model: disease characteristics, background inputs, monitoring, severity of illness, dependency, uncertainty, enabling skill, and self-help. The dependent variable was life quality. Subjects completed the mail-back Self-Help in Chronic Illness Questionnaire which contained randomly ordered items from seven scales. The seven scales and the variable each measured were as follows: the Krantz Health Opinion Survey Information Subscale measured monitoring, the Disease Course Graphic Scale measured severity of illness, the Reliance Scale measured dependency, the Mishel Uncertainty in Illness Scale measured uncertainty, Rosenbaum's Self-Control Schedule measured enabling skill, the Inventory of Adult Role Behavior measured self-help and the Index of Well-Being measured life quality. All instruments were scaled according to a visual analog response format. Detail including instrument author, number of items, instrument scoring, conceptual definition for each variable, adequate standardized item Cronbach's alpha and omega values for the study sample were included in the report. A causal modeling approach was used to test each stage of the Self-Help Model.

Findings revealed that enabling skills were the strongest predictor of self-help by minimizing the influence of uncertainty and dependency on self-help. Findings also revealed self-help to be a strong predictor of life quality $\left(R^{2}=.47\right)($ Braden, 1990). Braden concluded that the findings support interventions that enhance enabling skills, increase selfhelp, and reduce dependency and uncertainty; and that this will subsequently result in increased life quality.

A major strength of this study is the clearly developed and described theoretical framework from which the research questions and causal modeling approach were 
constructed. Study instruments were appropriate (with adequate validity and reliability data reported) for the variables included in the model. Characteristics of the sample limit generalization of the study findings to similar groups of primarily college educated, married, white women with arthritis or arthritis-related conditions.

The review of research studies on learned resourcefulness in cancer and chronic illness documents the ability of individuals to help themselves when faced with situations that impinge on QOL. In general, the study findings support learned resourcefulness as a significant variable in explaining QOL and lend support to the inclusion of this variable in the current HRQL study.

\section{Cancer and Social Support}

Historically, cancer has assumed symbolic aspects that make it, at least theoretically, a social phenomenon (Veronesi \& Martino, 1978). It is a disease that often affects people in age groups that are most socially productive. It is also the product of a society unable to control carcinogenic substances in the environment, as well as the interaction of environmental factors, lifestyle, and heredity. An additional aspect that gives cancer its social definition is the belief that it is a painful disease which leads to social isolation and death. It has become a symbol of terror and torture that has both physiological and psychological consequences.

Since cancer has become identified as a social phenomenon, some aspects of the cancer experience can be addressed by utilizing social resources. For example, the National Coalition for Cancer Survivorship and survivors of other life-threatening health problems has found that individuals who have successfully survived the trauma of cancer or similar 
losses constitute a psychosocial resource for other survivors of life threatening health problems like cancer (Card, 1993). Further, in an examination of connections between social ties, health status, and death, Berardo (1985) discussed research which provided strong evidence for the life-enhancing properties of social relationships and networks.

According to social exchange theory, social support provides the individual with needed resources of love, information, worth, tangible aid, and companionship through interpersonal transactions. Social support is also viewed as acting to protect or buffer people from the psychological stress of daily life and life-threatening illness. Regular social interaction increases access to useful community resources, as well as having a pervasive positive effect on mood, emotional states, self-esteem and self-acceptance (Wills, 1985).

The literature on social support is vast and indicates that it is a complex concept. The oncology literature alone is rich in the continued study of this important variable in the cancer experience. Blanchard et al. (1995) and Krishnasamy (1996) both provide comprehensive reviews of social support in adaptation and adjustment to cancer and survival. An in-depth review of the social support literature is beyond the scope of this dissertation. Thus the primary aim of the sampling of empirical studies that follows is to highlight the significant role of social support in cancer survivorship.

Ell et al. (1992) reported on a prospective examination of the relationship between two social relationship indicators (material status and social integration) and one social support indicator (perceived adequacy of emotional support from close ties) and survival following diagnosis of breast, colorectal, or lung cancer. Data were obtained from a sequential sample of 369 patients from the cancer registries of 23 hospitals affiliated with the 
Cancer Management Network of the University of Southern California's comprehensive Cancer Center. Structured interviews were conducted in patients' homes by experienced, graduate-level social workers. Valid and reliable instruments included the following: Duncan's Socioeconomic Index, the Role-Limitation Measure used in the Rand Health Insurance Study, the AVSI and ADAT scales from the Interview Schedule for Social Interaction, and the Mental Health Inventory developed for the Rand Health Insurance Study. Univariate and stepwise multivariate analyses were conducted using the Cox proportional hazards model. To control for effects of cancer site and stage, the analyses were conducted separately for each cancer site (breast, colorectal and lung) and for those with localized versus non-localized cancers.

Findings provided evidence to suggest a positive relationship between social support and survival, although social support was not found to be the sole or primary mechanism. Stepwise multivariate analyses were conducted by cancer site to identify which of the following factors were independently predictive of survival: stage of illness, role limitations, adequacy of emotional support, availability of social integration, marital status, and psychological distress. The multivariate models which emerged differed by cancer site. Marital status was the only significant risk factor and emotional support the only significant protective factor predicting survival for patients with breast cancer. For patients with colorectal or lung cancer, stage of illness and role limitations were the only significant risk factors predicting survival. The models which emerged in the analysis by cancer stage also differed. Role limitations and adequacy of emotional support were significant predictors of survival for patients with localized cancer. In patients with more advanced disease, stage of 
illness was a significant predictor of survival. The multivariate regression models also suggested that emotional support from primary network members is protective with respect to survival during earlier stages of disease and among women with breast cancer. No such effect was found at more advanced stages of illness or among lung or colorectal cancer survivors.

The investigators concluded that the relationship among these variables may operate differently depending on cancer site and extent of disease. Although findings indicate that social relations and social support are strong, positive predictors of survival in relation to different cancer sites and extent of established disease, the study did not examine the interactional processes of social support following a new diagnosis. Thus caution must be taken not to extrapolate the findings to patients with a new diagnosis of cancer. Study instruments were appropriate (with adequate validity and reliability data reported) for the study variables. Sample size was adequate for the statistical tests used. Results included comparisons between sample characteristics of patients who were survivors and those who were deceased. This was helpful in determining any bias in sampling. Characteristics of the sample limit the study findings to similar groups of primarily female, married, Caucasian women with breast cancer.

A qualitative study of 47 breast cancer patients by Lugton (1997) sought to answer the questions "What is the essence of social support?" and "Why does it promote wellbeing in recipients?" Twenty-nine women attending a breast unit clinic were interviewed in the clinic. Eighteen more patients were interviewed at home. Twelve open-ended questions were used to explore their anxieties and sources of support. Following this, their 
perceptions of the nature and value of the support that volunteer health visitors provide at various stages of the disease were explored. Grounded theory methodology and social contact analysis were used to enhance the knowledge gained from interviews. Each patient also drew her social network, placing herself at the center and including all people with whom she had had contact since diagnosis. She then described supportive and nonsupportive ways in which her social network had reacted to the illness.

In addition to the social contact analysis, discourse analysis was employed to analyze patients' statements about social support. Respondents reported facing six threats to their identities associated with the breast cancer experience (uncertainty/mortality, threats to a healthy identity, threats to autonomy/independence, isolation/stigma, threats to sexuality, and threats to normal relationships) and perceived social support to be actions/attitudes from formal or informal sources which maintained or assisted changes to their established identities. Data provided evidence concerning how others can enhance or undermine these identities and the vital role of informal support in maintaining identity as a means of coping with breast cancer (Lugton, 1997). Lugton concluded that the findings support the promotion, maintenance and creation of effective informal support strategies to enable breast cancer patients to pass through the critical phases of cancer with greater selfacceptance.

The strength of this qualitative study is reflected in the mechanisms used to increase the reliability and accuracy of findings. For example, two or three interviews were conducted with a follow-up interview a year after the first contact with respondents. Network diagrams increased the reliability of the interviews by providing an opportunity for 
patients to confirm or refute what they had said during interviews. Generalization of the study findings, however, is limited to women with breast cancer who attend breast clinics.

Social support has also been found to contribute to self-esteem. Dirksen (1989) used a nonexperimental, correlational design with a causal modeling approach to investigate the relationship of variables, including social support and self-esteem, to the well-being of survivors of malignant melanoma. The sample consisted of 31 Caucasian malignant melanoma survivors who had a mean age of 55.2 years (range $25-83$ years). Twelve were male $(38.7 \%)$ and 19 were female $(61 \%)$. Sixty-eight percent $(n=21)$ were married. The gross family income of the majority was between $\$ 30,000$ and $\$ 39,000$ with income levels ranging from below $\$ 10,000(n=2)$ to above $\$ 60,000(n=10)$. Most of the subjects were either employed full-time $(n=14,45 \%)$ or were retired $(n=13,42 \%)$. Thirty-nine percent $(n=14)$ of the sample had a college education, with $23 \%(n=10)$ having a graduate or professional degree.

Multiple regression analysis was used to test the strength of the predicted relationships in the conceptual framework for the major study variables. Path analysis used to analyze the relationships among internal locus of control, social support, and self-esteem revealed that: (a) internal locus of control did not have a statistically significant effect on self-esteem, (b) social support had a direct positive effect on self-esteem $(\beta=0.42$; $p$ s 0.03 ), and (c) social support accounted for $11 \%$ of the explained variance in self-esteem. Path analysis was used to examine well-being in relationship to internal locus of control, social support and self-esteem revealed. Statistical analysis revealed that: (a) internal locus of control $(\beta=0.31, p \leq 0.02)$ and self-esteem $(\beta=0.31, p \leq 0.02)$ both had a 
significant effect on well being; (b) the predicted relationship between social support and well-being was not significant; (c) the exogenous variables, that is, number of chronic illnesses and treatment with immunotherapy and Vitamin A, were significantly related to well-being; and (d) $52 \%$ of the variance in well-being was explained by the four separate variables; internal locus of control $(\beta=0.48, p \leq 0.05)$, self-esteem $(\beta=0.31, p \leq 0.05)$, chronic illnesses $(\beta=-0.46, p \leq 0.05)$, and treatment (immunotherapy and vitamin $A)(\beta=$ $0.40, p \leq 0.05)$.

Based on the study findings, Dirksen (1989) concluded that feelings of self-esteem are positively influenced by the degree of perceived support from significant others. Thus, nursing interventions such as support groups for cancer survivors can be proposed for inclusion in long-term, rehabilitative nursing care for the growing cancer survivor population.

Strengths of the study included a comprehensive conceptual framework from which to estimate each linkage between variables in the causal modeling approach. Valid and reliable instruments were used to measure each study variable. Four of the six scales met the minimum reliability criterion value of 0.70 for the study. Data from the two scales that did not have adequate estimates of reliability for this sample were deleted (Dirksen, 1989). Generalizability of findings is limited to groups with characteristics similar to the sample: primarily Caucasian, college educated, married malignant melanoma patients.

The empirical studies reviewed in this section regarding social support and cancer illustrate its vital role in cancer survival (Ell et al., 1992), in maintaining identity as a means of coping (Lugton, 1997), and in contributing significantly to self-esteem and, thus, well- 
being (Dirksen (1989). These studies encourage further research to enhance understanding of social support as a key variable in the cancer experience.

\section{Cancer Survivorship and Health-Related Ouality of Life}

Professionals in the field of oncology have begun to recognize the need for studies focusing on survivorship. The immediate impact of adjusting to the diagnosis of cancer is well documented, unlike the long-term psychosocial adjustments required of survivors (Carter, 1989). Therefore, greater attention is now being given to HRQL as an outcome variable for cancer survival (Padilla et al., 1990). Health-related quality of life for the cancer survivor has been broadened to include, not only the extension of life, but the client's perceptions of the quality of survival at each stage of the experience (Holland, 1992; Morrow, Lindke, \& Black, 1992; Padilla, Grant, \& Ferrell, 1992). Within the last two decades there has been a growing consensus among health care providers in oncology that the effectiveness of clinical trials must encompass the assessment of both quality and length of survival. This is especially true as new treatments are available that significantly lengthen survival. With increased survival comes the opportunity to expand our knowledge about the effects of cancer on QOL (King et al., 1997).

The HRQL literature is presented here in the context of the survivor of cancer. Since the literature related to quality of life is vast, a selected slice of the literature is explored as it relates to the research questions for this study. The vastness of the HRQL literature is related to the dynamic nature of life and the considerable variety of ways in which life is viewed and people choose to find meaning and purpose in life (Phillips, 1995). The importance of studying QOL as related to cancer survivorship is reflected in the 
number of studies that have been done (Aaronson, 1988; Cella, 1994; de Haes \& van Kippenberg, 1985; Ferrell, 1996; King et al., 1997).

Two related terms, overall quality of life (QOL) and health-related quality of life (HRQL), are used in the literature. From a general perspective, QOL refers to the subjective judgment of the individual about his/her happiness, life satisfaction, and sense of well-being. This definition of QOL is commonly used in sociological research. Overall, QOL may include consideration of illness or health-related factors, as well as nonmedical factors such as employment and social status. HRQL, on the other hand, focuses on those aspects of life upon which the health care system can have a direct impact (Aaronson, 1988). Gill and Feinstein (1994) underscore the importance of this distinction to avoid either overestimating the impact of HRQL factors or undervaluing the effect of non-medical factors. This clarification of definition also has implications for measurement and evaluation of the concept of HRQL in this study. Since health care professionals are responsible for assisting a client with the health-related aspects of their lives, the specificity of the term HRQL provides a more focused approach to the study of the QOL concept by health care researchers. Although happiness and life satisfaction in the context of overall QOL are worthwhile goals, they seem to be beyond the scope of practice in the healing arts (Aaronson, 1988). One might view HRQL as one component of overall QOL; the component related to the sense of well-being.

As the focus on QOL (and more specifically on HRQL) has evolved, authors and researchers have struggled with its definition because of the complexity of the concept. Authors generally agree that, for cancer clients, the HRQL concept is multidimensional, 
Survivors HRQL 50

subjective, temporal, and relates to a state of physical, psychological, and social well-being, not merely absence of disease (Cella, 1994; Ferrans, 1990; Schipper, 1990, King et al., 1997). The construct is usually described as being composed of four domains: functional status, disease-related and treatment-related symptoms, psychological functioning and social functioning (Aaronson, 1988). More recently, the spiritual domain as been included in frameworks of HRQL studies (Ferrell, 1995; King et al., 1997).

A review of instruments commonly used in assessing HRQL in cancer patients supports the use of disease-specific (in this study, cancer-specific) measures over global measures. This provides for a more accurate description of patients' experiences with cancer and its treatment (Aaronson, 1991; Cella \& Tulsky, 1990). In addition, global or unidimensional measures may not fully capture the status of the individual's perceptions of HRQL. The multidimensional nature of HRQL makes it important to identify the dimensions most relevant to a particular patient population - in this study, the long-term cancer survivor.

Gill and Feinstein (1994) recommended the following guidelines for the assessment of QOL instruments. Because QOL is intrinsically a patient attribute, the best source for items is the self-report (both spontaneous and requested) from cancer patients regarding their experiences. In addition to responses to forced-choice items, it has also become standard practice to give respondents the opportunity to respond to an open-ended question, such as, What additional information would you like to share regarding your quality of life? (King et al., 1997). Weighting of items or rating the importance of an item to QOL is argued to be just as important as the occurrence of the item. This provides information 
regarding the significance to the respondent of various aspects of QOL (Gill \& Feinstein, 1994). One of the few QOL instruments that incorporates the rating of the importance of QOL items is Ferrans and Powers Quality of Life Index-Cancer Version (Ferrans, 1990) which was chosen for use in this study.

The selection of a QOL instrument should include an analysis of the fit of the instrument to the specific aims and design of the study and the reliability and validity of the instrument. In terms of reliability, a test-retest or a check of internal consistency is a minimal requirement. It is recommended that an initial test of validity, such as content validity, be included (King et al., 1997). According to Donovan, Sanson-Fisher, and Redman (1989) an acceptable QOL instrument would have the following characteristics: (a) a short completion time, (b) a closed question format, (c) categorical scaling, (d) language comprehensibility to the majority of the population, and (e) relevancy of the items to the respondents.

An issue related to QOL research involves the distinction between the dimensions and determinants of HRQL. According to Padilla, Hurwicz, Berkanovic, and Johnson (1996), determinants are factors that affect or influence quality of life and dimensions are the attributes or characteristics of the QOL construct. In research reports, the dimensions and determinants are discussed interchangeably, leading to confusion regarding both the conceptual and operational definitions of this variable. Padilla et al. (1996) addressed this issue by examining QOL within the context of a theoretical framework. A specific theoretical framework provides a context from which to study QOL variables. Padilla et al. (1996) used the example of the illness adaptation model as the context in which they studied 
stress, coping, and QOL in arthritis. This particular model combines discrepancy theory with the stress process model. In this context variables related to potential stress, coping resources, and strategies would be considered determinants of QOL (what contributes to QOL). Whereas dimensions of QOL (what it is) are the affective, psychological and spiritual attributes of an individual involved in the appraisal of the discrepancy between the experienced stress and the expected level of well being. The use of such a model gives clarity and decreases potential confusion as to how study variables are viewed in a research study.

Recently published works by nurse scientists in the field of oncology have attempted to focus on the HRQL for survivors in the permanent season of survival as described in this study ( 5 years beyond diagnosis and recurrence-free or without evidence of disease). A sample of these HRQL studies served as a reference point for the present study. The majority of research on adult long-term cancer survivors has studied survivors of either breast cancer or bone marrow transplants for leukemia, both conditions with relatively higher rates of survival than other cancers.

Quality of life studies on survivors of bone marrow transplant have provided additional knowledge regarding the medical and psychosocial sequelae in life after cancer diagnosis and treatment. Bush, Haberman, Donaldson, and Sullivan (1995) conducted a descriptive study of adults surviving 6-18 (mean 10) years after bone marrow transplant (BMT) to examine QOL, late medical complications, psychological distress, demands of long-term recovery, and health perceptions. Questionnaire packets were mailed to eligible subjects with a response rate of $70 \%$. The 125 respondents (61 women and 64 men) were 
Survivors HRQL 53

predominantly Caucasian (93\%), married (72\%) and younger (with a mean age of 38 years and a range from 26-62 years). In addition, the sample was well educated (with 2 or more years of college) and relatively affluent (with $63 \%$ reporting a total family income of greater than $\$ 30,000 /$ year). Demographic, disease, and treatment data from nonrespondents examined for biases in respondent characteristics revealed no statistical difference between respondents and nonrespondents.

Among the QOL studies reviewed that focused on BMT, the Bush et al. (1995) study examined the largest sample of patients with the longest mean survival time of 10 years beyond transplant. The study used a descriptive survey design to examine QOL using the dimensions of physical, psychological and social functioning, and disease/treatment symptoms. The study also attempted to give particular attention to the unique demands of recovery from BMT. The instrument packet consisted of seven self-report instruments that were mailed to patients who met study criteria, including: (a) biodemographic questionnaire; (b) the European Organization for Research and Treatment of Cancer (EORTC)QLQ-C30, a QOL tool specific for cancer patients; (c) the Late Complications of BMT module developed by the primary investigator as an addendum to the EORTC QLQ-30; (d) the Demands of BMT Recovery Inventory; (e) the Profile of Mood States; (f) the Ware Health Perceptions Questionnaire; and (g) the Long-term BMT Recovery Questionnaire, an open ended questionnaire designed by the authors to capture qualitative data.

Bush et al.'s (1995) findings revealed that the majority of long-term survivors of BMT reported QOL after BMT, as compared with before BMT, to be the same or better, with benefits of transplantation outweighing the side effects. In spite of the moderate self- 
care demands from the sequelae of BMT, most survivors consistently reported the severity or degree of their distress from the complications to be low. Both global QOL and Health Status were rated as poor by only $5 \%$ of the study sample. In regards to the demands of BMT recovery, survivors reported the following in order of frequency of occurrence: people were less supportive over time, thinking about the value of life, dissatisfaction with looks, unable to always rely on body, reordering life priorities, thinking about sexual appeal, closely monitoring any new symptoms, and need for information about long-term side effects. When compared to cancer survival and general population norms, these survivors demonstrated good mood and low psychological distress, and were no different in their assessment of current health and health outlook.

The researchers concluded that the transplant survivors in this study were productive, stable and well-adjusted, despite ever-present but relatively innocuous physical complications. In their eyes, these survivors are 'cured'. Lastly, the investigators concluded that the narrative data strongly suggest that the actual process of renormalizing and adapting to life after transplantation is not all that important in the bigger scheme of things for this group of BMT survivors.

Strengths of the study included the appropriateness of design (descriptive survey) for the purpose of the study (examination of the medical and psychosocial sequelae of BMT survivors). Valid and reliable instruments were used to measure each study variable. The sample size was adequate for the statistical analyses performed. The focus on a wider window of survival (mean of 10 years as opposed to 1-5 years in studies of cancer survivors) was important to broaden the understanding of $\mathrm{HRQL}$ for long-term cancer 
survivors.

In the qualitative component of this study reported by Haberman, Bush, Young, and Sullivan (1993), eight open-ended questions were asked to elicit information on survivors' reestablishment of daily life after BMT, demands of recovery, coping skills, limitations, current health problems, QOL, and concerns about the future. The themes that emerged from the content analysis performed on the written responses indicated that long-term BMT recovery is positive, dynamic, highly individualized, and marked with fluctuations between periods of improvement and lack of improvement. Quality of life was reported to be the same or better than before BMT. Although the qualitative findings have a positive tone, the investigators believe bias resulted from the study's use of self-report measures which depend on selective recall and may reflect wishful thinking and simply the passage of time.

Restricting the data collection to BMT survivors also limits the generalizability of the study.

A study by Molassiotis, Boughton, Burgoyne and van den Akker (1995) aimed to compare the QOL of long-term survivors of autologous and allogenic BMT and to identify their post-BMT needs. The study utilized three standardized questionnaires; (a) the Psychosocial Adjustment to Illness Scale, (b) the Hospital Anxiety and Depression Scale, and (c) the Rotterdam Symptom Checklist. The sample was comprised of 32 males and 18 females who had a mean age of 36.9 years. Ninety-eight percent were Caucasian, $62 \%$ were married and almost half had earned a university/college degree. Their mean time since BMT was 3.5 years, with a range of 6 months to 8 years.

Although no statistically significant differences were detected between the two groups, the findings revealed psychological dysfunction to be present in $26.4 \%(n=24)$ of 
the autologous bone marrow transplant (ABMT) patients as opposed to $8.4 \%(n=26)$ of the allogeneic (Allo) BMT patients. Greater physical dysfunction was also reported by the ABMT group, although symptoms were reported to be more intense in the Allo group. Both the ABMT and the Allo groups described their QOL as good to excellent. However, a quarter of both groups were unable to return to full-time work or education. The main predictor of the degree of QOL in this sample was found to be physical symptomatology $\left(R^{2}=0.59\right)$ (Molassiotis et al., 1995).

Another QOL study with adult BMT survivors was conducted by Whedon, Stearns, and Mills (1995). The study aimed to describe QOL in a population surviving longer than one year after autologous BMT and to evaluate validity and reliability of a measure used previously only with allogeneic BMT survivors. The inclusion criteria for this study were: (a) surviving at least one year following date of transplant; (b) over age 18; (c) able to read, write, and understand English. Thirty-seven questionnaire packets were mailed. The packets consisted of a demographic questionnaire, the City of Hope QOL-BMT instrument (4 forced-choice items and 26 visual analog scales), and a qualitative questionnaire (with 6 open-ended questions). Of the 34 eligible patients, 29 returned surveys (85\% response rate). The respondents had diagnoses of acute myelogenous leukemia $(n=15)$, lymphoma $(n=8)$, and breast cancer $(n=6)$ and had been treated as part of a clinical trial with one of six regimens. The sample consisted of $45 \%$ male $(n=13)$ and $55 \%$ female $(n=55)$ Caucasians. Sixty-six percent were married and $66 \%$ had a college education. The mean age at the time of the survey was 38.5 years (range $=20-54$ years) and the mean time since BMT was 37 months (range $=14-76$ months). 
Study findings were similar to the ABMT findings in Malassiotis et al. (1995) QOL study. Whedon et al.'s (1995) sample of ABMT survivors had a high mean global QOL score. Most survivors experienced minor physical disruptions, with fatigue being the most frequently reported problem. Psychological distress was reported to be moderate to severe, with distress about being a burden to the family receiving the most negative mean rating of the entire QOL instrument. The QOL social domain scores reflected distress in the areas of sexual functioning and achieving financial goals. A sense of purpose and hope received the highest scores in the spiritual domain of QOL. In comparison to allogeneic BMT survivors from their previous study, this study sample of ABMT survivors tolerated and recovered from BMT quite well (Whedon et al., 1995). The researchers concluded that, despite the overall good QOL reported, there remained a certain amount of physical, psychological, and social distress and dysfunction even long after transplant. The findings of this study provide further evidence of the lasting effects of cancer.

Whedon et al.'s (1995) study is an excellent example of clinically relevant oncology nursing research as evidenced by their attempt to: (a) extend the knowledge of QOL of survivors of BMT to include survivors of autologous BMT; and (b) determine the appropriateness of using a reliable, valid, allogeneic BMT QOL instrument for survivors of autologous BMT. Other strengths of the study were the accrual of a homogeneous sample, a complete description of the population from which the sample was drawn, and a high participant response rate. The investigators appropriately restricted their analysis of a descriptive, replication survey to a conservative reporting of means, frequencies, and percentages because of the small sample size. The investigators selected a brief but 
informative set of tools which reflected their sensitivity to the burden placed on the respondents in studies of this nature. Lastly, the researchers chose two complementary methods of data collection as a form of methodologic triangulation which enriched data collection.

Belec (1992) examined the QOL perceptions of 24 long-term survivors of BMT as designated by the researcher ( $1-3$ years post BMT). Both autologous and allogeneic transplant survivors were included in the study and responded to the cancer version of the Quality of Life Index (QLI) and an interview. Belec's (1992) findings revealed that BMT survivors perceived their QOL as acceptable and reported having fuller, more meaningful lives post-transplant. Family relationships had the strongest positive influence on overall QOL, and issues related to health and employment were of greatest concern in this sample of BMT survivors. Findings from the interviews revealed that, in spite of the lifethreatening illness experienced and its sequelae, these BMT survivors were able to adapt and adjust to their situation in life which, in turn, positively influenced their perception of their QOL.

Strengths of the study included a complete description of the sampling method, as well as analysis of both quantitative and qualitative data. Generalizability of findings were limited by the small sample size from one BMT center. Subjects were at various stages post-BMT and, since data were collected at only one point in the subjects' experience following transplantation, the most accurate picture of QOL may not have emerged. The study findings may have been unduly favorable due to the sample only including BMT recipients who had survived and were not presently hospitalized. The investigators 
recommended future studies to include focus on multisite study of BMT survival to enhance generalizability of findings. They also recommended prospective longitudinal studies to more accurately describe the impact of BMT on QOL at various stages post-BMT.

The purpose of an exploratory study by Wyatt and Friedman (1996) was to identify the concerns and issues related to QOL in long-term female cancer survivors (58\% breast cancer, $13 \%$ uterine cancer; and $29 \%$ other cancers affecting women). One hundred eightyeight females who had survived a range of 5 to 33 years (mean of 8.42 years) participated in the study by completing a newly-developed Long-Term Quality of Life questionnaire. The new instrument was designed using Ferrell's QOL model as a framework and included the four domains of QOL: (a) physical well-being, (b) psychological well-being, (c) social concerns, and d) spiritual well-being.

Wyatt and Friedman (1996) anticipated that the physical concerns of long-term female cancer survivors would be minimal in comparison with their concerns in the psychological, social and spiritual domains. The findings supported this, since concerns for this sample were reported in the following high-to-low order of significance: social/emotional support, health habits (e.g. diet and exercise), spiritual/philosophical view of life and, finally, somatic concerns. These findings suggest that, although physical concerns persist, the need to address such concerns may be more relevant earlier in the survivor process and that the psychological, sociological and spiritual concerns need to be addressed more at this later stage. Finally, the social/emotional support domain revealed that women who believed in their ability to help other newly-diagnosed women reported experiencing a lack of support in their own lives. In spite of these women's positive belief 
Survivors HRQL 60

about their ability to help other women, they expressed continued lack of support from family and friends. The researchers speculated that these women either were not accessing support or felt that the support did not benefit them. They suggested that support groups which focused on the unique needs of long-term cancer survivors were needed. Wyatt and Friedman (1996) concluded that this group of long-term cancer survivors did not simply "return to normal"but had evolved into women who were able to put the physical aspect of the cancer experience into perspective and now were focusing on relational, existential and healthy lifestyle issues.

The study's strength lies in the use of a theoretical framework which had been utilized in previous, well-designed studies related to the QOL of cancer survivors. An expanded discussion regarding the development of the new instrument and a comparison with other QOL instruments was needed. The generalizability of the findings are limited to white, married, unemployed, women with breast cancer.

Fredette (1995) interviewed a convenience sample of 14 breast cancer survivors in a qualitative study to delineate their concerns and coping strategies. The age range of the women was 31-58 (mean $=45.8$ years) and their years of survival ranged from 8-30 years (mean=13.7 years). They were primarily Caucasian, well-educated, and employed.

Content analysis of interview transcripts revealed four major themes: coping strategies, impact of the cancer, self-perception about survivorship, and the personal meaning of having cancer. The findings provided evidence of a survivor personality with a determination to survive that utilized multiple methods of coping, resourcefulness, optimism, and assertiveness in the process of survival. In addition, social support was an 
Survivors HRQL 61

important part of these women's coping strategies, with support from family (specifically husbands) being reported as more meaningful than support from friends, who tended to treat them differently after cancer was diagnosed. Fredette (1995) concluded that a requirement for cancer survival was perseverance in the face of the uncertainty that lingers even in breast cancer, a cancer site known to have the highest 5-year survival rate. This supports the idea that cancer has an enduring impact and that further study of long-term survivors of cancer is needed.

The concerns and coping strategies reported by these cancer survivors may have been biased by self-selection by women who were eager to participate in order to share information about their survival. The study findings that social support was an important part of these women's coping strategies would have been enhanced if informants had been asked to expand on their concept of support. The investigators had a follow-up study in progress to investigate this in more depth. Replication of the study including women of different cultures, geographic locations and educational levels would strengthen the generalizability of the current findings. The investigators recommended multisite, prospective, longitudinal studies to determine $\mathrm{QOL}$ and salient issues that emerge for the survivor of breast cancer at different lengths of time after treatment in order to document a trajectory of breast cancer survival.

Wyatt et al. (1993), using a qualitative design with focus group discussions, studied 11 women with breast cancer who had survived for 5-14 years. The interview guide addressed Ferrell's four domains of QOL: physical, social, psychological and spiritual. Content analysis of the discussion transcripts revealed four major themes: integration of the 
disease process into current life, changes in relationships with others, restructuring of life perspective and unresolved issues.

The researchers concluded that women do survive breast cancer with many positive outcomes and that people do not fit their lives into separate domains. Rather, concerns/issues often cross over into two or more domains of life. This supports the idea that QOL is dynamic. In addition, the researchers concluded that it was nearly impossible for breast cancer survivors to begin to tell their story at the 5-year survival point and that who these women are today is rooted in the experience they had at the time of diagnosis (Wyatt et al., 1993). Recommendations from the study included the need for: (a) nursing interventions to focus on key issues for the long-term cancer survivor, and (b) the study of larger populations of long-term cancer survivors using quantitative measures.

This research study focused on a small self-selected population. This type of qualitative research cannot be generalized to larger populations but can only suggest trends. These trends may later be tested for generalization through larger quantitative research studies. Strengths of the study included: (a) sequencing of questions which allowed women to become comfortable with each other leading to discussion of more personal private issues, (b) the provision of peer support using the focus group format for shareing and elaborating on ideas/issues; and (c) the appropriate use of descriptive qualitative methodology because there was a paucity of research in this area.

As a result of improved survival rates, and in an effort to provide appropriate research-based care, studies are emerging in the area of HRQL specifically for long-term survivors of cancer. Although the literature theoretically and empirically links the variables 
self-esteem, learned resourcefulness and social support to HRQL, further study is needed of the relationship between these variables and the HRQL of the long-term cancer survivor. There is a need to expand this research by ascertaining the influence of ethnicity, stage of disease within specific cancer sites and gender on HRQL.

\section{Critique of Related Research Studies}

In general, empirical studies exploring and describing relationships among the variables in this study are supported by the theoretical literature. Quality of life has emerged as an important variable in both the planning and evaluation of patient outcomes and, more specifically, in the care of individuals with cancer. Both qualitative and quantitative research on the HRQL of cancer survivors has been gaining ground. Yet, after an integrative review and meta-analysis of oncology nursing research, Smith and Stullenbarger (1995) identified gaps in patient-related studies, including a lack of studies focusing on survivorship. In the last 5 years there has been an increase in the number of HRQL studies of survivors of cancer reported. This trend stems from the growing consensus among health care professionals that the therapeutic effects of new and emerging treatments for cancer must be assessed within the context of quality as well as quantity of survival.

At first glance, the oncology literature seems daunting until one understands and is able to organize the various levels of the cancer experience. This writer used "seasons of survival", HRQL and selected variables contributing to HRQL as organizational points for this literature review. The literature conceptualizing the cancer experience into "seasons" provided direction in differentiating specific events from which to examine HRQL for cancer survivors. 
The overall strength, validity and generalizability of the studies reviewed was moderated by small sample sizes, publication form, and lack of an explicit theory base. This knowledge base can be expanded by replication of both qualitative and quantitative research, longitudinal studies, and the inclusion of survivors from broader demographic and ethnic backgrounds.

\section{Summary}

Review of theoretical and empirical literature on cancer survival revealed the emphasis to have been primarily on either the early phases of acute diagnosis and treatment or the phase following treatment where there is constant worry of cancer recurrence. Research is beginning to emerge which includes survivors in the later stage of permanent or long-term survival. The focus on the long-term cancer survivor in this study is in part a response to prior research. As documented in the literature, the idea of wellness and high QOL in long-term cancer survivorship are not automatic sequelae to being cured of cancer (Thorne, 1989).

Psychosocial variables of self-esteem, learned resourcefulness and social support have been conceptually linked to HRQL. The research findings reviewed support the influence of these variables on the HRQL of survivors in permanent survival. Despite research support for the influence of these individual variables on HRQL, few studies have described the relationship of these variables specifically in long-term cancer survivors. 


\section{Chapter 3}

\section{Methods and Procedures}

This chapter details the research design, method and procedures used in this study. The sample, setting, data collection methods, and approach to data analysis are discussed..

\section{Research Desion}

A descriptive, correlational, and noninterventional study design was used to examine the relationships between three independent variables (self-esteem, learned resourcefulness, and social support) and one dependent variable (HRQL) among long-term cancer survivors. This design is appropriate for studying a situation as it naturally happens, when there is no treatment and the primary purpose is examination of relationships in a single group (Burns \& Grove, 1995).

\section{Instruments}

The six self-administered instruments used in this study were: (a) a demographic profile sheet; (b) Rosenberg Self-Esteem Scale (1982); (c) Rosenbaum Self-Control Schedule (SCS) (1980); (d) the Norbeck Social Support Questionnaire (NSSQ) (Norbeck, 1981); (e) Ferrans and Powers Quality of Life Index - Cancer Version (QLI) (1985); and (f) the Long-Term Cancer Survivors Quality of Life Inventory (Pedro, 1995). Permission for use of instruments was obtained from each author as necessary (See Appendix A). Table 1 contains a summary description of the tools used to measure the study variables, including the variable measured, subscales included, source, reliability and validity, number of items and the approximate length of time needed to complete each tool as reported by each 
instrument author.

Table 1

Summary of Characteristics of Instruments Used to Measure the Independent and

\section{Dependent Study Variables}

\begin{tabular}{|c|c|c|c|c|c|}
\hline Descriptors & & & Tools & & \\
\hline Title & $\begin{array}{l}\text { Rovenberg Self- } \\
\text { Eveem Scake }\end{array}$ & $\begin{array}{l}\text { Roucabunom Self- } \\
\text { Coutrol Schectule }\end{array}$ & $\begin{array}{l}\text { Narbeck Social } \\
\text { Support } \\
\text { Questionnaire }\end{array}$ & $\begin{array}{l}\text { Ferrens Powers } \\
\text { Quatity of Life Index- } \\
\text { Cancer Verion }\end{array}$ & $\begin{array}{l}\text { Long-Term } \\
\text { Cencer Survivors } \\
\text { Quatiny of Life } \\
\text { Inventory }\end{array}$ \\
\hline Variable & Self-Esteen & $\begin{array}{l}\text { Leamed } \\
\text { Resourcefulmess }\end{array}$ & Social Support & $\begin{array}{l}\text { Health-Relved Quniny } \\
\text { of Life }\end{array}$ & $\begin{array}{l}\text { Lang-Term } \\
\text { Sunivors HRQL }\end{array}$ \\
\hline Subacales & & $\begin{array}{l}\text { Setf-Control, } \\
\text { Self-Direction, } \\
\text { Setf-Efficacy }\end{array}$ & $\begin{array}{l}\text { Functional, Nerwork } \\
\text { Properties }\end{array}$ & $\begin{array}{l}\text { Health \& Functioning } \\
\text { Sociooconomic, } \\
\text { Poychologic Spiritual, } \\
\text { Fanily }\end{array}$ & $\begin{array}{l}\text { Physiological, } \\
\text { Prychological } \\
\text { Sociological } \\
\text { Spiritual }\end{array}$ \\
\hline Reference & Rosenbers 1982 & Rosenbaum, 1980 & Norbeck, 1981 & Farms \& Powers 1985 & Pedro. 1995 \\
\hline Vabidity & Construct & Comtent Construact & $\begin{array}{l}\text { Construct, Combent, } \\
\text { Concurrens }\end{array}$ & $\begin{array}{l}\text { Construch Contenth } \\
\text { Criterion }\end{array}$ & Content $(0.98)$ \\
\hline Reliability & $\begin{array}{l}\text { Test-Reteat (0.85) } \\
\text { Cronbach's Aphx } \\
(0.92)\end{array}$ & $\begin{array}{l}\text { Cronbech's Alpha } \\
\text { (0.93) }\end{array}$ & $\begin{array}{l}\text { Text-Retent (0.85- } \\
0.92) \text {, Cronbach's } \\
\text { Alpha }(0.76)\end{array}$ & $\begin{array}{l}\text { Croubech's Alphs } \\
(0.95) \\
\text { TextReted } 0.87 \text {. }\end{array}$ & In process \\
\hline \# of hems & 10 & 36 & 13 & 68 & 60 \\
\hline $\begin{array}{l}\text { Reported } \\
\text { Approximute } \\
\text { Completion } \\
\text { Time }\end{array}$ & 10 minures & 5 minures & 10 minneses & 5 minutes & 10 minites \\
\hline
\end{tabular}


The Long-Term Cancer Survivors Quality of Life Inventory was developed by the investigator for this study. Each of the other tools are supported theoretically and have been tested and utilized successfully in prior cancer research. The following section contains a description of each instrument.

\section{Demographic Profile Sheet}

This tool includes 5 fill-in-the-blank items and 13 open-ended questions requesting information such as: (a) age; (b) gender; (c) ethnicity; (d) marital status; and (e) type, stage, and date of cancer diagnosis etc. (See Appendix B). This information was gathered to describe the sample. Additional information, not directly relevant to the current study (e.g., alternate therapies used, type of last treatment etc), was obtained with the demographic profile sheet for use in subsequent research.

\section{Rosenberg Self-Esteem Scale (RSE)}

This ten-item self-administered instrument, first published 35 years ago, measures the self-acceptance aspect of self-esteem or the overall sense of being capable, worthwhile and competent (Rosenberg \& Kaplan, 1982) (See Appendix C). It has a Likert scale format with four-point responses ranging from "strongly agree" (1) to "strongly disagree" (4). Possible scores range from 10 to 40 . After reversing the scoring direction on five negatively phrased items, a higher score is indicative of higher self-esteem. Curbow and Somerfield (1991) reported this instrument's successful use in a variety of research studies with adult cancer patients. Included in their report are descriptive data from 14 studies that used the intact RSE with adult cancer patients. Six of the 14 studies provided reliability estimates data. The six Cronbach alpha coefficients reported were: $0.34, .076,0.77,0.81$, 0.84 , and 0.87 respectively. All but one of these reported reliability estimates were 
sufficient since estimates in the vicinity of .70 are usually sufficient when making grouplevel comparisons (Polit \& Hungler, 1991). No validity data were reported.

\section{Rosenbaum Self-Control Schedule (SCS)}

This instrument was used as a measure of learned resourcefulness (See Appendix D). For each of the 36 items in the SCS, subjects indicate the degree to which it describes their behavior on a 6-point scale ranging from extremely descriptive (+3) to extremely nondescriptive (-3). Possible scores range from -108 to +108 . After reversing the scoring direction for 11 negatively phrased items, a higher score is indicative of greater resourcefulness (Rosenbaum, 1990).

The instrument's developer determined content validity from study in psychiatric and mental health practice using master's prepared psychiatric nurse clinicians employed as clinical nurse specialists. The nurse clinicians independently classified the SCS items into three categories reflecting the three conceptual dimensions of resourcefulness, self-control, self-direction and self-efficacy (Rosenbaum, 1990). Convergent and discriminant validity of the SCS were examined by comparing scores obtained on the SCS to scores obtained on Rotter's I-E Scale and the Irrational Beliefs Test. These two scales were found to be conceptually related to the SCS. In two groups of undergraduate students, the Pearson correlation between scores on the SCS and Rotter's I-E scale was -.40 $(p<.01)$. Pearson correlations computed between SCS scores and eleven Irrational Beliefs Test scores were moderate-to-low and statistically significant on all except one test scale (Rosenbaum, 1980).

Test-retest reliability of the SCS was assessed using data collected on a group of undergraduate engineering students. The Pearson product moment correlation between the 
scores on the two testing periods was $.86(p<.01)$, indicating a fairly high stability of test scores over a four week period. Internal consistency was computed on data obtained from 5 different samples. The alpha coefficients were $.81, .80, .84, .78$, and .80 respectively. Data from three different student groups revealed a slight tendency for females to score higher than males. However, $t$-tests performed on the data for each sample revealed no significant differences between the means across the sexes.

Estimates of internal consistency for the SCS were reported in Braden's (1990) study to measure enabling skill in 396 adult subjects with diagnoses of rheumatoid arthritis or arthritis-related conditions. The standardized-item Cronbach's alpha was .85 and the omega was .86 for this study. A Cronbach's alpha reliability estimate of .93 was obtained for the SCS in Zauszniewski's (1995b) study of 63 acutely depressed inpatients.

\section{Norbeck Social Support Questionnaire (NSSO)}

This self-administered instrument (See Appendix E) contains a total of 9 items and measures the multiple dimensions of social support, including: functional components of affirmation, aid, and affection; social network properties of frequency of contact, number in network, and duration of relationships; and recent losses of supportive relationships. Scores for the functional and network components are derived from the subject's rating for each significant person in their network on a Likert-type scale ( 0 "not at all" to 4 " a great deal") in response to eight questions. For example, an item asking the subject to rate the affirmation component of social support asks "How much does this person make you feel liked or loved?". The ninth question requires a "yes", "no" response about any recent loss of an important relationship.

This instrument has been used in previous research studies with cancer patients 
(Dirksen, 1989; Lindsey, Ahmed, \& Dodd, 1985; Mishel \& Braden, 1988). Construct validity has been established with the related convergent constructs of affection and inclusion with evidence for predictive validity. Significant correlations were observed between the NSSQ subscales and the constructs of need for inclusion and affection from the Fundamental Interpersonal Relations Orientation Scale (Norbeck et al., 1983).

Reliability for the NSSQ has been reported with test-retest correlations ranging from .85 to .92 (Norbeck et al., 1981; Norbeck et al., 1983) in two subject groups: first students in a nursing masters program and senior baccalaureate nursing students. Gulick (1994) used the NSSQ to study social support among persons with multiple sclerosis. Intercorrelations between paired items for the functional component of social support in this study were .98 for affect, .94 for affirmation and .97 for aid. Intercorrelations for the social network properties of social support in this study ranged between .20 and .57 .

Wortman (1984), in addressing conceptual and methodological issues in the study of social support in the cancer patient, encouraged using measures that define social support precisely, as opposed to a global definition. In addition, distinct types of support (e.g. emotional, advice etc.) from different providers (e.g. family, friends, physician, other health providers) should be assessed since available evidence suggests that the impact of support is strongly affected by the type of support given and by whom it is given. Lastly, self-report of social support is more valid than the assessment by another person. This provides a description of social support from the subject perspective. Norbeck's Social Support Questionnaire captures these essentials in the measurement of social support. The NSSQ does not attempt to assess negative support or the perspective of the provider in assessing the effectiveness of particular kinds of support. However, the instrument 
Survivors HRQL 71

attempts to measure a multidimensional, complex concept in a fairly simple, user-friendly format.

\section{Eerrans and Powers Quality of Life Index - Cancer Version (OLI-CV)}

This self-administered instrument was originally developed for dialysis patients and has been modified for and used with cancer patients (Ferrans \& Ferrell, 1990) (See Appendix F). This quality of life measure is unique in that it not only measures satisfaction with life in the various domains, but also the importance of satisfaction in each domain to the subject. This aspect allows measurement of individual differences in perception of QOL.

This instrument was selected from the various QOL tools to measure HRQL because of its impressive reliability and validity and its inclusion of items in four domains (health and functioning, socioeconomic, psychological/spiritual, and family) to assess the multidimensionality of HRQL. The major disadvantage of the instrument is its cumbersome scoring; yet its appropriateness for the study outweighed this drawback.

The instrument consists of two parts, each with 34 items (a total of 68 items). The first part measures satisfaction with the various domains of life, and the second measures the importance of each domain to the subject. Items address a broad range of aspects of life. Items in the health and functioning subscale address one's own health, health care, pain, energy (fatigue), physical independence, control over own life, long life, sex life, family responsibilities, usefulness to others, stress, leisure activities, travel, and retirement. Items in the socioeconomic subscale address friends, emotional support, home, neighborhood, standard of living, job/employment, education, and financial independence. Peace of mind, faith in God, goals, happiness, life satisfaction, and personal appearance are 
addressed in items included in the psychological/spiritual subscale. Lastly, family health, children, and family happiness are addressed in items included in the family subscale.

Responses are made on a six-point Likert-type scale with Part 1 items ranging from 1 (very dissatisfied) to 6 (very satisfied). Part 2 responses are also made on a six-point Likert-type scale with items ranging from 1 (very unimportant) to 6 (very important). Scores are calculated by weighting each satisfaction response with its paired importance response. A computer program performs specific calculations to prevent bias due to missing scores and to eliminate negative values. These calculations produce final overall scores and four subscale scores ranging from $0-30$, with higher scores indicating greater QOL. In addition to English, the instrument is available in the following languages: Japanese, Korean, Mandarin Chinese, Mexican-Spanish, Rumanian, Swedish.

Validity and reliability of the QLI-CV were established with a sample of 111 female patients with breast cancer. Content validity was based on an extensive review of oncology and QOL literature. Concurrent validity was evidenced by a strong correlation $(r=0.80)$ between the QLI-CV and a global measure of life satisfaction (Ferrans, 1990). Construct validity was established using the known groups technique. A comparison of overall QOL scores for subjects grouped by pain, depression and coping with stress was made. Ferrans (1990) predicted (based on results from previous QOL research) that subjects who had less pain, less depression, and were coping better with stress would have higher QOL scores. Subjects were divided into groups based on self-reports on levels of pain, depression, and success in coping with stress. Subjects rated themselves on 3 seven-point scales. Subjects were then divided into groups for each variable. Those marking 1,2 , or 3 were placed in one group, and those marking 5,6 , or 7 were placed in a second group. Subjects marking 
Survivors HRQL 73

the middle number of the scale (4) were dropped from the analyses. Student t-tests were used to compare mean scores for each of the three grouping variables. Subjects who had less pain, less depression, or who were coping better with stress had significantly higher mean QOL scores. These findings demonstrated that the mean QOL scores of the QLI-CV did differentiate between people who had greater and lesser difficulty with the three variables and supported the construct validity of the QLI-CV (Ferrans, 1990).

Cronbach's alphas were calculated to assess internal consistency reliability. The alpha for the total instrument was 0.95 . In addition, the internal consistency of the health and functioning, socioeconomic, psychological/spiritual, and family subscales also was demonstrated by alphas of $0.90,0.84,0.93$, and 0.66 respectively.

\section{Long-Term Cancer Survivor's Quality of Life Inventory}

This new HRQL instrument was developed by the investigator to operationalize HRQL for the long-term cancer survivor (See Appendix G). Few valid and reliable tools are available which measure HRQL of the long-term cancer survivor. It is different from the QLI-CV in its specific focus on measuring the HRQL of the adult long-term cancer survivor. In addition, it does not attempt to measure both satisfaction and the importance of satisfaction in each domain as a measure of HRQL. The new HRQL instrument may have the advantage of measuring a different HRQL construct, one that has specific relevance for the long-term cancer survivor population. The instrument consists of 60 items which ask for a response on a Likert-type scale of 0-3. Zero on the scale represents "not true" and 3 "very true". The total score possible is 180 with subscale scores for physiological, psychological, sociological, and spiritual well-being. The four subscales are based on the conceptualization of HRQL as a multidimensional construct having four major 
underlying dimensions.

Content validity was based on a review of the long-term adult cancer survivor and HRQL literature. In addition 10 individuals, 5 doctoral nursing candidates in a psychometric theory and measurement course and 5 doctorally-prepared nurse researchers, were called on to analyze the items included in the instrument. Each individual judge rated the representativeness or validity of each item as a QOL item on a scale of 0-3 with 0 representing "not valid" and 3 "very valid. Content validity was figured by first calculating a score for each instrument item. This was done by dividing the number of judges rating an item as 2 "quite valid" to 3 "very valid"by the total number of judges (10 judges).

Secondly, the total number of items receiving a score of .8 or higher (58 items) was divided by the total number of items in the instrument ( 60 items). This process resulted in a high content validity score of 0.98 . Room for interpretation continues to exist based on the judgement of seasoned researchers as opposed to the judgment of actual long-term cancer survivors who might judge item validity from a different perspective. Further reliability and validity procedures are needed to establish its value as a measure of the construct HRQL. The Pearson correlation coefficient calculated between the scores on the two QOL instruments indicated a very weak nonsignificant relationship between the two scores for the study sample $(r=.172)$. This finding suggests that the instrument may measure a different HRQL construct from that measured by the QLI-CV instrument.

The study instruments were appropriate for the measurement of each study variable. Each instrument has been tested for reliability and validity with samples of subjects with either cancer or another chronic illness. Previous research studies reported sufficient reliability coefficients for each study instrument for group-level comparisons. Similar 
statistics were calculated for each instrument in the current study. The reliability coefficients for each instrument for the sample in the current study were calculated using the Cronbach's alpha. The reliability estimates used for each instrument were acceptable, inculding: RSE (self-esteem) 0.88, SCS (learned resourcefulness) 0.86, NSSQ (social support) 0.95, QLI-CV (HRQL) 0.96, and LTCSQLI (investigator-generated HRQL instrument) 0.94 .

\section{Sample}

Once approval to conduct the study was obtained from the investigator's dissertation committee, the University of San Diego Committee on the Protection of Human Subjects Committee, and Institutional Review Boards for both the Loma Linda University Cancer Institute (LLUCI) Data Center and the Desert Sierra Cancer Surveillance Program (Region 5) (See Appendices H \& I), a nonprobability, purposive sample of cancer survivors was recruited. Table 2 summarizes the characteristics of data bases from which the sample was drawn and the participant selection process.

These two data bases were selected primarily for their familiarity with graduate student research and their convenience for the investigator in terms of her knowledge of the personnel and their proximity to her work environment. A contact person was assigned to work with the investigator within each agency to facilitate the process of sending and receiving letters from physicians and potential subjects. 
Table 2

Summary of Data Base Characteristics, and Participant Selection Process

\begin{tabular}{|c|c|c|c|}
\hline Agency Name & Description & Composition & Selection Process \\
\hline $\begin{array}{l}\text { Loma Linda University Cancer } \\
\text { Instionte Cancer Dav Center } \\
\text { (LIUCD) }\end{array}$ & 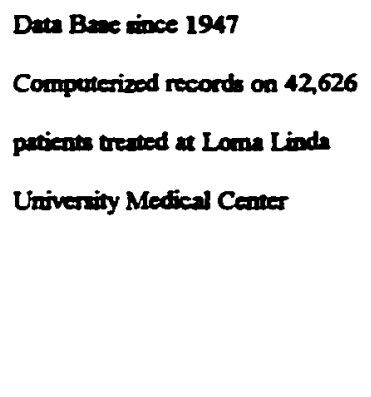 & 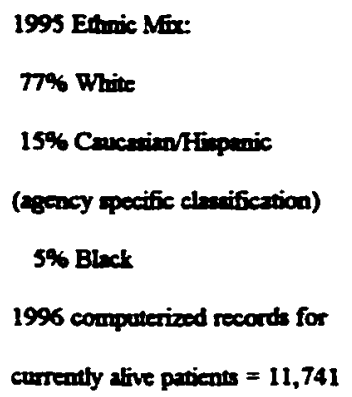 & 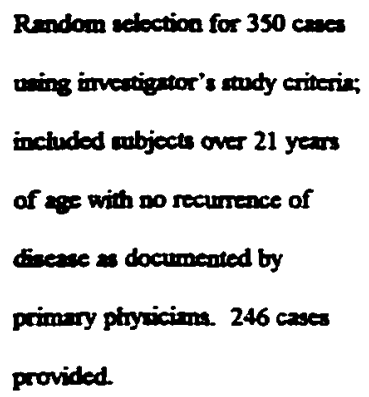 \\
\hline $\begin{array}{l}\text { Desert Sierra Cancer Survellance } \\
\text { Program (Region 5) }\end{array}$ & $\begin{array}{l}\text { Started Jamury } 1988 \\
1 \text { of } 10 \text { reporting centers in } \\
\text { Califormiz } \\
\text { Reponting center for Riverside, } \\
\text { San Bemardino, Inyo, Mono } \\
\text { Countiex } \\
40 \text { reporting boupitals }\end{array}$ & $\begin{array}{l}15,000 \text { reports and } 11,000 \text { cases } \\
\text { yearty }\end{array}$ & 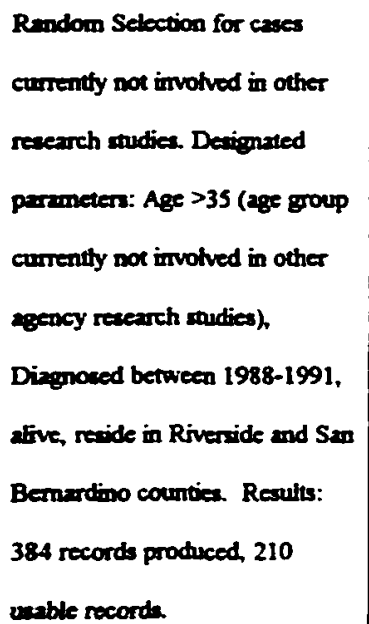 \\
\hline
\end{tabular}

Inclusion criteria for the convenience sample for the study were as follows: (a) volunteer adults over 21 years of age, (b) diagnosed and treated for cancer and at least 5 years beyond diagnosis, (c) recurrence-free (no active disease needing treatment) by selfreport (item on demographic profile sheet) or as identified by their physician, (d) able to speak, write, and understand English, and (e) no known cognitive disabilities. There were no cancer site, gender, ethnicity, or upper age limitations.

Additional criteria used for sample selection from Region 5 included: (a) individuals not currently involved in a research study and (b) individuals living in Riverside and San 
Bernardino Counties (to minimize telephone and mailing costs for both the investigator and participants).

\section{Brocedure}

\section{Bilot Study}

A pilot study was conducted to test the data collection procedures with 8 consenting cancer survivors known to the investigator. Approval was obtained from the University of San Diego Committee on the Protection of Human Subjects to conduct this pilot study. The pilot study revealed the following: (a) the set of questionnaires took 34-45 minutes to complete, (b) directions for completing each instrument were understood, (c) some questions didn't apply to all survivors, (d) some respondents had not previously thought of how cancer influenced their self-esteem or how important social support continues to be for them, (e) a statement was needed in the instructions for each instrument asking participants to think about the questions in terms of TODAY as opposed to when they were diagnosed with cancer or at another time period, and (f) another question "What additional information would you like to share regarding your quality of life as a long-term cancer survivor?" needed to be included on the demographic profile sheet.

\section{Main Study}

Information regarding the study, including the purpose and extent of subject participation, was sent to LLUCI Cancer Data Center and the Desert Sierra Cancer Surveillance Program physicians inviting their patients to participate in this study (See Appendices J \& K). This process informed physicians of the study and enabled them to contact the investigator to prevent the sending of study materials to potentially unwilling or deceased individuals as identified by these physicians. Once consent was obtained from the 
physician to contact their patients, a letter from LLUCI or Region 5 explaining the study (see Appendices L \& M) the informed consent form (see Appendix N), and a selfaddressed, stamped envelope were mailed to potential participants from each agency. After consent from potential participants was received, a packet containing a cover letter (see Appendix 0), a copy of their signed informed consent form, a set of instruments measuring the four study variables, and a self-addressed stamped return envelope were mailed to them.

Following feedback from physicians from both agencies, a total of 456 records were presented to the investigator. A total of 111 questionnaire packets were returned for a total response rate of $24.3 \%$. However, only 62 contained usable data, which for this study meant completion of all study instruments. LLUCI mailed 246 letters to potential subjects which resulted in a $32.5 \%$ response rate ( 80 returned questionnaire packets, 246 mailed questionnaire packets). Fifty of the 80 individuals who returned packets had completed all study instruments and were included in the study. Region 5 mailed 210 letters to potential subjects which resulted in a $14.7 \%$ response rate ( 31 returned questionnaire packets, 210 mailed questionnaire packets). Tweive of the 31 individuals who returned packets had completed all study instruments and were included in the study. Table 3 summarizes the number of cases recruited from each agency, the number of cases deleted by physicians, the number of questionnaire packets mailed, and the response rate for each. Incorrect addresses were identified as a factor contributing to both the number deleted by physicians (by a call to the agency or crossing out a name from a list sent to them) and the low response rate. Almost half (49\%) of the returned questionnaire packets had large portions of missing data which could not be used in the study. Eight individuals, phoned the 
investigator and declined to participate in the study due to death in the family, vacations, or the sever stress anticipated from filling out the questionnaires.

Table 3

Number of Cases Available, Cases Deleted by Physicians. Packets Mailed. Response Rate. and Usable Data

\begin{tabular}{|l|l|l|l|l|l|}
\hline Agency & \# Cases & \# MD Deleted & \# Mailed & Response Rate (n) & $\begin{array}{l}\text { Usable Data Sets } \\
\text { (\% of \# mailed) }\end{array}$ \\
\hline \hline LLUCI & 350 & 104 & 246 & $32.5 \%(80)$ & $50(20.3 \%)$ \\
\hline Region 5 & 384 & 174 & 210 & $14.7 \%(31)$ & $12(5.7 \%)$ \\
\hline Combined Total & 734 & 278 & 456 & $24.3 \%(111)$ & $62(13.6 \%)$ \\
\hline
\end{tabular}

The information provided with the informed consent form advised subjects that participation was voluntary and that they could remove themselves from the study at any time without penalty. The investigator's telephone number was provided to allow participants to be debriefed by having the opportunity to express concerns and questions at any time before, during, or after their completion of the study instruments. A copy of the signed informed consent was mailed to the study participant. Once the participants completed and returned the set of questionnaires to the investigator, their participation in the study was completed.

Participants were asked to return their completed study instruments within a twoweek time frame. Returned study instruments were assigned an identification number by the investigator to ensure confidentiality and anonymity. To assure further confidentiality, the raw data and lists of names and code numbers were kept in a locked location accessible only to the investigator. Due to the adequacy of the sample pool, the need to manage 
costs, and to provide anonymity, no follow up phone calls or written reminders to participants were used. Instruments were scored by the investigator in preparation for data entry and analysis.

\section{Ethical Considerations}

During the process of filling out the study instruments, recollection of events and buried anxieties or other types of psychological and emotional distress may have arisen. To address this potential risk, a statement was included in the consent form stating that participants understood that in the process of filling out the questionnaires they might be reminded of uncomfortable feelings that have been part of their cancer experience and that they had the right to withdraw at any time without jeopardy. In addition, participants could choose to contact the investigator, via a telephone number provided, to discuss any distressing feelings that may have been generated. Only one individual called the investigator to report distressing feelings and to provide an explanation for the condition of the returned questionnaires. The individual reported completing each questionnaire and then tearing the questionnaires in half as a result of feeling distressed. However, wishing to share his/her experience via the questionnaires, this individual taped the two halves together prior to returning them to the investigator.

\section{Data Analysis}

Data were analyzed using SPSS (SPSS Inc., Chicago, IL). Descriptive, correlational, and regression statistics were used to describe findings and answer the research questions. An alpha level of 0.05 was used to indicate statistical significance of all inferential statistical results.

Descriptive statistics were computed on demographic items and all instrument 
scores. Reliability coefficients were calculated on all instruments and subscales using the split-half technique to assure adequate internal consistency of instruments for this sample.

The Pearson product-moment correlation statistic was used to determine the strength of the association between the independent variables of self-esteem, social support, and learned resourcefulness and with the dependent variable, HRQL, for longterm cancer survivors. Step-wise, forward multiple regression procedures were used to estimate to what extent the variables self-esteem, social support, and learned resourcefulness predict HRQL among long-term cancer survivors. This allows the researcher to control the sequence of the independent variables entered into the equation based on the strength of correlation computed for each independent variable (takes strongest correlation equation). Table 4 summarizes statistical tests used to answer each of the research questions.

Table 4

Summary of Statistical Tests Used to Answer Each Research Question

\begin{tabular}{|l|l|}
\hline \multicolumn{1}{|c|}{ Research Question } & \multicolumn{1}{|c|}{ Statistical Test } \\
\hline $\begin{array}{l}\text { 1. What is the relationship of self-esteem to health-related } \\
\text { quality of life for long-term cancer survivors? }\end{array}$ & Pearson product-moment correlation \\
\hline $\begin{array}{l}\text { 2. What is the relationship of learned resourcefulness to } \\
\text { HRQL for long-term cancer survivors? }\end{array}$ & Pearson product-moment correlation \\
\hline $\begin{array}{l}\text { 3. What is the relationship of social support to health-related } \\
\text { quality of life for long-term cancer survivors? }\end{array}$ & Pearson product-moment correlation \\
\hline $\begin{array}{l}\text { 4. To what extent are self-esteem, learned resourcefulness, and } \\
\text { social support predictive of HRQL for long-term cancer } \\
\text { survivors? }\end{array}$ & Step-wise forward multiple regression \\
\hline
\end{tabular}




\section{Limitations}

Because of the multidimensionality of HRQL, the study instruments did not measure all of the variables that may affect $\mathrm{HRQL}$ such as coping strategies, somatic concerns of individuals, personality, and locus of control. These confounding variables were not able to be controlled for in this descriptive study. Due to the lack of control of general extraneous variables, as well as extraneous variables unique to long-term cancer survivors, and participants who were primarily older adults, the probability of inaccurate reflections of reality for young and middle-age adult long-term cancer survivors exists. Also, the study was not designed to assure that all the instruments would be completed only by the consenting survivor. The majority of participants were older adults, and some may have required assistance to complete the questionnaires and this may have biased their responses to some extent. In addition, because of the changing and dynamic nature of life, there are factors which affect HRQL that cannot be measured by current paper-and-pencil instruments. These unavoidable limitations are addressed in the analysis and discussion of the study findings.

The study had a low response rate of $24.3 \%$. A response rate greater than $60 \%$ is generally sufficient for most purposes (Polit \& Hungler, 1991). This study reports data gathered from 62 participants. This number is different from the proposed minimum sample size of 80 participants (estimated using guidelines in Cohen, 1977) due to death, incorrect addresses, incomplete returned instruments, study deadlines, and limited funding for follow up calling and/or sending out reminders to complete and return questionaires. The large proportion ( $49 \%$ had large portions of missing questionnaire data) of incomplete returned questionnaire packets may partially be explained by the lengthiness of some of the 
instruments leading to fatigue, particularly in a primarily older population. In addition, distress related to reminders about the cancer experience may have contributed to the omission of certain items or groups of items. The low response rate (24.3\%) and low percentage of usable data (13.6\%) introduces bias which may make it unreasonable to assume that those long-term cancer survivors who responded with fully complete questionnaires were somehow "typical" of the whole population. Therefore, the findings cannot be generalized to all long-term cancer survivors. Generalizability of findings is limited to long-term cancer survivors similar to those in the study sample who provided complete data. Caution should be used in generalizing findings of the study to all longterm cancer survivors.

\section{Summary}

This study utilized a quantitative, descriptive, correlational, noninterventional design. The study methods and procedures described in this chapter were used to investigate the relationship between: (a) self-esteem, (b) learned resourcefulness, and (c) social support and HRQL for long-term cancer survivors. A non-probability, purposive sample of long-term adult cancer survivors was recruited with permission from the Loma Linda University Cancer Institute Data Center and the Desert Sierra Cancer Surveillance Program Region 5. Six instruments, one for each of the three independent variables, two to measure the dependent variable and a demographic profile sheet were used. A sample of 62 volunteer cancer survivors fully completed the mail-back questionnaires (13.6\%). The Pearson product-moment correlation was used to determine the strength of the associations between the independent variables self-esteem, social support and learned resourcefulness and the dependent variable, HRQL, for long-term cancer survivors. Multiple regression 
Survivors HRQL 84

analysis was then used to measure the extent to which the independent variables self-

esteem, learned resourcefulness, and social support are predictive of HRQL for long-term

cancer survivors. 


\section{Chapter 4}

\section{Results and Discussion of Findings}

The research findings are presented in this chapter. Following a description of the sample, the results related to each research question are presented and discussed in relation to the study's conceptual framework and literature review. Lastly, the results of the supplementary analyses are presented and discussed.

\section{Description of the Study Sample}

The study sample is described in regard to the following characteristics: age, gender, general demographic characteristics (marital status, education, etc.), and cancer demographics (cancer site, type of treatment, etc.). The percentages reported are based on those who provided the requested information on the demographic profile.

Age

Table 5 presents the percentage of the sample in each age category. The mean age of the sample was 65.8 years $(S D=13.78)$ and the range was $24-88$ years. The largest percentage (37.7\%) were in the $70-79$ year age group. While only $15.4 \%$ were less than 50 years of age, over half of the sample (57.4\%) were between 60 and 79 years old.

Gender

The study sample consisted of 44 females (72.1\%) and 17 males (27.9\%). The predominantly female sample was due in part to selection from a data base with a large proportion of breast cancer survivors. 
Table 5

Age of the Sample by Category

\begin{tabular}{|c|c|c|}
\hline Age Categories $(\mathrm{n}=61)$ & $n$ & $\%$ \\
\hline $21-29$ yrs & 1 & 1.6 \\
\hline $30-39$ yrs & 2 & 3.3 \\
\hline $40-49$ yrs & 7 & 11.5 \\
\hline $50-59$ yrs & 8 & 13.1 \\
\hline $60-69$ yrs & 12 & 19.7 \\
\hline $70-79$ yrs & 23 & 37.7 \\
\hline 80 and above & 8 & 13.1 \\
\hline
\end{tabular}

\section{General Demographics}

Table 6 presents general demographic data for this sample. The largest percentage of the sample were married $(n=39,63.9 \%)$ while close to one quarter were widowed $(n=14,23 \%)$. The high percentage of older participants may account for the sizable percent of widowed individuals in this sample. This sample was primarily Caucasian $(n=51,84 \%)$. This high percentage may be associated with higher rate of questionnaire return from more educated, English-speaking cancer survivors. This would also be expected when recruiting from primarily Caucasian data bases. Forty-three individuals reported their annual income, with over $60 \%$ reporting an annual income below $\$ 40,000$. The sample was well educated with $62.3 \%$ having gone to college and $16.4 \%$ with graduate degrees. This level of education may be associated with the dominant ethnicity and annual income bracket of this sample. Over $60 \%$ of the 59 participants who reported employment status were retired, which is to be expected in a primarily older sample. Fortyeight $\%$ of the sample reported their occupation. This may be related to the high 
percentage of retired individuals in the sample. Forty-two percent (of 31 who reported occupation) listed a profession or trade as their occupation. This may be associated with the high percentage of college-educated participants. The fact that only $42 \%$ reported an occupation may be due to the large percentage of retired individuals in the sample.

Table 6

General Demographics of the Sample

\begin{tabular}{|c|c|c|c|c|c|}
\hline Marital Status $(n=61)$ & n & $\%$ & Education $(n=61)$ & n & $\%$ \\
\hline $\begin{array}{l}\text { married } \\
\text { single } \\
\text { widowed } \\
\text { separated }\end{array}$ & $\begin{array}{r}39 \\
5 \\
14 \\
3\end{array}$ & $\begin{array}{r}63.9 \\
8.2 \\
23.0 \\
4.9\end{array}$ & $\begin{array}{l}\text { elementary } \\
\text { High school } \\
\text { college } \\
\text { graduate } \\
\text { post-graduate }\end{array}$ & $\begin{array}{r}2 \\
19 \\
28 \\
10 \\
2\end{array}$ & $\begin{array}{r}3.3 \\
31.1 \\
45.9 \\
16.4 \\
3.3\end{array}$ \\
\hline Ethnicity $(n=61)$ & n & $\%$ & Employment $(n=59)$ & $\mathbf{n}$ & $\%$ \\
\hline $\begin{array}{l}\text { Hispanic/Latino } \\
\text { Caucasian/white } \\
\text { African American } \\
\text { Native American/Alaskan }\end{array}$ & $\begin{array}{r}6 \\
51 \\
1 \\
3\end{array}$ & $\begin{array}{r}9.8 \\
83.6 \\
1.6 \\
4.9\end{array}$ & $\begin{array}{l}\text { full-time } \\
\text { part-time } \\
\text { unemployed } \\
\text { retired }\end{array}$ & $\begin{array}{r}12 \\
4 \\
3 \\
40\end{array}$ & $\begin{array}{r}20.3 \\
6.8 \\
5.1 \\
67.8 \\
\end{array}$ \\
\hline Annual Income $(n=43)$ & $\mathbf{n}$ & $\%$ & Occupation ( $\mathrm{n}=62)$ & $\mathbf{n}$ & $\%$ \\
\hline $\begin{array}{l}\$ 1,000-19,000 \\
\$ 20,000-39,000 \\
\$ 40,000-59,000 \\
\$ 60,000-89,000 \\
\$ 90,000 \text { and above }\end{array}$ & $\begin{array}{r}14 \\
12 \\
8 \\
5 \\
4\end{array}$ & $\begin{array}{r}32.6 \\
27.9 \\
18.6 \\
11.6 \\
9.3\end{array}$ & $\begin{array}{l}\text { none reported } \\
\text { student } \\
\text { unskilled labor (e.g., } \\
\text { janitor) } \\
\text { skilled labor (e.g., } \\
\text { personnel officer) } \\
\text { professional (e.g., } \\
\text { nurse, physician, } \\
\text { engineer) }\end{array}$ & $\begin{array}{r}31 \\
1 \\
7 \\
10 \\
13\end{array}$ & $\begin{array}{r}50.0 \\
1.6 \\
11.3 \\
16.1 \\
\\
21.0\end{array}$ \\
\hline
\end{tabular}

\section{Cancer Demographics}

Table 7 presents data regarding cancer demographics for this sample. The most common sites reported were breast $(n=22,35.5 \%)$, followed by gynecological and other cancers $(n=11,17.7 \%)$. This is congruent with the majority of the sample being female. 
represented 18 individuals or $29.5 \%$ of the study sample. Over half $(n=33,54.1 \%)$ of the sample reported having been treated with surgery alone or a combination of surgery and radiation. This is in keeping with available treatment options for the predominant types of cancers in this sample, that is, breast and gynecological cancers.

Participants reported being from 0-5 years to $30-35$ years beyond diagnosis. Five individuals left this item blank on the demographic profile. The majority of those who reported this information $(n=45,72.6 \%)$ were between $5-10$ years beyond diagnosis. This finding is associated with the study's inclusion criteria, that individuals must be at least 5 years beyond diagnosis. The two individuals in the $0-5$ year category were not deleted since there was a question mark next to this item on the demographic profile. Due to the large percentage of older subjects it is likely these respondents did not remember the exact date of their diagnosis and, thus, the number of years beyond diagnosis. Furthermore, their returned instruments were complete which was desirable in light of the large percentage of study instruments that were returned incomplete (over 50\%). In addition, the fact that the largest percentage of individuals in the study were 70-79 years of age makes it less likely for individuals to be living more than 10 years beyond diagnosis (due to death from natural causes or other acute or chronic illnesses).

Subjects were asked to identify their cancer stage at diagnosis, if known. It is surprising to note that only $37 \%(n=23)$ of the sample reported their cancer stage at the time of their diagnosis, particularly since this was a well-educated sample. It may be that this information has been forgotten because it is no longer relevant to long-term survivors of cancer. Another explanation may be that they were not clearly informed of this at the time of their diagnosis. Those who did report this information are almost evenly divided between 
being at the early stage $(n=12,19.4 \%)$ or advanced stage $(n=10,16.1 \%)$ at diagnosis.

Table 7

Cancer Demographics of the Study Sample

\begin{tabular}{||l|c|c|l|c|c||}
\hline Type of Cancer Diagnosed & $\mathrm{n}$ & $\%$ & \multicolumn{1}{|c|}{ Type of Treatment } & $\mathrm{n}$ & $\%$ \\
\hline \hline breast & 22 & 35.5 & Surgery & 19 & 31.1 \\
prostate & 5 & 8.1 & Chemotherapy & 7 & 11.5 \\
gynecological & 11 & 17.7 & Radiation & 4 & 6.6 \\
colon & 4 & 6.5 & Other & 1 & 1.6 \\
kidney/bladder & 2 & 3.2 & Surgery \& Chemotherapy & 6 & 9.8 \\
lung & 1 & 1.6 & Surgery \& Radiation & 14 & 23.0 \\
melanoma & 4 & 6.5 & Surgery \& other & 2 & 3.3 \\
leukemia & 1 & 1.6 & Chemotherapy \& radiation & 3 & 4.9 \\
multiple myeloma & 1 & 1.6 & Radiation and other & 2 & 3.3 \\
other & 11 & 17.7 & Surgery, chemotherapy \& radiation & 3 & 4.9 \\
\hline Years since Diagnosis & $\mathrm{n}$ & $\%$ & Cancer Stage at Diagnosis & $\mathrm{n}$ & $\%$ \\
\hline \hline Non-respondents & 5 & 8.0 & Unknown & 39 & 62.9 \\
$0-5$ & 2 & 3.5 & Early & 12 & 19.4 \\
$5-10$ & 45 & 72.6 & Advanced & 10 & 16.1 \\
$10-15$ & 5 & 8.8 & Inoperable/metastasis & 1 & 1.6 \\
$15-20$ & 1 & 1.8 & & & \\
$20-25$ & 2 & 3.5 & & & \\
$25-30$ & 1 & 1.8 & & & \\
$30-35$ & 1 & 1.8 & & & \\
\hline
\end{tabular}

In summary, the sample demographics reveal a group that consisted primarily of older, married, retired, Caucasian, college-educated females with breast cancer 5-10 years beyond diagnosis. Their cancers had been treated primarily by surgery or a combination of surgery and radiation. At the time they completed the questionnaires, they were recurrencefree by self-report.

\section{Bresentation of Findings}

Following presentation of the descriptive findings, the inferential statistical findings 
are presented sequentially in relationship to each of the research questions.

\section{Descriptive Findings}

Table 8 and Table 9 present the descriptive statistics for the sample in regard to each of the study variables. Highlights regarding the descriptive statistics for this sample of longterm cancer survivors include the following: (a) they scored high in terms of self-esteem, with moderate variability in scores (refer to range, mean, and standard deviation for selfesteem scores in Table 8); (b) they varied widely on degree of learned resourcefulness, (c) they also varied widely on two of the three main social support variables, functional and network support (however, the scores mostly clustered around mid-range), and (d) they scored moderately high on HRQL with greater variability in scores on the LTCSQLI measure than the QLI-CV.

Table 8

Descriptive Statistics for the Study Variables Self-Esteem Learned Resoucefulness, and $\mathrm{HROL}$

\begin{tabular}{||l|l|l|l|l||}
\hline \hline \multicolumn{1}{|c|}{ Variabie } & Possible Score Range & \multicolumn{1}{|c|}{ Mean } & \multicolumn{1}{|c|}{ SD } & Sample Score Range \\
\hline \hline Self-Esteem -RSE & $10-40$ & 34.15 & 4.90 & 23 to 40 \\
\hline Learned Resourcefulness SCS & $-108-+108$ & 24.11 & 23.78 & -64 to 74 \\
\hline QLI - CV Total Score & $0-30$ & 22.19 & 4.90 & $6.62-29.23$ \\
\hline Health \& Functioning & $0-30$ & 20.82 & 5.49 & $6.43-29.08$ \\
\hline Socioeconomic & $0-30$ & 22.70 & 5.50 & $4.22-30.0$ \\
\hline Psychological/Spiritual & $0-30$ & 23.22 & 5.60 & $3.93-30$ \\
\hline Family & $0-30$ & 23.96 & 6.8 & $0-30$ \\
\hline LTCSQLI - Total Score & $0-180$ & 129.85 & 25.15 & $62-172$ \\
\hline Physiological & $0-33$ & 24.23 & 3.82 & $13-31$ \\
\hline Psychological & $0-57$ & 43.79 & 8.97 & $19-57$ \\
\hline Spiritual & $0-39$ & 26.19 & 9.49 & $5-39$ \\
\hline Sociological & $0-51$ & 35.65 & 9.16 & $10-51$ \\
\hline
\end{tabular}


Table 9

Descriptive Statistics for the Study Variable Social Support

\begin{tabular}{|c|c|c|c|c|c|}
\hline Social Support - NSSQ & $\begin{array}{cc}\text { Norma } & \\
\text { Female } \\
\times \quad \text { (SD) } \\
\end{array}$ & $\begin{array}{r}\text { tive Values } \\
\text { Male } \\
\times \quad \text { (SD) } \\
\end{array}$ & Mean & SD & $\begin{array}{l}\text { Sample } \\
\text { Range }\end{array}$ \\
\hline Emotional Support & $127.2(72.7)$ & $119.3(75.2)$ & 125.45 & 94.07 & $0-370$ \\
\hline Tangible Support & $53.1(33.4)$ & $55.3(36.0)$ & 49.11 & 42.01 & $0-166$ \\
\hline Functional Support & $179.4(102.1)$ & $173.6(108.3)$ & 174.57 & 133.74 & $0-527$ \\
\hline Network Support & $98.5(53.8)$ & $95.0 \quad(55.3)$ & 93.81 & 62.25 & $0-220$ \\
\hline Total Loss & & & 6.37 & 10.61 & $0-54$ \\
\hline Spouse/Partner & & & 11.81 & 17.10 & $0-100$ \\
\hline Family/Relatives & & & 47.78 & 22.01 & $0-91.93$ \\
\hline Friends & & & 27.63 & 19.02 & $0-75.60$ \\
\hline Work/School & & & .76 & 4.01 & $0-28.64$ \\
\hline Neighbor & & & 2.40 & 4.50 & $0-13.95$ \\
\hline Health Care Provider & & & 2.96 & 6.49 & $0-31.43$ \\
\hline Counselor/Therapist & & & .37 & 2.19 & $0-15.79$ \\
\hline Minister/Priest/Rabbi & & & 2.18 & 4.52 & $0-21.43$ \\
\hline Other & & & .25 & 1.37 & $0-9.29$ \\
\hline
\end{tabular}

\section{Eindings Related to Research Questions}

Relationship between self-esteem and HRQL. A statistically significant positive correlation was found between self-esteem (RSE scores) and HRQL as measured by the calculated scores on the QLI-CV $(r=.69 ; \mathrm{p}=<.05)$. In addition, statistically significant positive correlations were found between self-esteem scores and all subscale scores of the QLI-CV; health and functioning, socioeconomic, psychological/spiritual, and family $(r=.64$, $50, .66, .54$ respectively; $\mathrm{p}=<.05$ ). A statistically significant positive correlation was found with only the psychological subscale of the LTCSQLI $(r=.27 ; p=<.05)$. The finding that self-esteem is strongly assnciated with HRQL in this group of long-term cancer survivors is 
consistent with prior research findings related to self-esteem in cancer survivors. A sufficient Cronbach's alpha coefficient of 0.88 was calculated for the RSE. This statistic adds psychometric support for the reliability of the RSE and the finding of a strong relationship of self-esteem and HRQL in the study sample.

Both HRQL instruments, QLI-CV and LTCSQLI, had high Cronbach's alpha reliability values of 0.96 and 0.94 respectively with the current study sample of long-term adult cancer survivors (See Table 10). Overall, the internal consistency of both HRQL instruments was high.

Table 10

Reliability Estimates from Study Sample for HROL Instruments

\begin{tabular}{||l|c|l|c|}
\hline \multicolumn{1}{|c|}{ QLI-CV } & Crohbach's Alpha & LTCSQLI & Crohbach's Alpha \\
\hline \hline Total Score & 0.96 & Total Score & 0.94 \\
\hline Health \& Functioning & 0.90 & Physiological & 0.53 \\
\hline Socioeconomic & 0.83 & Psychological & 0.88 \\
\hline Psychological/Spiritual & 0.86 & Spiritual & 0.91 \\
\hline Family & 0.68 & Sociological & 0.88 \\
\hline
\end{tabular}

The relationship between learned resourcefulness and HROL. Learned resourcefulness was found to be inversely related to HRQL as measured by the overall score on the QLI-CV $(r=-.32 ; \mathrm{p}=<.05)$. This finding suggests that there is a moderate tendency for increased learned resourcefulness to be associated with decreased overall HRQL in this group of long-term cancer survivors and vice versa. The subscale findings were parallel for all but the psychological/spiritual subscale of the QLI-CV. The significant correlation coefficients between learned resourcefulness and the health and functioning, socioeconomic, and family subscales of the QLI-CV were $-.26,-.44$, and -.27 respectively 
$(p=<.05)$. However, a statistically significant positive correlation was found between learned resourcefulness (SCS scores) and overall HRQL ( $r=.40, p$ value .00$)$ as measured by the calculated scores on the LTCSQLI as well as between learned resourcefulness and scores on all four HRQL subscales (physiological, $\Gamma=30$, p value .02 ; psychological, $\Gamma=.30$, $\mathrm{p}$ value .02 ; spiritual, $r=.20$, $\mathrm{p}$ value .11 ; and sociological, $r=.47, \mathrm{p}$ value .00 ). This finding suggests that there is a moderate tendency for increased learned resourcefulness to be associated with increased overall HRQL. The discrepancy in the direction of the relationship between learned resourcefulness and HRQL as measured by the two HRQL instruments may be partially explained by the possibility that the two instruments each measure a different construct of HRQL, one a more global HRQL construct and one more specific to HRQL as perceived by long-term cancer survivors. An alternate, and more likely explanation, is related to the validity of the LTCSQLI since it has not yet been tested.

Similar to the previous research studies which used the SCS with patients with chronic illnesses such as cancer, the SCS demonstrated a high internal consistency $(r=0.86)$ for the study sample of 62 long-term adult cancer survivors. This again adds psychometric support for the reliability of the SCS results.

Relationship between social support and HRQL. No statistically significant relationships were found between scores on the NSSQ and HRQL scores on the QLI-CV for two of three main social support variables, including: total function (emotional support and tangible aid) and total network (number in network, duration of relationships and frequency of contact) (See Table 10). However, as expected, a statistically significant inverse relationship was found to exist between the total loss variable (recent loss, number of individuals lost and amount of that loss) and the total HRQL scores. This was also true 
for all four QLI-CV subscales (health and functioning, socioeconomic, psychological/spiritual, family) (See Table 11). No significant relationships were found between scores on the NSSQ and the investigator-generated HRQL measure, the LTCSQLI. Again the discrepancy in findings between the two HRQL measures may be partially explained by the fact that these instruments may each measure a different construct of HRQL.

These findings suggest that increases in recent loss are strongly associated with decreases in HRQL (as measured by the QLI-CV) for this group of long-term cancer survivors. The sample was composed of primarily older individuals who may have lost more individuals from their support network due to the natural consequences of aging. In addition to the number of individuals lost, the respondents were asked to rate the amount of support lost from each of these individuals from "none" to "a great deal". Assuming that individuals lost were known to these cancer survivors for quite some time based on age, the amount of support lost may have been rated as "a great deal"-- thus negatively influencing their scores on this variable of social support. The statistically significant relationships between the total loss variable of social support and scores on all 4 subscales of the QLICV suggest that this variable has a pervasive influence on HRQL. This pervasive influence may be a reminder to long-term survivors of their own mortality, in spite 
Table 11

Correlation Coefficients for Social Support (NSSO) and HROL Usine OLL-CY

\begin{tabular}{|c|c|c|c|c|c|}
\hline \multirow[t]{2}{*}{ NSSQ Variables } & \multicolumn{5}{|c|}{ QLI-CV scores (p values) } \\
\hline & $\begin{array}{l}\text { Health \& } \\
\text { Functioning }\end{array}$ & Socioeconomic & $\begin{array}{l}\text { Psychological } \\
\text { Spiritual }\end{array}$ & Family & Total \\
\hline Total Function & $.10(p=.42)$ & $-.01(\mathrm{p}=.93)$ & $-.11(p=.39)$ & $.02(p=.85)$ & $.02(p=.86)$ \\
\hline Total Network & $.07(p=.58)$ & $.00(p=.98)$ & $-.11(p=.40)$ & $-.02(p=.91)$ & $.01(p=.96)$ \\
\hline Total Loss & $-.25(p=.05)^{*}$ & $-.41(p=.001)^{*}$ & $-.43(p=.001)^{*}$ & $-.29(p=.02)^{*}$ & $-.38(p=.00)^{*}$ \\
\hline
\end{tabular}

*significance at $<.05$

of their living and surviving beyond a cancer diagnosis. However, this experience of loss may not be limited to the long-term cancer survivor since increased losses of social relationships are associated with age in the general population.

In contrast, no significant relationships were found between scores on the NSSQ and HRQL using the investigator-generated instrument (the LTCSQLI) and its four subscales (physiological. nsurhological sociological and spiritual) (See Table 12). The lack of significant relationships is not necessarily related to reliability of this tool which was noted to have generally high reliability estimates for the study sample (See Table 10). But, rather, the lack of a demonstrated relationship between these two study variables may be due to lack of instrument validity (validity for the LTCSQLI has not been tested) or may reflect that truly no relationship exists between these variables.

A high internal consistency of 0.95 (Cronbach's alpha) was calculated for the NSSQ in this sample of long-term cancer survivors. In addition, high internal consistency was calculated for both the QLI-CV and the LTCSQLI in this sample (0.96 and 0.94 respectively). However, there is currently no evidence of the validity of the new HRQL instrument, the LTCSQLI. Thus, the strength of the finding of a statistically significant 
inverse relationship between the loss component of social support and HRQL is best supported only as measured by the QLI-CV which has sufficient reliability and validity (See discussion regarding instruments in Chapter 3).

Table 12

Correlation Coefficients for Social Support (NSSO) and HROL Using LTCSOLI.

\begin{tabular}{||l|l|l|l|l|l||}
\hline \multirow{2}{*}{$\begin{array}{c}\text { NSSQ } \\
\text { Variables }\end{array}$} & \multicolumn{5}{|c|}{ LTCSQLI Scores (p values) } \\
\cline { 2 - 7 } & Physiological & Psychological & Spiritual & Sociological & Total \\
\hline \hline Total Function & $.06(p=.61)$ & $.04(p=.75)$ & $.17(p=.19)$ & $.13(p=.32)$ & $.14(p=.30)$ \\
\hline Total Network & $.07(p=.61)$ & $.03(p=.83)$ & $.12(p=.35)$ & $.16(p=.22)$ & $.12(p=.34)$ \\
\hline Total Loss & $.08(p=.53)$ & $-.09(p=.47)$ & $-.11(p=.38)$ & $-.04(p=.78)$ & $-.08(p=.55)$ \\
\hline
\end{tabular}

\section{Self-esteem. leamed resourcefulness and social support as predictors of HROL.}

Multiple regression analyses were performed with self-esteem, learned resourcefulness, and the total loss score for social support (the only statistically significant component of social support) as the three independent variables and HRQL as measured by the QLI-CV as the dependent variable (See Table 13). Forward stepwise multiple regression analysis revealed the adjusted $R$ square for this model was .53, with self-esteem contributing $52 \%$ to the variance in $H R Q L$. This finding suggests that a little over half of the variance in the HRQL scores in this group of long-term cancer survivors can be explained by self-esteem $\left(\mathbf{R}^{\mathbf{2}}=\right.$ .52), with learned resourcefulness and the total loss component of social support contributing only $1 \%$ more to the variance in HRQL. These findings suggest that, of the three variables, self-esteem had the greatest predictive value for HRQL and the total loss component of social support the least in this sample of long-term cancer survivors. Learned resourcefulness also made a significant contribution to the variance in HRQL. The strength of these findings is 
supported by the moderate to high reliability estimates of each instrument used to measure each variable in the regression equation. This is further supported by the strong evidence of validity for the QLI-CV (see Chapter 3 for discussion regarding content, concurrent and construct validity of the tool with sample of female breast cancer patients).

Table 13

Eorward Stepwise Multiple Regression Statistics for Independent Variables and HROL Using the OLI-CY

\begin{tabular}{|l|l|l|l|l|}
\hline \multicolumn{1}{|c|}{ Variables } & \multicolumn{1}{c|}{$\mathrm{df}$} & \multicolumn{1}{c|}{$\mathrm{F}$} & $\mathrm{p}$ value & \multicolumn{1}{c|}{$\mathrm{r}^{2}$} \\
\hline Self-Esteem \& HRQL & 5 & 10.14 & .000 & .52 \\
\hline Learned Resourcefulness \& HRQL & 5 & 2.93 & .025 & .19 \\
\hline Total Loss (significant Social Support variable) \& HRQL & 5 & 1.67 & .165 & .07 \\
\hline Combination of 3 Variables \& HRQL & 3 & 24.22 & .000 & .53 \\
\hline
\end{tabular}

Supplementary Analysis

Analysis of the data revealed additional findings that were not directly related to the four research questions. These findings are briefly presented in the following section.

Relationship between significant demographic variables and HRQL as measured by

QLI-CV. Age was found to be significantly related to the overall QLI-CV scores $(r=.32$., $p<.05)$ and scores on the socioeconomic $(r=.41, p<.05)$ and psychological/spiritual $(r=.38$, $\mathrm{p}<.05$ ) subscales of the QLI-CV. These findings suggest that, as age increases, HRQL (particularly in the socioeconomic and psychological/spiritual dimensions) also increases. Age was also found to be significantly related to the social support subscale scores for total functional support from minister/priest/rabbi $(r=.30, p<.05)$. In contrast, there was a slight nonsignificant, negative relationship between age and functional support from friends, work or school associates and counselors or therapists. These findings suggest that, for this group 
of long-term survivors, as age increases there was a tendency to experience spiritual resources as more supportive than counselors or therapists, friends (whose number and availability may have diminished with age) and work or school associates (as a function of retirement or disability associated with age).

Cancer stage at diagnosis was found to be inversely related to learned resourcefulness $(r=-.25, p<.05)$. This finding suggests that with advanced disease at diagnosis, learned resourcefulness (self-control, self-direction, self-efficacy) tends to decrease.

Findings related to LTCSOLI. Other supplementary findings worth mentioning are related to the investigator-generated HRQL instrument designed for this study, the LTCSQOLI. Two sets of findings will be described: those related to the independent variables (self-esteem, learned resourcefulness and social support) and those related to QLI$\mathrm{CV}$, the established HRQL measure.

A statistically significant inverse relationship was found to exist between social support from health care providers (HCP) and the total LTCSQOLI score for this sample $(r=-28, p<.05)$. Furthermore, the HCP support score (one among 9 categories of support; spouse/partner, family or relatives, friends, work/school associates, neighbors, health care providers, counselor or therapist, minister/priest/rabbi, other) was found to be inversely related to the psychological, spiritual and sociological LTCSQOLI subscale scores $(r=-.24$, $-.25,-.25$ respectively, $p=>.05$ ). Although not statistically significant for these subscale scores, these findings suggest there was a tendency for HRQL (especially in the psychological, spiritual, and sociological dimensions) to increase as support from health care providers decreases, for this group of long-term cancer survivors. This finding suggests 
that, for this sample, the less support individuals perceived from HCP's the higher they rated their HRQL as measured by the LTCSQLI. In other words, as HRQL increased individual perceived less support from HCP. Maybe this finding is expected, particularly in the case of long-term cancer survivors who are disease-free and, thus, would have limited contact with HCPs.

Minister, priest, or rabbi was a second source of support that did not demonstrate a statistically significant relationship to HRQL as measured by QLI-CV. Yet results indicate a positive relationship that approached significance between all support scores from minister, priest, or rabbi and QLI-CV subscale scores (socioeconomic subscale, $r=.24, p$ value .08; psychological/spiritual subscale, $\Gamma=.23$, p value .09 ; family subscale, $r=.26, \mathrm{p}$ value .06 ) except those on the health and functioning subscale. This was not the case with the LTCSQLI. The QLI-CV findings suggest that, as support from minister/priest/rabbi increased there was a mild tendency for HRQL to also increase for this sample of long-term cancer survivors. The different findings between the two HRQL instruments indicate that the LTCSQLI may, in fact, measure a different HRQL construct from that measured by the QLI-CV instrument. An alternate explanation for this finding is the lack of validity of the LTCSQLI. This needs to be explored with further psychometric testing of the new HRQL instrument.

Qualitative findings. At the end of the demographic profile the following statement was included, "Please add any information you would like to share regarding your quality of life as a long-term cancer survivor". Twenty-six of the 62 participants (42\%) responded to this question. The responses mentioned more than once fell into four general areas: (a) physical concerns/comments $(n=6,23 \%)$, (b) family and social comments $(n=6,23 \%), \quad c)$ thankfuiness for being alive $(n=5,19 \%)$, and d) comments related to health care 
providers $(n=4,15 \%)$. Responses were both negative and positive, with the majority being

positive. Responses mentioned only once included sexual concerns accompanied by feelings of rejection, relinquishing guilty feelings, value of support groups, and the lack of time to focus on self since the needs of others took priority. Verbatim examples from the four general areas mentioned more than once include the following:

Physical concerns/comments "This year I have felt periods of tiredness and light depression with periods of unhappiness - this is not me. I am a very happy person. My Dr. has told me to drop the Tamoxifen for 2 months. I'm concerned about going without the medication as I have had no signs of a recurrence"

Family and social

Thankfulness for being alive

"Keeping busy doing things that maintain and/or improve the high quality of life the wife and I enjoy". "My quality of life has been very good. I have been well supported by family and friends"

"I appreciate being alive and realize good health is the most important thing". "I am glad to be alive, each day brings a new beginning. I hope I live to see my great grandchildren. Most of all I hope my health stays good and my husband lives long too".

Comments related to health care providers

"The counseling and information I received is helpful and informative. Continuing medical check ups are extremely important and should be stressed to patients. Good doctors and nurses are key ingredients!!!!" "I wore a 'bag' for 7 years. Thanks to surgeon I was put back together. My feeling about myself improved immediately. I feel so fortunate, thanks to all my care givers".

In general, these comments reflect a positive HRQL. Caution in interpreting these comments is needed since over half the sample $(58 \%, n=36)$ (who may have had less positive experiences as survivors) did not respond to this question. It is also important to note that physical concerns should continue to be included in the assessment of QOL, even 
with participants over 5 years beyond initial diagnosis. It could be implied, from the social support statements embedded in three of the four areas of qualitative data, that there is a contradiction to the lack of significant findings for the social support variable as measured by the NSSQ. However, the social support items of the NSSQ (study measure for social support) are intended to assess specifically functional and network properties of social support along with losses of support. The comments volunteered differ in that they seem more general in nature and may not be the same as the functional and network properties intended to be measured by the NSSQ.

\section{Discussion of the Findings}

Discussion of the findings of this descriptive study has as its purpose adding to nursing's understanding of $\mathrm{HRQL}$, particularly in the long-term survivor of cancer. This study was designed to accomplish two objectives. First, it was a deliberate attempt to specifically describe the long-term cancer survivor. The second focus of this study was to examine the relationships between selected variables identified in the literature to be associated with HRQL during earlier seasons of survival in the later season of survival. The following discussion first briefly explores the characteristics of long-term cancer survivors as evidenced in this study and then presents a synthesis of the results in relation to the conceptual framework of the study and prior research in this area.

In general, long-term survivors of cancer, despite lingering side effects from treatment and a variety of difficulties in continuing to survive, perceive themselves as leading full, meaningful lives (Haberman et al., 1993). Studies with long-term survivors of bone marrow transplants indicate that they report few physiologic disruptions and aboveaverage QOL. This information can have a positive influence on newly-diagnosed patients 
Survivors HRQL 102

going through the decision-making process (Whedon et al., 1995). In addition to long-term survivors' perception of meaningful lives with cure, they share an optimistic outlook for the future and effective adjustment (Belec, 1992). Long-term survivors of breast cancer report emerging from the cancer experience with a clearer sense of self, gratitude for life and strength, and confidence in their ability to manage the challenges of life (Carter, 1993). Many of these positive sentiments were also reported in the current study by the subjects who chose to respond to the statement "Additional information you would like to share as a cancer survivor". Although (as in Whedon et al.'s (1995) study) few physiological disruptions were reported, they continue to be present in the experience of the long-term survivor. This was supported by the qualitative findings in the current study.

Although many long-term survivors have gotten "on with living beyond diagnosis" and are able to describe positive aspects of the cancer experience, there are those whose experience is less positive. Some continue to struggle with unresolved issues and many fear recurrence. Long-term survivors of Hodgkin's disease report more physical restrictions which, in turn, affect role function. They perceive overall health as lower, they are less satisfied with their sexual lives, employment is limited and there are financial obstacles in acquiring loans and life insurance (van Tulder, Aaronson, \& Bruning, 1994). Negative sentiments did not predominate in the results of the current study, yet there was a significant inverse relationship between social support losses and HRQL in this sample of long-term survivors. Subjects in the study were primarily older adults who may experience multiple, significant losses associated with aging. This could, in turn, potentially have a negative influence on the experience of this group of long-term cancer survivors. The relationship of social support losses to decreased HRQL is not unique to the experience of long-term 
cancer survivorship as this relationship exists in life generally and particularly among the aged population.

This study examined relationships between the variables self-esteem, learned resourcefulness, and sorial support and HRQL. Self-esteem was found to be moderately associated with HRQL as measured by the QLI-CV. This is congruent with previous research with survivors of cancer. Both Polinsky (1994) and Thome (1989) reported selfesteem as a mediator in the process of adjustment to cancer via affirmation from either family, friends or health care providers. This study's findings regarding self-esteem also lend support to Dirksen's (1990) study in which self-esteem was found to be an important determinant of subjective well-being. Curbow and Somerfield (1991) found support for the idea that self-esteem may play a central role in managing the stress of the diagnosis of cancer. The current study supports the role of self-esteem in the ongoing process of living beyond cancer as long-term survivors.

The general description of the positive outlook of cancer survivors may be linked with Hobfoll and Walfisch's (1984) description of self-esteem as a resource variable that helps individuals withstand the negative effects of cancer. This idea of self-esteem as a resource variable may be similar to what Heidrich and Ward (1992) found in their research which indicated that positive adjustment of women with cancer may be the result of their ability to manipulate their self-esteem to prevent psychological distress. These may be the processes which are reflected in the current study finding that self-esteem is positively associated with HRQL.

Learned resourcefulness was found to have a slight inverse association with HRQL. Perhaps cognitive attempts to control undesirable thoughts, feelings, sensations associated 
with cancer (i.e., use of increased learned resourcefulness behaviors) reminded the subjects of their unpleasant experiences of feeling out of control and thus the need to implement learned resourcefulness behaviors to maintain control over cancer which, in turn, negatively influenced their present perceptions of HRQL. The lack of a significant relationship between learned resourcefulness (the cognitive-behavioral repertoire of specific coping skills to cope with adversity) and the QLI-CV psychological/spiritual subscale scores may be explained by the buffering influence or transcendent quality associated with this dimension of HRQL (subscale items asked about peace of mind, faith in God, and life satisfaction). If a longterm cancer survivor experiences peace and life satisfaction within the psychological/spiritual dimension of HRQL they may not perceive a need to implement the coping skills of learned resourcefulness. Or it may be due to an assumption contained in the conceptual model of self-control (which is the basis of learned resourcefulness): that there are multiple and interactive factors (other than those isolated in this study) influencing this cognitive skill. Another interpretation of this finding may be that long-term survivors who truly "let go of" or have accepted all the meanings and experiences associated with a cancer diagnosis experience a decreased need for control and do not implement the skill of learned resourcefulness.

Guillory (1992) suggested that social support enhances mastery over cancer. If the ongoing impact of cancer continues into the permanent season of survival, the presence of social support would then be necessary to master the long-term challenges of cancer such as those faced by long-term survivors. It follows, then, that if there are losses of social support networks (particularly those support systems that provide personal meaning to one's wellbeing), one's satisfaction with life would decrease. This was reflected in the study finding 
that total loss component of social support demonstrated a slight imverse association with HRQL. However, this must be interpreted along with the finding that only $15 \%$ of the study sample were below 50 years of age. Losses of friends and family members is to be expected with increased age. Thus the older long-term cancer survivor may be at increased risk for decreased HRQL based on this relationship of the total loss component of social support with HRQL. Although the accumulation of all losses of relationship cannot be avoided, help may be available to develop strategies to buffer these losses.

Tempelaar et al. (1989) have suggested that positive and negative social exchanges are associated with feelings of self-esteem. If these social exchanges are also with individuals who provide support to the long-term cancer survivor, self-esteem may be enhanced or decreased depending on the nature (positive or negative) of the social exchange. If positive support is perceived from these exchanges the effect on self-esteem may be positive. Based on the study findings that self-esteem is strongly associated with HRQL, social support, which can have a positive effect on self-esteem, may indirectly influence HRQL. This has implications for long-term survivors who experience increased losses of social support, particularly this sample of long-term cancer survivors in which there was an inverse association between the loss component of social support and HRQL.

On a more general note, the literature documents the presence of social support in the positive experience of cancer survivorship, although it is not the sole mechanism of survival (Ell et al., 1992). The resources for support are many. Fredette's (1995) study with breast cancer survivors reported social support from family, especially husbands, to be more meaningful than from friends. In contrast, Lugton's (1997) study, also with breast cancer patients, reported the vital role of informal support in maintaining identity as a means 
of coping with breast cancer. The current study findings indicated no significant association between a particular source of support and HRQL. However, support from ministers, priests and rabbi approached significance using the QLI-CV in this group of long-term cancer survivors. A variety of variables may help to explain this tendency such as age, gender or cancer site. This question was explored by Ell et al. (1992) who reported evidence to suggest cancer site and stage influences social relations which, in turn, may predict survival. The research questions in the current descriptive study did not focus on the influence of cancer site in regards to social support.

The overwhelming predominance of self-esteem as the strongest predictor deserves further discussion. The finding that self-esteem explained the greatest proportion of HRQL is reflected in findings in other research studies with cancer patients (Dirksen, 1989; Temmpelaar et al. 1989). In addition self-esteem is associated with many aspects of HRQL that long-term cancer survivors face in the experience of life after cancer. For example, role function, sexuality, and intimacy issues are ongoing concerns reported by BMT survivors (Haberman et al., 1993) and survivors of Hodgkin's disease (van Tulder et al., 1994). These issues are associated with how people feel about how they see themselves, in other words with their self-esteem. Therefore, it is logical that self-esteem contributes strongly to HRQL. The current study provided strong evidence to support this.

Based on study findings, the diagram of the conceptual framework for the study was modified (See Figure 2). The study supports both the interrelatedness of the independent study variables and their association with HRQL. However, the proportion of the contribution of self-esteem, learned resourcefulness, and social support varies. This is represented in the modified diagram of the conceptual framework by the varying sizes of 
circles representing the independent variables.

The circle representing self-esteem is the largest since it explained the largest proportion $\left(R^{2}=.52\right)$ of HRQL in this group of long-term cancer survivors. The second largest circle represents learned resourcefulness which explained 17\% of HRQL for the study sample. The smallest circle represents the loss component of social support which contributed the least $\left(R^{2}=.07\right)$ to $H R Q L$ in this group of long-term cancer survivors. The finding that self-esteem was the strongest predictor of HRQL is consistent with the literature. The ranking of learned resourcefulness and the loss component of social support as second and third is not explicit in the cancer survivor literature other than that they may predict $H R Q L$ in cancer survivors.

The placement of the three independent variables in the psychological and social domains of HRQL may not be completely accurate. Rather they may influence all four domains of the model. This idea was implied in a qualitative study with breast cancer survivors by Wyatt et al. (1993) where they stated “...people do not fit their lives into domains. Instead, concern/issues often cross over into two or more domains of life..." 
Survivors HRQL 108

Eigure 2. Diagram of Modified Conceptual Framework for this study.

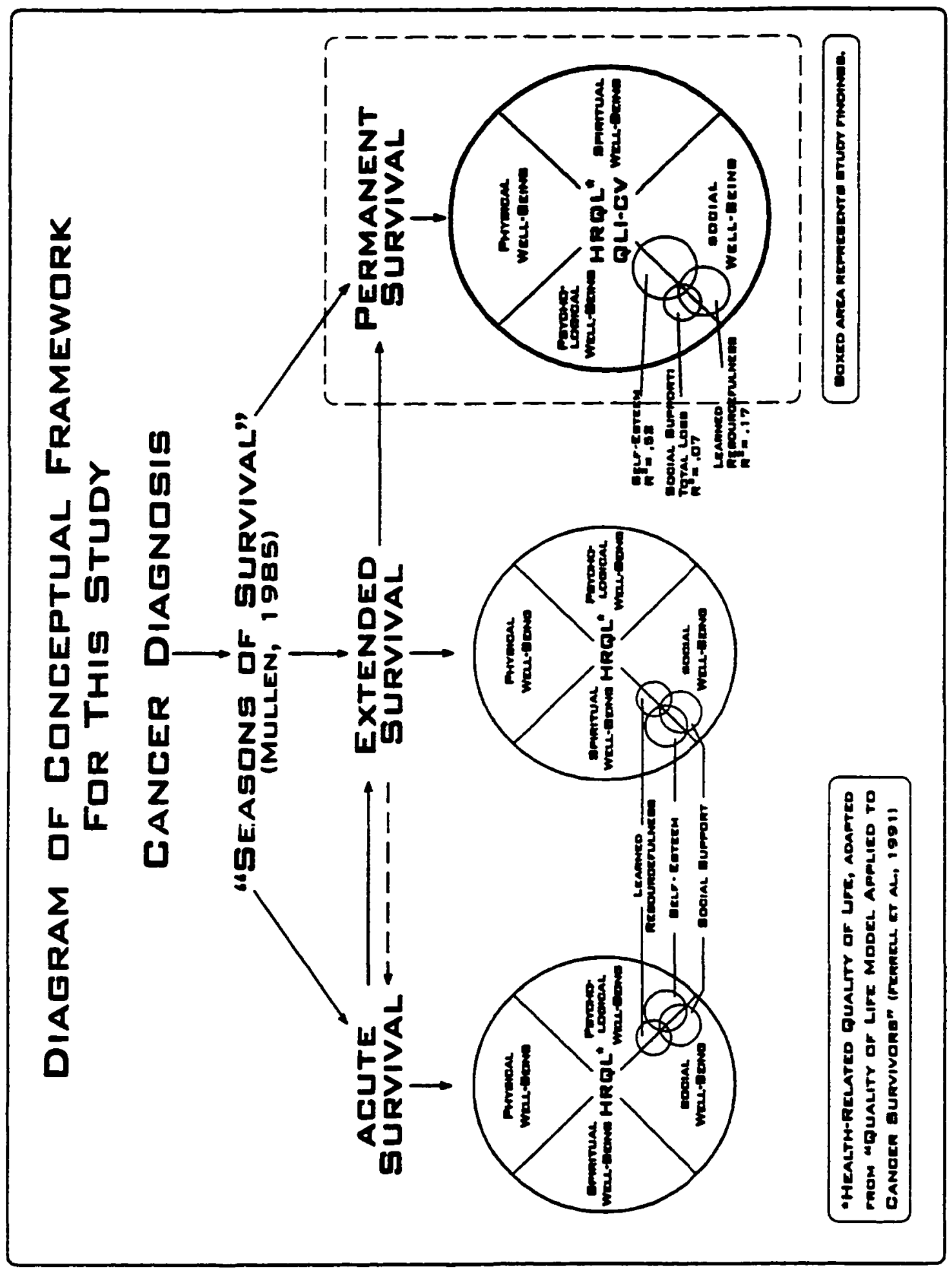


(p. 445). It would be important in future HRQL research with long-term cancer survivors to explore the literature to expand this conceptual framework, and then ask the questions that could make possible a more accurate depiction of the relationship between the independent variables and $\mathrm{HRQL}$.

\section{Summary}

In summary, the study data suggest the following for this sample of long-term cancer survivors: (a) self-esteem has a strong positive association with HRQL, (b) there is a moderate tendency for learned resourcefulness to be associated with decreased overall HRQL, (c) an increase in recent losses of social support is moderately associated with decreased HRQL, and (d) self-esteem, learned resourcefulness and the total loss component of social support combined are moderately strong predictors of HRQL, with self-esteem explalining by far the largest proportion of the variance in the dependent variable. Supplementary analyses of the findings suggest the following for this sample of long-term cancer survivors: (a) as age increases, $\mathrm{HRQL}$ increases, particularly in the socioeconomic and psychological/spiritual dimensions; (b) as age increases there is a tendency for long-term cancer survivors to experience spiritual resources as more supportive than counselors, therapists, friends, and work or school associates; and (c) the LTCSQLI may measure a different HRQL construct from that measured by the QLI-CV. Lastly, a brief analysis of the qualitative findings suggest an overall positive outlook on HRQL among these long-term cancer survivors despite persistence of ongoing physical concerns. 


\section{Survivors HRQL}

\section{Chapter 5}

\section{Summary, Conclusions, and Recommendations}

The documented and anticipated growth in the population of cancer survivors indicate that cancer is a survivable disease. Cancer no longer is necessarily a death sentence, yet it continues to have major impact on the appraisal of and satisfaction with health aspects of life that cancer survivors value. The lasting effects of cancer diagnosis and treatment impact HRQL in the three seasons of survival, acute, extended and permanent. With the progression of technology and science in cancer treatment, survival time has increased. The interactions of health care providers with survivors of cancer has led to new questions regarding the long-term survivor's judgements about and satisfaction with life.

\section{Summary of Study and Findings}

The oncology and QOL literature addresses the phenomenon of the adult cancer experience, cancer survival, and its effect on HRQL. The experience is reported and described as multi-faceted and ongoing in nature (Carter, 1989; de Haes \& Van Knippenberg, 1985; Dobkin \& Morrow, 1986; Ferrell, 1996). With the increase in survival time has come the need for health care professionals to be informed about the life experience of survivors following the treatment of cancer. Cancer survivors face not only physiological sequelae of their treatment but psychological, sociological and spiritual sequelae as well. In addition, the diagnosis of cancer often changes one's life forever. These lasting effects of cancer can take their toll on HRQL for cancer survivors.

Mullen (1985) conceptualized the experience of cancer as "Seasons of Survival" 
with three seasons; acute survival, extended survival, and permanent survival. The survivor in permanent survival, or the long-term cancer survivor was the focus of this study. Much has been written in the theoretical, empirical and anecdotal literature about the first two "seasons of survival" and less about permanent survival. In addition, approximately $20 \%$ of cancer survivors experience significant psychologic adjustment difficulties (Dobkin \& Morrow, 1986). Specific variables have been identified in cancer survivor studies to influence HRQL in the acute and extended "seasons". With increased survival, the question remains whether the influence of variables influencing HRQL in the acute and extended "seasons" continues into the "season" of permanent survival.

The purpose of this study was to describe the relationships between selected psychosocial variables and HRQL in permanent cancer survivors. A descriptive, correlational, and noninterventional study design sought to answer 4 research questions: (a) What is the relationship of self-esteem to HRQL for long-term cancer survivors? (b) What is the relationship of learned resourcefulness to HRQL for long-term cancer survivors? (c) What is the relationship of social support to HRQL for long-term cancer survivors? and (d)To what extent are self-esteem, learned resourcefulness, and social support predictive of HRQL for long-term cancer survivors? The conceptual framework for the study was derived from a combination of elements from both Mullen's (1985) "seasons of survival"and Ferrell et al.'s (1991) Quality of Life Model Applied to Cancer Survivors.

Following a pilot study to test data collection procedures, informed consent was sought from 456 eligible subjects from two cancer databases to participate in the study by completing six mail-back, self-report instruments (demographic profile, Rosenberg's SelfEsteem Scale, Rosenbaum's Self-Control Schedule, Norbeck's Social Support 
Ferrans and Power's Quality of Life Index-Cancer Version and The Long-Term Cancer Survivor's Quality of Life Inventory). Usable data from 62, primarily older, female, Caucasian, breast cancer survivors were analyzed using descriptive, correlational, and forward stepwise multiple regression procedures.

A summary of major study findings is presented here. Demographic data revealed over half $(57.4 \%)$ the study sample were between 60 and 79 years old. The predominantly female sample $(77.1 \%, n=44)$ were mostly married and Caucasian with college degrees and had been diagnosed with and treated for breast cancer. Self-esteem, as measured by the Rosenberg Self-Esteem Scale, was found to be significantly positively associated with HRQL as measured by the QLI-CV. A moderate tendency was found for increased learned resourcefulness to be associated with decreased overall HRQL, as measured by scores on the Rosenbaum Self-Control Schedule and the QLI-CV. Only the total loss component of social support, as measured by scores on the NSSQ, showed a statistically significant relationship to HRQL as measured by the QLI-CV. The relationships between each independent variable and the investigator-generated HRQL instrument were not included in the findings and discussion because validity has not been established. Lastly, self-esteem $\left(R^{2}=.52\right)$ accounted for all but $1 \%$ of the total variance $\left(R^{2}=.53\right.$ ) in the HRQL scores (as measured by the QLI-CV) for the regression model using self-esteem, leamed resourcefulness and the total loss component of social in this group of long-term cancer survivors. The same regression model was not used with the investigator-generated HRQL instrument due to lack of validity testing of the LTCSQLI. 


\section{Conclusions}

The conclusions based on the study findings are as follows: (a) long-term cancer survivors have ongoing issues and concerns regarding the experience of living beyond the diagnosis and treatment for their cancer, (b) to understand HRQL for long-term cancer survivors one must consider both age-appropriate as well as cancer survivor "season"appropriate factors that may influence HRQL; (c) maintenance and promotion of self-esteem may be an important way of promoting increased HRQL; (d) anticipation and minimization of social support losses, where possible, may help to prevent decreases in HRQL.

The strength of the relationship between self-esteem and HRQL proved to be similar to those reported in prior studies with cancer survivors. The variations from findings in other research related to psychosocial variables and HRQL in cancer survivors may be accounted for by specific differences in the phases of cancer survivorship studied (acute, extended, and/or permanent).

\section{Recommendations for Nursing Practice}

This research confirms the literature describing the ongoing effects of cancer on HRQL. The results most strongly underscore the importance of assessing and supporting selfesteem in the long-term cancer survivor as a means of enhancing HRQL. This assessment and support could begin with the cancer survivor in the "acute" season and continue into the "extended" and "permanent" seasons. Specific strategies and approaches to increasing selfesteem need to be explored. The study findings have implications for the assessment and evaluation by the nurse of the strategies currently in place that influence the long-term cancer survivor's self-esteem. These could range from the use of community groups to more individually culturally-sensitive strategies. 
Client assessments should also include data regarding the losses in the support system of the long-term cancer survivor. Included in this nursing assessment should be the number of individuals lost, as well as, the intensity and meaning of each loss for the long-term cancer survivor. The meanings behind the anticipated loss of social support may be influenced by factors related to specific gender, age or ethnicity. This knowledge can further assist the nurse to provide specific, effective care to increase HRQL for the long-term cancer survivor.

Assessment of the strategies used by long-term cancer survivors to promote selfcontrol (learned resourcefulness) and cognitive strategies used to manage living as a long-term survivor of cancer may provide further understanding of HRQL in long-term cancer survivors. Age-appropriate sources of social support (e.g., religiously- oriented support rather than counselors and therapists for older adult cancer survivors) should be identified and fostered to promote HRQL for older long-term survivors.

\section{Recommendations for Nursing Education}

The oncology component in nursing curriculums should be broadened to include both theory and experience related to long-term needs of cancer survivors. The growing knowledge about this special group of clients will prepare future oncology nurses to learn to think and practice in the context of living as opposed to the well-known fear context of loss and death historically associated with cancer. In addition, the findings provide an empirical basis from which to teach planning of care specific to the long-term cancer survivor.

Career counseling for students considering an oncology specialty may be enhanced by the knowledge that the effects of a diagnosis of cancer and its treatment are ongoing and can be influenced positively by nurses. This specific knowledge regarding the diagnosis of cancer and the role of the nurse may be an important element in an individuals decision for or against 
pursuing a career in nursing. Lastly, study findings may imply a need to examine clinical placement sites related to oncology rotations for nursing students. Community-based settings where students can observe and participate in specific programs directed at supporting and increasing self-esteem and social support for long-term cancer survivors may impress them with the importance of the role of these variables in successful living beyond cancer.

\section{Recommendations for Further Research}

Additional research is warranted to replicate these findings. However, several limitations of this study should be addressed in future research. Findings from this study cannot be generalized to any specific gender, age, cancer site, ethnic, or income group nationwide. Rather, generalization of the findings is limited by the homogeneity of the sample (Caucasian, highly educated, and predominantly older females with breast cancer). Inclusion of subjects of both genders with different ethnic heritages, educational and income levels, and with a higher percentage of younger adults is needed to enhance generalizability of findings. Also, the sample was drawn from cancer survivors living in the Western United States; therefore, generalization of these findings to individuals living in other geographic regions is limited. Furthermore, a strong self-selection bias exists based on the low response rate of the study. Perhaps the response rate in future studies could be improved by the use of phone calls or postcards as reminders to potential subjects to return the questionnaires or by reducing the number of and/or simplifying the study instruments.

Further analysis of the data from this study is recommended in order to tease out circularity of the instruments; that is whether and to what extent there maybe overlap of items and subscales. Once this is identified the data analysis can be re-run selecting out subscales that do not overlap. 
Further qualitative and quantitative study is needed concerning the specific variables that influence HRQL of long-term cancer survivors. Qualitative studies that focus on longterm cancer survivors with specific cancer sites is needed to provide an in depth understanding of the commonalities and differences in their experience and to generate further questions that may lead to and/or enhance future quantitative approaches to the study of these variables. A replication of this study with focus on a specific cancer site, gender and/or ethnicity would add to the knowledge base concerning the HRQL of long-term cancer survivors. Additionally, replication of the study using only one of the complex independent variables could further the understanding of their unique association to HRQL. The knowledge of relationships between each variable and HRQL will provide greater understanding of the dynamics of living beyond cancer. Lastly, further development and psychometric testing of the investigator-generated HRQL instrument is recommended.

Despite the inherent difficulties with long-term research, there is merit in replicating this study using a longitudinal design to capture and describe all 3 "seasons" in the same sample. This could increase knowledge regarding the variables of the current study (as well as other variables that may influence long-term cancer survivorship) throughout the process of moving from one season to another. This, again, could provide a more complete picture of the dynamics of living as a cancer survivor in both the acute and extended phases.

The cascading influence of the study variables (self-esteem, learned resourcefulness, and social support) may lend themselves to further exploration via path analysis regarding the direction and strength of the interrelatedness of these complex variables. The structure for this analysis may come from both the conceptual framework developed for this study or other theoretical frameworks related to processes associated with the experience of the long-term 
cancer survivor (e. g., adaptation, self-efficacy, cognitive restructuring). Further research in this area may also include the refinement and testing of this study's conceptual framework. 
Survivors HRQL

\section{References}

Aaronson, N. (1988). Quality of life: What is it? How should it be measured?

Oncology.2(5), 69-74.

Aaronson, N. (1991). Methodological issues in assessing a quality of life of cancer patients. Cancer. 67(3 Supplement), 844-850.

Adler, N., \& Matthews, K. (1994). Health psychology: Why do some people get sick and some stay well? Annual Review of Psychology 45, 229-259.

Allardt, E. (1980). Having loving being: About welfare in the nordic countries (in Swedish). Argos: Lund.

American Cancer Society (1995). Cancer facts and figures-1995, Atlanta, GA: Author.

American Nurses Association. (1980). Social Policy Statement. New York: Author.

Andersen, B. (1994). Surviving cancer. Cancer (Supplement). 74(4), 1484-1495.

Andersen, B., \& Lutgendorf, S. (1997). Quality of life in gynecologic cancer survivors. CA - A Cancer Joumal for Clinicians, 47, 218-225.

Belec. R. (1992). Quality of life: Perceptions of long-term survivors of bone marrow transplantation. Oncology Nursing Forum. 19, (1), 31-37.

Berardo, F. (1985). Social networks and life preservation. Death Studies. 2(1), $37-$ 50.

Bertero, C., \& Ek, A. (1993). Quality of life of adults with acute leukemia. Joumal of Advanced Nursing 18, 1346-1353. 
Survivors HRQL 119

Blanchard, C., Albrecht, T. L., Ruckdeschel, J. C., Grant, C. H., \& Hemmick, R. M. (1995). The role of social support in adaptation to cancer and to survival. Journal of Psychosocial Oncology. 13(1-2), 75-95.

Braden, C. (1990). A test of the self-help model: Learned response to chronic illness experience. Nursing_Research 39, 42-47.

Braden, C., McGlone, K., \& Pennington, F. (1993). Specific psychosocial and behavioral outcomes from the systemic lupus erythematosus self-help course. Health Education Quarterly, 20(1), 29-41.

Burns, N., \& Grove, S. (1995). Understanding Nursing Research. Philadelphia: W. B. Saunders Company.

Bush, N.E., Haberman, M., Donaldson, G., \& Sullivan K.M. (1995). Quality of life of 125 adults surviving 6-18 years after bone marrow transplantation. Social Science Medicine $\underline{40}, 479-490$.

Calman, K. (1989). Definitions and dimensions of quality of life. In N. K. Aaronson \& J. Beckmann (Eds.). The quality of life of cancer patients (pp. 1-9). New York: Raven.

Caplan, G. (1974). Support systems and community mental health: Lectures on concept development. New York: Behavioral Publications.

Card, I. (1993). National coalition for cancer survivorship perspective. Group V: Resources for care. Cancer. 71 (10 Supplement), 3244.

Carter, B. (1989). Cancer survivorship: A topic for nursing research. Oncology Nursing Forum 16(3), 435-437.

Carter, B. (1993). Long-term survivors of breast cancer: A qualitative descriptive study. Cancer Nursing. 16, 354-361. 
Cella, D. (1994). Quality of life: Concepts and definition. Loumal of Pain and Symptom Management. 9(8), 186-192.

Cella, D. F. \& Tross, S. (1986). Psychological adjustment to survival from Hodgkin's disease. Journal of Consulting \& Clinical Psychology. 54(5), 616-622.

Cella, D., \& Tulsky, D. (1990). Measuring quality of life today: Methodological aspects. Oncology 4(5), 29-38.

Cobb, S. (1976). Social support as a moderator of life stress. Psychosomatic Medicine, 38, 300-314.

Cohen, J. (1977). Statistical power analysis for the behavioral sciences. (2nd ed.). New Jersey: Lawrence Erlbaum Associates.

Cohen, S. \& Syme, S. (Eds.). (1985). Social support and health. New York: Academic Press, Inc.

Cowan, M., Graham, G., \& Cochrane, B. (1992). Comparison of a theory of quality of life between myocardial infarction and malignant melanoma: A pilot study. Progress in Cardiovascular Nursing. 7(1), 18-28.

Curbow, B. \& Somerfield, M. (1991). Use of the Rosenberg self-esteem scale with adult cancer patients. Јoumal of Psychosocial Oncology. 2, 113-131.

de Haes, J., \& Van Knippenberg. F. (1985). The quality of life of cancer patients: A review of the literature. Social Science and Medicine, 20, 809-817.

deHaes, J.C.J.M., Ruiter, J.H., Tempelaar, R, \& Pennink, B.J.W. (1992). The distinction between affect and cognition in the quality of life of cancer patients - sensitivity and stability. Quality of Life Research _ 1(5), 315-322. 
Dirksen, S. R. (1989). Perceived well-being in malignant melanoma survivors.

Oncology Nursing Forum. 16, 353-358.

Dirksen, S. R. (1990). Theoretical modeling to predict subjective well-being. Westerm Joumal of Nursing Research. 12, 629-643.

Dobkin, P. L. \& Morrow, G. R. (1986). Long-term side effects in patients who have been treated successfully for cancer. Joumal of Psychosocial Oncology 3(4), 23-51.

Donovan, K., Sanson-Fisher, R., \& Redman, S. (1989). Measuring quality of life in cancer patients. Joumal of Clinical Oncology. 7, 959-968.

Elkins, P. H. (1985). Individual education: A critical review. Individual Psychology Journal of Adlerian Theory. Research. and Practice, 41(1), 30-38.

Ell, K., Mantell, J., Hamovitch, M., \& Nishimoto, R. (1989). Social support, sense of control, and coping among patients with breast, lung, or colorectal cancer. Joumal of Psychosocial Oncology. 7, 63-89.

Ell, K., Nishimoto, R., Mediansky, L., Mantell, J., \& Hamovitch, M. (1992). Social relations, social support and survival among patients with cancer. Joumal of Psychosomatic Research.36(6), 531-541.

Evans, D. Pellizzari, J. R., Culbert, B. J., \& Metzen, M.E. (1993). Personality, marital, and occupational factors associated with quality of life. Joumal of Clinical Psychology 49, 477-485.

Evans, D., Thompson, A., Browne, G., Barr, R., \& Barton, B. (1993). Factors associated with the psychological well-being of adults with acute leukemia in remission. Joumal of Clinical Psychology, 49, 153-160. 
Fernsler, J., Holcombe, J., \& Pulliam, L. (1984). A survey of cancer nursing research: January 1975-1982. Oncology Nursing Forum U(4), 46-52.

Ferrans, C. (1994). Quality of life through the eyes of survivors of breast cancer. Oncology Nursing Fonum. 21, 1645-1651.

Ferrans, C. E. \& Ferrell, B. R. (1990). Development of a quality of life index for patients with cancer. Oncology Nursing Forum. 17(3, supplement), 15-21.

Ferrans, C., \& Powers, M. (1985). Quality of life index: Development and psychometric properties. Advances in Nursing Science, 8(1), 15-19.

Ferrell, B. R. (1995). The impact of pain on quality of life. Nursing Clinics of North America 30(4), 609-624.

Ferrell, B. R. (1996). The quality of lives: 1,525 voices of cancer. Oncology Nursing Eorum, 23, 907-916.

Ferrell, B., Grant, M., Padilla, G., Vemuri, S., \& Rhiner, M. (1991). The experience of pain and perceptions of quality of life: Validation of a conceptual model. The Hospice Journal, 7(3), 9-24.

Ferrell, B., Wisdom, C., \& Wenzl, C. (1989). QOL as an outcome variable in the management of cancer pain. Cancer 63(11 suppl), 2321-2327.

Foltz, A. T. (1987). The influence of cancer on self-concept and life quality. Seminars in Oncology Nursing, 3, 303-312.

Fredette, S. (1995). Breast cancer survivors: Concerns and coping. Cancer Nursing. 18(1), 35-46.

Gambosi, J. \& Ulreich, S. (1990). Recovering from cancer: A nursing intervention program recognizing survivorship. Oncology Nursing Forum. 17, 215-219. 
George, L. (1980). Role transition in later life. California: Brooks Cole.

Gill, T.M., \& Feinstein, A. R. (1994). A critical appraisal of the quality of quality-oflife instruments. JAMA. 272, 619-626.

Guillory, J. A. (1992). Relationships of selected physiological psychosocial and spiritual variables associated with survivorship in socioeconomically disadvantaged African American women with breast cancer. Unpublished doctoral dissertation, Medical College of Georgia.

Gulick, E. E. (1994). Social support among persons with multiple sclerosis. Research in Nursing and Health 17, 195-206.

Guyatt, G. J., Naylor, C. D., Juniper, E., Heyland, D. K., Jaeschke, R., \& Cook, D. (1997). User's guides to the medical literature: XII. How to use articles about health-related quality of life. Joumal of the American Medical Association. 227, 1232-1237.

Haberman, M., Bush, N., Young, K., and Sullivan, K.M. (1993). Quality of life of adult long-term survivors of bone marrow transplantation: A qualitative analysis of narrative data. Oncology Nursing Forum 20, 1545-1553.

Halstead, M., \& Fernsler, J. (1994). Coping strategies of long-term cancet survivors. Cancer Nursing 17, 94-100.

Hassey-Dow, K. (1990). The enduring seasons in survival. Oncology Nursing Forum. 17, 511-616.

Hassey-Dow. K. (1993). An analysis of the experience of surviving and having children after breast cancer. (Doctoral Dissertation, Boston College, 1992). Dissertation Abstracts International. 53(11), 5461-B.* 
Survivors HRQL 124

Heidrich, S. \& Ward, S. (1992). The role of the self in adjustment to cancer in elderly women. Oncology Nursing Fonum. 19, 1491-1496.

Hinds, C. (1990). Personal and contextual factors predicting patients' reported quality of life: Exploring congruency with Betty Neuman's assumptions. Joumal of Advanced Nursing $15,456-462$.

Hobfoll, S. E., \& Walfisch, S. (1984). Coping with a threat to life: A longitudinal study of self-concept, social support, and psychological distress. American Joumal of Community Psychology 12(1), 87-100.

Holland, J. (1992). Psychooncology: Where are we, and where are we going? Joumal of Psychosocial Oncology. 10, 103-113.

Kahn R., \& Antonucci, T. (1980). Convoys over the life course: Attachment, roles and social support. In P. B. Baltes \& O. Brim (Eds.). Lifespan development and behavior (pp.80-96). Boston: Lexington Press.

Kelman, G. \& Minkler, P. (1989). An investigation of quality of life and self-esteem among individuals with ostomies. Joumal of Enterstomal Therapy. 16(1), 4-11.

King, C. R., Haberman, M., Berry, D. L., Bush, N., Butler, L., Hassey-Dow, K., Ferrell, B., Grant, M., Gue, D., Hinds, P., Kreuer, J. Padilla, G., \& Underwood. S. (1997). Quality of life and the cancer experience: The state-of-the-knowledge. Oncology Nursing Forum. 24, 27-41.

Krishnasamy M. (1996). Social support and the patient with cancer: A consideration of the literature. Joumal of Adyanced Nursing. 23, 757-762.

Lackner, S., Goldenberg, S., Arrizza, G., \& Tjosvold, I. (1994). The contingency of social support. Qualitative Health Research, 4, 224-243. 
Survivors HRQL 125

Landis, S. H., Murray, T., Bolden, S., \& Wingo, P. A. (1998). Cancer statistics, 1998. CA-A Cancer Journal for Clinicians, 48(1), 6-9.

Lewis, F. M. (1989). Attributions of control, experienced meaning, and psychosocial well-being in patients with advanced cancer. Џoumal of Psychosocial Oncology. $7(1 / 2), 105-$ 119.

Lindsey, A., Ahmed, N., \& Dodd, M. (1985). Social support: Network and quality as perceived by Egyptian patients. Cancer Nursing 8(1), 37-42.

Loescher, L., Weich-McCaffrey, D., Leigh, S., Hoffman, B., \& Meyskens, F. (1989). Surviving adult cancers. Part I: Physiologic effects. Annals of Intemal Medicine. 111,411 432.

Loescher, L.J., Clark, L., Atwood, J. R., Leigh, S., \& Lamb, G. (1990). The impact of the cancer experience on long-term survivors. Oncology Nursing Forum. 17, 223-229.

Lugton, J. (1997). The nature of social support as experienced by women treated for breast cancer. Joumal of Advanced Nursing. 25, 1184-1192.

Mishel, M. H. (1990). Reconceptualization of the uncertainty in illness theory. Image: Journal of Nursing Scholarship. 22, 256-262.

Mishel, M., \& Braden, C. J. (1988). Finding meaning: Antecedents of uncertainty in illness. Nursing Research. 37, 98-103.

Molassiotis, A., Boughton, B. J., Burgoyne, T., van den Akker, O.B.A. (1995). Comparison of the overall quality of life in $\mathbf{5 0}$ long-term survivors of autologous and allogeneic bone marrow transplantation. Journal of Advanced Nursing. 22, 509-516. 
Morrow, G., Lindke, J., \& Black, P. (1992). Measurement of quality of life in patients: Psychometric analyses of the Functional Living Index-Cancer (FLIC). Quality of Life Research _ 1, 287-296.

Mullen, F. (1985). Seasons of survival: Reflections of a physician with cancer. New England Journal of Medicine, 313, 270-273.

Muzzin, L. J., Anderson, N. H., Figueredo, A. T., \& Gudelis, S. O. (1994). The experience of cancer. Social Science and Medicine. 38, 1201-1208.

Najman, J., \& Levine, S. (1981). Evaluating the impact of medical care and technologies on the quality of life: A review and critique. Social Science and Medicine. 15 F(2 \& 3), 107-115.

Nessim, S., \& Ellis, J. (1991). Cancervive: The challenge of life after cancer. Boston: Houghton Mifflin.

Norbeck, J. S. (1981). Social support: a model for clinical research and application. Advances in Nursing Science, 3(4), 43-59.

Norbeck, J., Lindsey, A., \& Carrieri, V. (1981). The development of an instrument to measure social support. Nursing Research. 30, 264-269.

Norbeck, J., Lindsey, A., \& Carrieri, V. (1983). Further development of the Norbeck Social Support Questionnaire: Normative data and validity testing. Nursing Research, 32, 49.

Northouse, L. (1981). Mastectomy patients and the fear of cancer recurrence. Cancer Nursing $4,213-220$.

Padilla, G. (1992). Validity of health-related quality of life subscales. Progress in Cardiovascular Nursing. 7, 13-20. 
Padilla, G., Ferrell, B., Grant, M. \& Rhiner, M. (1990). Defining the content domain of quality of life for cancer patients with pain. Cancer Nursing 13, 108-115.

Padilla, G., \& Grant, M. (1985). Quality of life as a cancer nursing outcome variable. Advances in Nursing Science, $8(1), 45-60$.

Padilla, G., Grant, M., \& Ferrell, B. (1992). Nursing research into quality of life. Quality of Life Research. 1, 341-348.

Padilla, G., Hurwicz, M., Berkanovic, E., \& Johnson, D. (1996). Rheumatoid arthritis related stress, coping and quality of life. Unpublished manuscript.

Padilla, G., Presant, C., Grant, M., Metter, G., Lipsett, J., and Heide, F. (1983). Quality of life index for patients with cancer. Research in Nursing and Health. 6, 117-126.

Pedro, L. (1995). Quality of life for cancer survivors: Concept operationalization. Unpublished manuscript.

Phillips, J. R. (1995). Quality of life research: Its increasing importance. Nursing Science Quarterly 8, 100-101.

Polinsky, M. (1994). Functional status of long-term breast cancer survivors:

Demonstrating chronicity. Health and Social Work 19, 165-173.

Polit, D., \& Hungler, B. (1991). Nursing research: Principles and methods (4th ed.). Philadelphia: J. B. Lippincott.

Pollock, $S$. (1986). Human responses to chronic illness: Physiologic and psychosocial adaptation. Nursing Research 36, 90-95.

Pollock, S. (1989). The hardiness characteristic: A motivating factor in adaptation. Advances in Nursing Science. $11(2), 53-62$. 
Quigley, K. (1989). The adult cancer survivor: Psychosocial consequences of cure. Seminars in Oncology Nursing. 5(1), 63-69.

Richardson, J. L., Zarnegar, Z., Bisno, B., and Levine, A. (1990). Psychosocial status at initiation of cancer treatment and survival. Lournal of Psychosomatic Research 34, 189201.

Rieker, P., Fitzgerald, E., Kalish, L., Richie, J., Lederman, G., Edbril, S., and Garnick, M. (1989). Psychosocial factors, curative therapies, and behavioral outcomes. Cancer. 64, 2399-2407.

Rose, M. (1989). Health promotion and risk prevention: Applications for cancer survivors. Oncolegy Nursing Forum. 16, 335-340.

Rosenbaum, M. (1980). A schedule for assessing self-controlling behaviors: Preliminary findings. Behavior Therapy. 11, 109-121.

Rosenbaum, M. (1983). Learned resourcefulness as a behavioral repertoire for the self-regulation of internal events: Issues and speculation. In M. Rosenbaum, C.M. Franks, \& Y. Jaffee (Eds.), Perspectives on behavior therapy in the eighties (pp. 54-73). New York: Springer.

Rosenbaum, M. (1990). The role of leamed resourcefulness in the self-control of health behavior. In M. Rosenbaum (Ed.), Learned resourcefulness: On coping skills, selfcontrol_and adaptive behavior (pp.3-30). New York: Springer.

Rosenbaum, M., \& Ben-Ari Smira, K. (1986). Cognitive and personality factors in the delay of immediate gratification of hemodialysis patients. Journal of Personality and Social Psychology, 51, 357-364. 
Rosenberg, M., \& Kaplan, H. (1982). Social psychology of the self-concept. Illinois: Harlan Davidson.

Rossenthal, D. (1998). Changing trends. CA - A cancer Joumal for Clinicians, 48(1), $3-4$.

Rowland, J. H. (1989). Interpersonal resources: Coping. In J. C. Holland \& J.. H. Rowland (Eds.), Handbook of Psychooncology: Psychological care of the patient with cancer (pp.44-57). New York: Oxford University Press.

Schaefer, C., Coyne, J., \& Lazarus, R. (1981). The health-related functions of social support. Joumal of Behavioral Medicine, 4, 381-406.

Schag, C. A.; Ganz, P. A.; Wing, D. S.; Sim, M. S., \& Lee, J. J. (1994). Quality of life in adult survivors of lung, colon and prostate cancer. Quality of Life Research. 3, 127-141.

Schipper, H. (1990). Quality of life: Principles of the clinical paradigm. Joumal of Psychosocial Oncology 8(2-3), 171-185.

Seligman, L. (1996). Promoting a fighting spirit: Psychotherapy for cancer patients. survivors, and their families. San Francisco: Jossey-Bass.

Shanfield, S. (1980). On surviving cancer: Psychological considerations. Comprehensive Psychiatry. 21, 128-134.

Smith, M. \& Stullenbarger, E. (1995). An integrative review and meta-analysis of oncology nursing research: 1981-1990. Cancer Nursing. 18, 167-179.

Stalker, M., Johnson, P., \& Cimma, C. (1989). Supportive activities requested by survivors of cancer. Journal of Psychosocial Oncology. 7(4), 21-31. 
Tempelaar, R., de Haes, J., de Ruiter, J., Bakker, D., van den Heuvel, W., \& van Nieuwenhuijzen, M. (1989). The social experience of cancer patients under treatment: A comparative study. Social Science and Medicine, 29, 635-42.

Thorne, S. (1989). Life after cancer. In Nursine Research: A Quantitative and Qualitative Approach (pp. 348-353). Boston: Jones and Bartlett.

van Tulder, M. W., Aaronson, N. K., \& Bruning, P. F. (1994). The quality of life of long-term survivors of Hodgkin's disease. Annals of Oncology, 5, 153-58.

Veronesi, U., \& Martino, G. (1978). Can life be the same after cancer treatment? Tumori. $64,345-351$.

Wagnild, G., \& Young, G. (1993). Development and psychometric evaluation of the resilience scale. Joumal of Nursing Measurement. 1, 165-178.

Watson, P. G. (1983). The effects of short-term postoperative counseling on cancerostomy patients. Cancer Nursing. 6, 21-29.

Watson, P. (1992). Cancer Rehabilitation: An overview. Seminars in Oncology Nursing. $8,167-173$.

Waxler-Morrison, N., Hislop, T., Mears, B., \& Kan, L. (1991). Effects of social relationships on survival for women with breast cancer: A prospective study. Social Science and Medicine. 33, 177-183.

Welch-McCaffrey, D., Hoffman, B., Leigh, S., Loescher, L., \& Meyskens, F. (1989). Surviving adult cancers, Part 2: Psychosocial implications. Annals of Internal Medicine. Wl, $517-524$.

Whedon M. \& Ferrell, B. (1994). Quality of life in adult bone marrow transplant patients: Beyond the first year. Seminars in Oncology Nursing. 10(1), 42-57. 
Whedon, M., Stearns, D., \& Mills L. E. (1995). Quality of life of long-term adult survivors of autologous bone marrow transplantation. Oncology Nursing Forum. 22, 1527 1537.

White, R., Tata, P., \& Burns, T. (1996). Mood, learned resourcefulness and perceptions of control in type 1 diabetes mellitus. Journal of Psychosomatic Research. 40, 205-212.

Wills, T. (1985). Supportive function of interpersonal relationships. In S. Cohen \& S. Syme (Eds.), Social Support and Health (pp. 61-82). London: Academic Press.

Wortman, C. B. (1984). Social support and the cancer patient. Cancer 53, 2339-2362.

Wyatt, G. \& Friedman, L. L. (1996). Long-term female cancer survivors: Quality of life issues and clinical implications. Cancer Nursing 19, 1-7.

Wyatt, G., Kurtz, M., \& Liken, M. (1993). Breast cancer survivors: An exploration of quality of life issues. Cancer Nursing 16, 440-448.

Zauszniewski, J. (1995a). Learned resourcefulness: A conceptual analysis. Issues in Mental Health Nursing. 16(1), 13-31.

Zauszniewski, J. A. (1995b). Theoretical and empirical considerations of resourcefulness. Image: Joumal of Nursing Scholarship. 27, 177-180. 
Appendix A

Approval Documents for Use of Copyrighted Materials

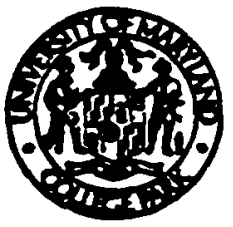

UNIVERSTY OF MARYLAND AT COLLEGE PARK

Darmonereacier

June 5. 2996

Iel1 Padro

11455 Baston Btreat

Loma Linda, a 92354

Dear Mr. Paero,

Thank you for your laterest in the celf-sotecm ceale of Dr. Morris Roseaberg. I apologlze for any deley in respending to your telephooe cald.

Regrettably, Dr. Rosenberg passed wray sour yeare ago. However, Dr. Floreace Rosenberg (Manny' widow) bas given permission to use the Belf-Boteem Bcale for educational and professional research. please be wure to give the credst due Dr. Morris Rosenberg when you use It. Me would also appreclate zesetving coples of any publiahed wortes resuleing from tbi. reses=ct.

Inclosed, plenee flíd a cojpy of the cente, along with briet Instructions on norming and ecoring lt. I fuliex deceription of the scale way be found in the dppendix of soctety and the Adolescent Self-Tmine. You may uldh to contact Rosenberg's coauthore lor more saformalem zelating to his work.

There is no eharge assockated with the wo of this seale in your professtomed researeh.

sineerely.

reves J. Kareb

Departemate of eoclology, Uxcp

Felowre

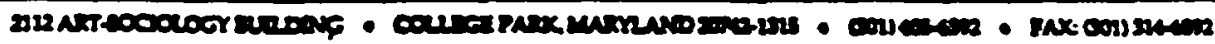




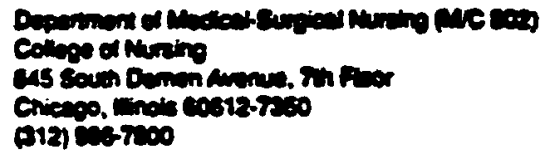

March 5, 1996

Ms. Lefi Pedro

11455 Bexton Struet

Loma Linde, CA 92354

Dear Ms. Pedro:

Thank you for your inerest in the Ferrans and Powess Qunlity of Life Index (QLI). I have enclosed the cencer version of the QUI end the computer proerum for enlaulating seores. I also have inchuded a bist of the weighted irems thrt are uned for each of four aubectes: beath and finctioning, cocinl and economic, paychologieal/spiriturl, and furity, as well as the computer

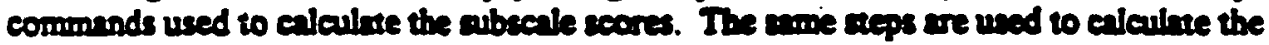
subseale seores and overall seores.

As the presem time there is no charge for une of the QLI. You have my permission to use the QLI for your mudy. In reurm, I ank thre you sead we a photocopy of all publications of your findings using the QLI. I then will add your publication(o) to the fis thrs I eand out to persons who requen permission to une the QLI.

$\therefore$

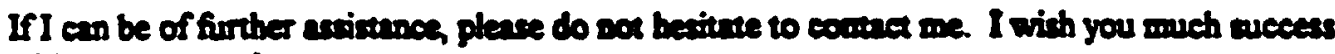
with your recerrech.

Sincerely,

Cärol Exwing Ferrens, PhD, RN, FAAN

Ascirtant Profeeseor

Chreapo

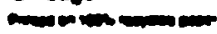

Provit

Ondening
Utena-Chamenon 


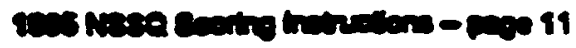

Appentixe

nopmation

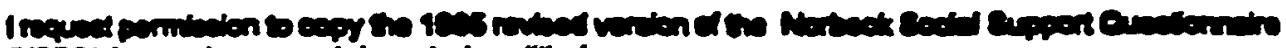

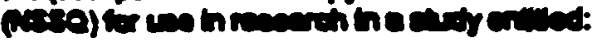

The relationshtp of self-esteen, learned resourcefulness and soctil

support to hesith-related quality of life for long-tem anncer survivers
\end{abstract}

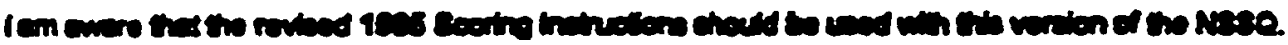

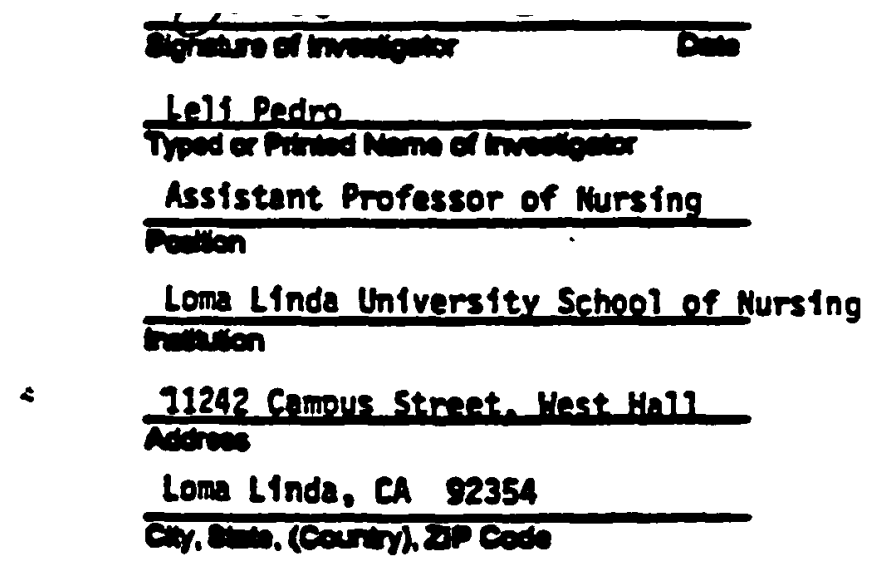

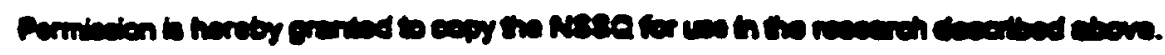

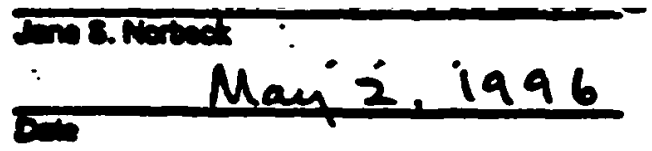

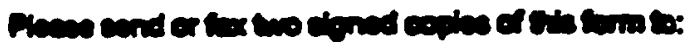

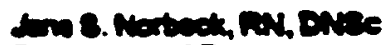

Profocor and Den

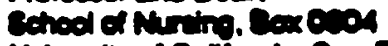

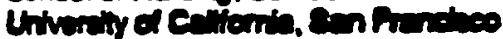

cor Purnemen Ameris

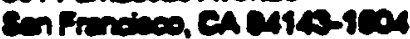

FAX: (415) 4T-N107 


\section{Appendix B}

\section{Demographic Profile}

Today's Date:

Date of Birth $\frac{1}{\text { Month Day Year }}$

Age:

Marital Status:

Male Female

Type of Cancer Diagnosed:

Date of Diagnosis Month Day Year

Cancer Stage at Diagnosis: (if known)

Type of treatment:(Check all that apply) __Surgery, _Chemotherapy, __Radiation

Is there any recurrence of your cancer today? _Yes _No

Alternate Therapies Used (example: Meditation, acupuncture)

Date of Last Treatment:

Type of Last Treatment:

Ethnic Background:

Annual Income to the closest \$1000:

Occupation:

Employment Status:

Additional information you would like to share as a cancer survivor. (Use back of page if necessary) 


\section{Appendix C}

\section{ROSENBERG SELF-ESTEEM SCALE}

Please answer the following questions about how you feel about yourself.

1 = strongly agree

$2=$ agree

$3=$ disagree

$4=$ strongly disagree

1. I feel that I have a number of good qualities.

$\begin{array}{llll}1 & 2 & 3 & 4\end{array}$

2. I feel I am a person of worth, at least on an equal plan with others.

$\begin{array}{llll}1 & 2 & 3 & 4\end{array}$

3. I take a positive attitude toward myself.

$\begin{array}{llll}1 & 2 & 3 & 4\end{array}$

4. I am able to do things as well as most other people.

$\begin{array}{lllll}1 & 2 & 3 & 4\end{array}$

5. On the whole, I am satisfied with myself.

$\begin{array}{lllll}1 & 2 & 3 & 4\end{array}$

6. I wish I could have more respect for myself.

$\begin{array}{llll}1 & 2 & 3 & 4\end{array}$

7. I feel I do not have much to be proud of.

$\begin{array}{lllll}1 & 2 & 3 & 4\end{array}$

8. I certainly feel useless at times.

$\begin{array}{llll}1 & 2 & 3 & 4\end{array}$

9. All in all, $I$ ' $m$ inclined to feel that I am a failure.

$\begin{array}{lllll}1 & 2 & 3 & 4\end{array}$

10. At times I think I am no good at all.

$\begin{array}{llll}1 & 2 & 3 & 4\end{array}$ 
Appendix D

\section{Rosenbaum's Self-Control Schedule}

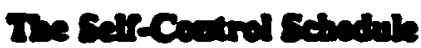

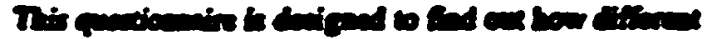

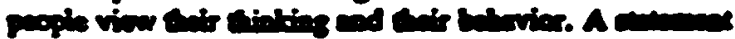

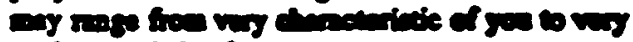

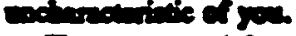

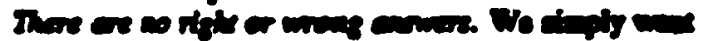

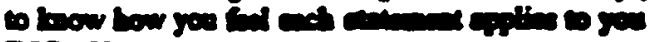
TOPAx.

Fin

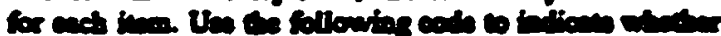

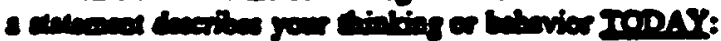

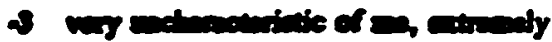
oncipive

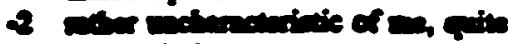
encinim

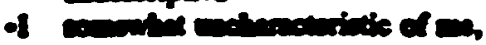

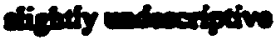

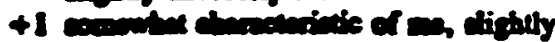
encintive

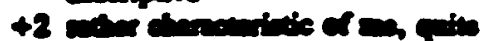
Cantion

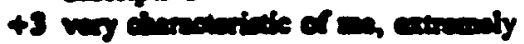
conitive

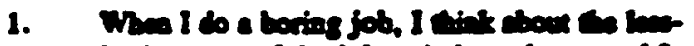

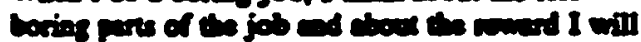
nomive wha 1 Gish

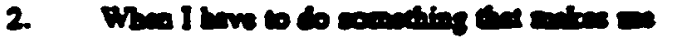

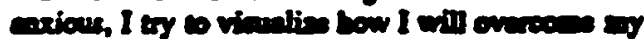
corioy will doing it.

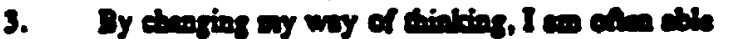

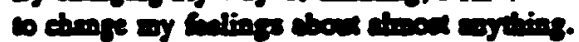

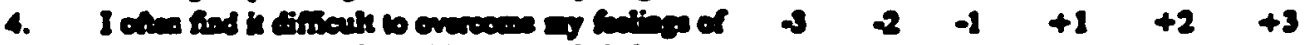

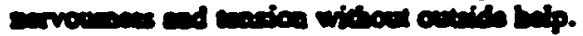

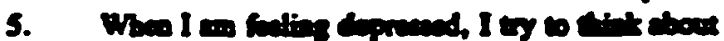
piecenterents.

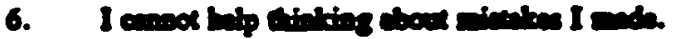

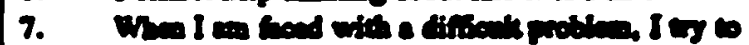

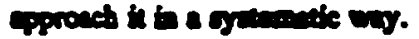

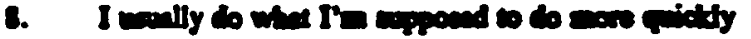

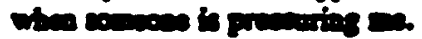

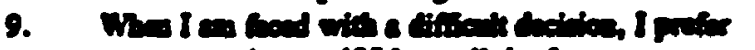

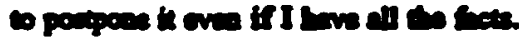

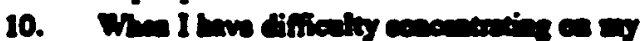

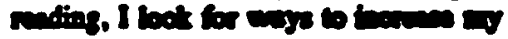
concention.

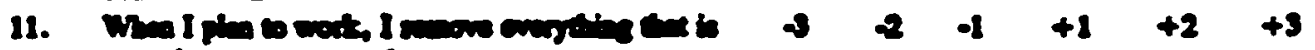

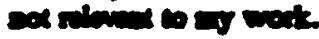

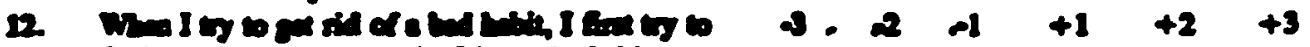

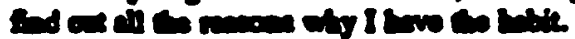

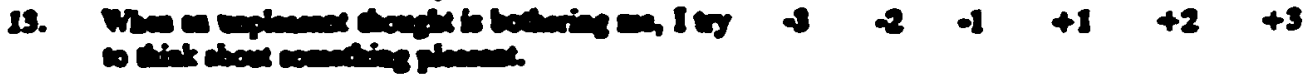

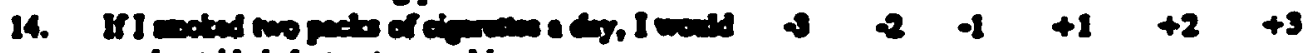

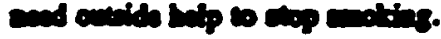

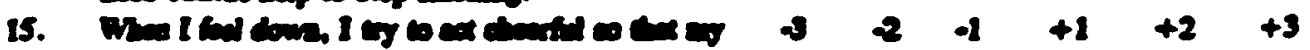
mod will obine.

Planse 80 bo seat pare) 


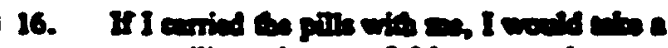

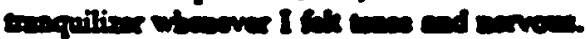

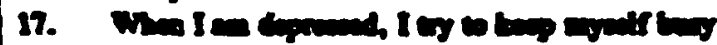
with tinger I Ben.

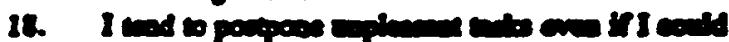

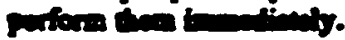

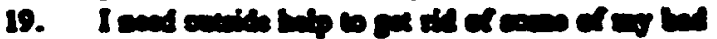
thite

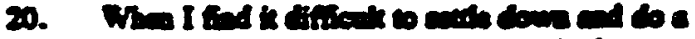

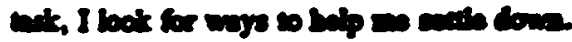

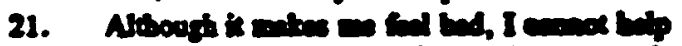

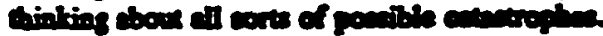

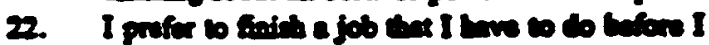

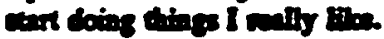

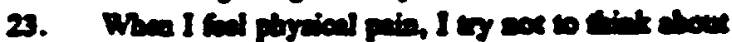
i2.

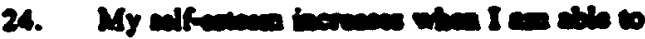
enveodes a bad mole.

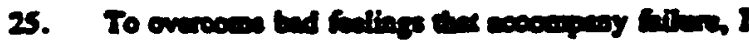

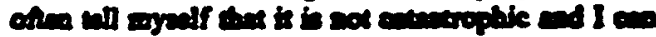

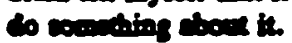

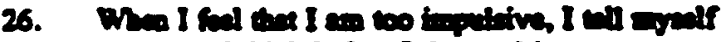

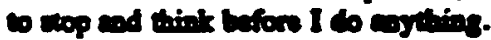

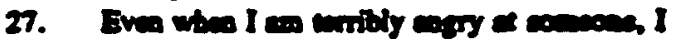
conider ay ection valy ardinly.

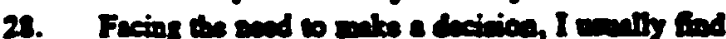

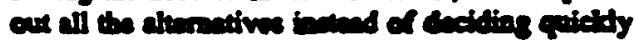
ad rovingoty.

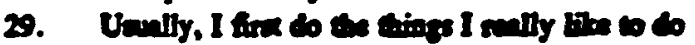

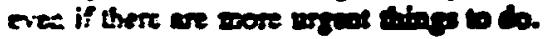

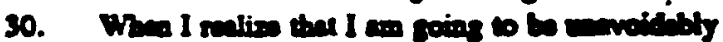

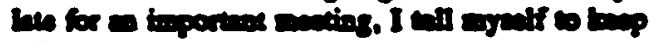
alia.

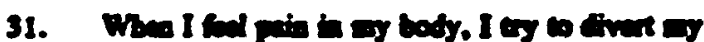
congter for is.

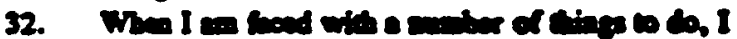

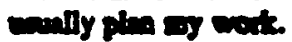

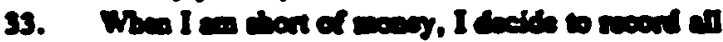

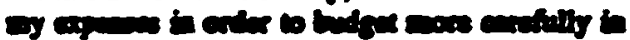
estime.

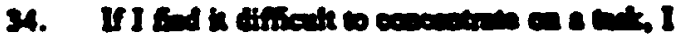

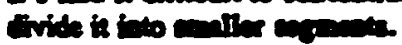

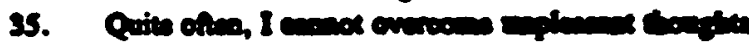
incolos

$\begin{array}{llllll}2 & -1 & +1 & +2 & +3\end{array}$

$+2-1+1+2+3$

$+4 \quad-1+1+2+3$

$-3+2+1+2+3$

$3+2+1+2+3$

$\begin{array}{llllll}- & 2 & -1 & +1 & +2 & +3\end{array}$

$3 \quad 2 \quad-1+1 \quad+2+3$

$\begin{array}{llllll}2 & -1 & +1 & +2 & +3\end{array}$

$\begin{array}{llllll}2 & -1 & +1 & +2 & +3\end{array}$

$\begin{array}{llllll}-3 & -1 & +1 & +2 & +3\end{array}$

$\begin{array}{llllll}3 & -2 & -1 & +1 & +2 & +3\end{array}$

$3+2-1+1+2+3$

$\begin{array}{llllll}-3 & 2 & -1 & +1 & +2 & +3\end{array}$

$3 \quad-2+1 \quad+1+2+3$

$3 \quad-2+1+1+2+3$

$3+2+1+2+3$

$3+2+1+2+3$

$-3+2+1+2+3$

$-3 \cdot \xi \quad i \quad+1+2+3$

$3+2+1+2+3$

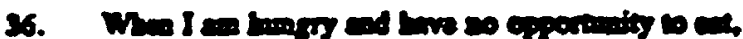

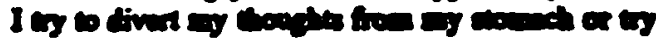

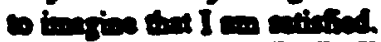

$3+2+1+2+3$ 
Plese lixt each dignificant person in sour life on the right Consider all the persoms who provide personal appont for you or who are importent io yos TODAY.

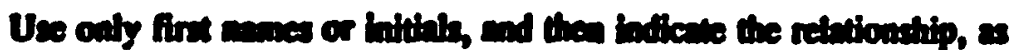
in the following exanpiles

\section{Bomopiles}

Pind Nume or bistibls Retationatip

1.

2.

3.

4.

..

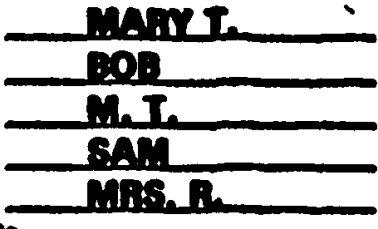

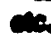

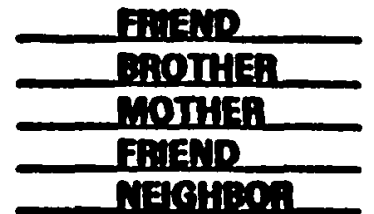

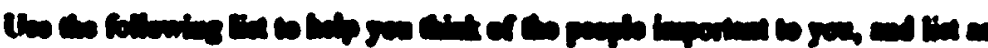

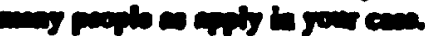

\section{- Tremer}

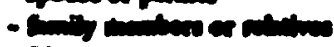

- Mtimar

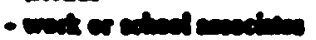

- rainiman

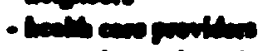

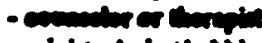

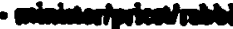

$-2$

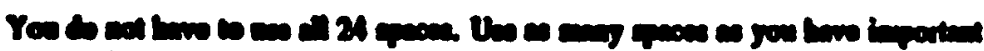

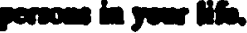

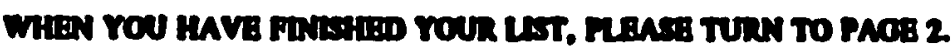

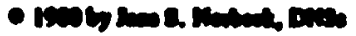

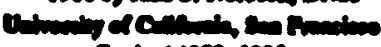

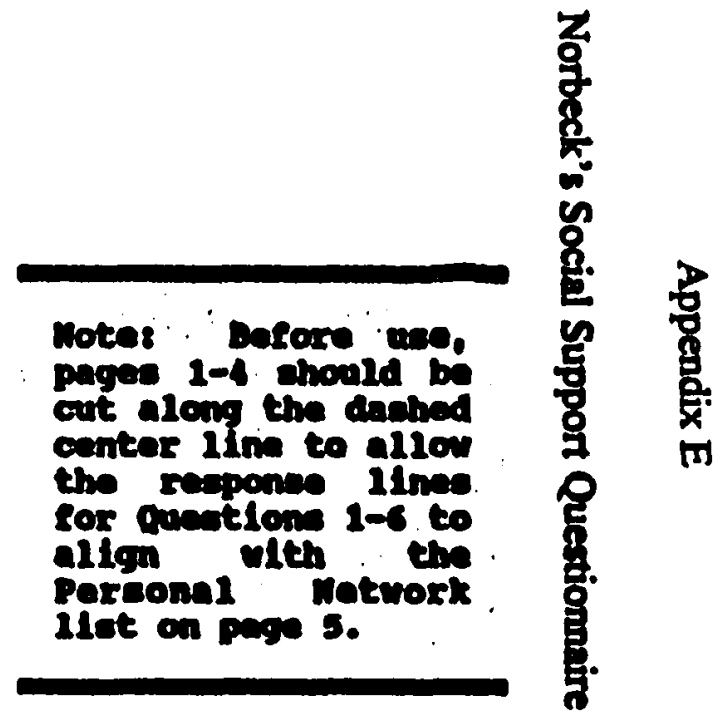


For each person you listod, please answer the following questions by writing in the number that applies.

$$
\begin{aligned}
& 0 \text { = not at all } \\
& 1 \text { = a littic } \\
& 2 \text { = moderidy } \\
& 3 \text { = quite a bit } \\
& 4 \text { = a greal ded }
\end{aligned}
$$
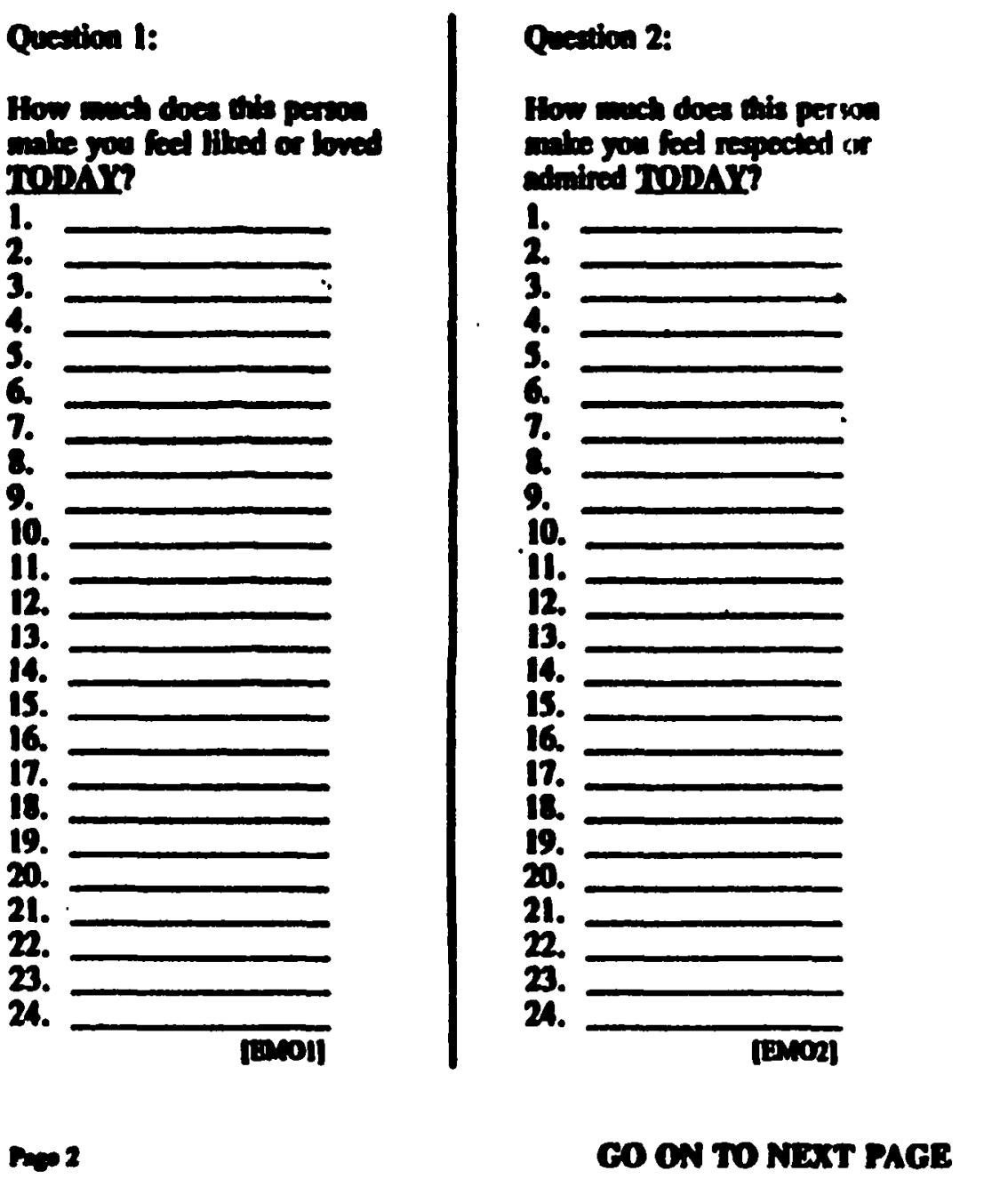


$$
\begin{aligned}
& 0 \text { = not at all } \\
& 1=\text { a liule } \\
& 2 \text { = moderably } \\
& 3 \text { - quile a bil } \\
& 1=\text { a great deal }
\end{aligned}
$$

Queation 3:

How mach cos you confich in this person TODAYT

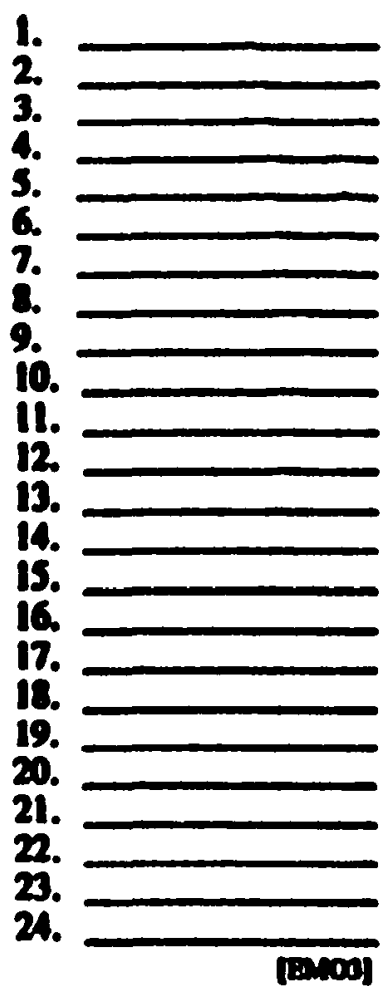

\section{Question 4:}

How much does this person atree with or suppont your ections or trought TORAM? 1.

2.

3.

4.

s.

\%.

a.

ia.

19.

12.

13.

14.

15.

-

18.

19.

20.

21.

22.

23.

24.

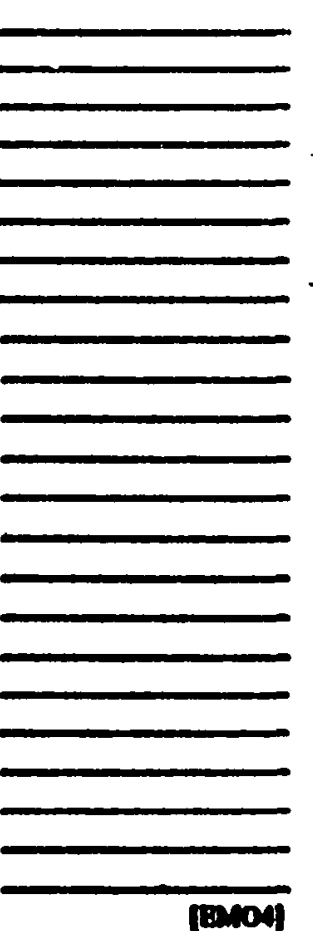

Motas: Dofors use, pagen 1-4 ehould bo cot alcon the dashed contar IIn to allo the remones ; Ilnes for ouction ist to rign or wen Peraomal i: Notwork lint on pere 5 , 


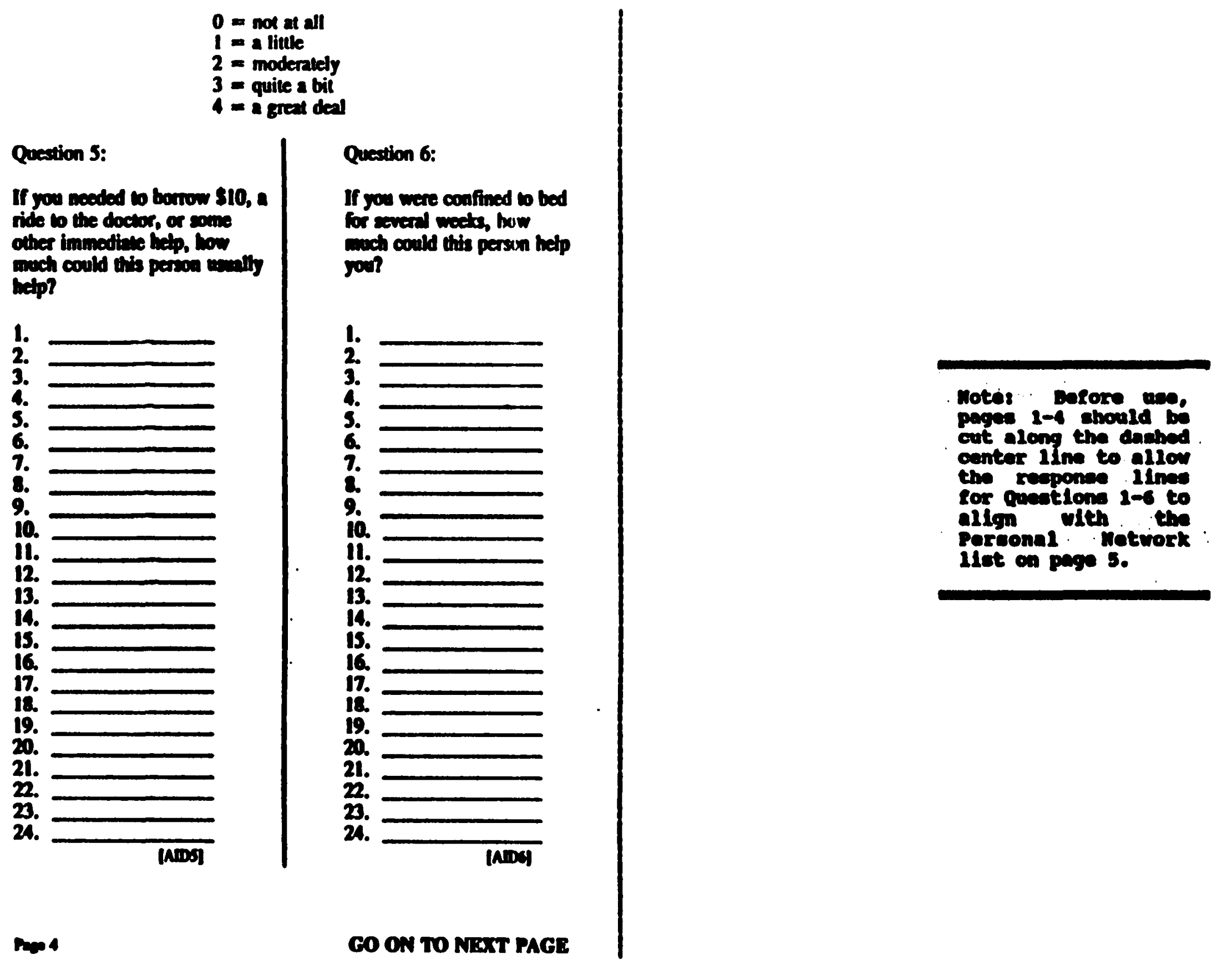


Question 7:

How long have you known this person?

\section{1 - lese than 6 moneth \\ $2=61012$ mondes \\ $3=102 \mathrm{ram}$ \\ $4=205$ your \\ 5 - more then 5 years}

1.

2.

4.

s.

7.

8.

9.

II.

12.

13.

14.

15.

16.

17.

18.

19.

21 .

21.

23.

24.

Duration
Queation 8:

How frequently do you usadly have contact with this person? (Pthone calls, visth, or letters)

5 a dily

$4=$ weeth

3 = monthly

2 - a few tines a year

1 a once a year of leas

1.

2.

4.

4.

6.

6.

i.

9.

14.

4.

12.

13.

15.

16.

17.

18.

19.

20.

21.

2.

23.

24.

$\overline{\text { mepcom }}$

Number

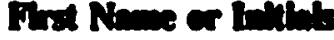

1.

2.

3.

4.

7.

8.

9.

10.

11.

12.

13.

14.

15.

16.

17.

18.

19.

20.

21.

22.

23.

24.
Date

[IINO]

FESONAL NETWOA

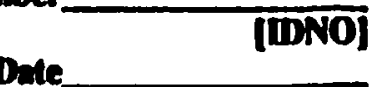

nows

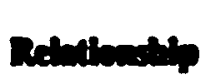

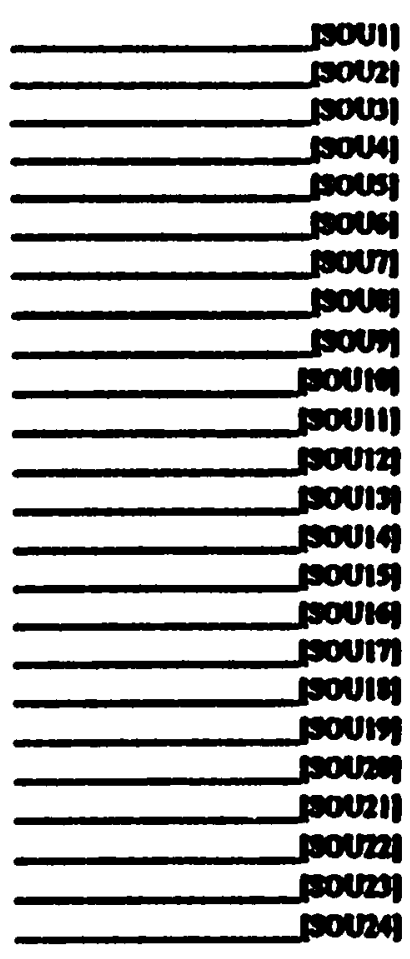


9. During the past year, have you lost any important relationships duc to moving, a job change, divorce or separation, death, or some other reason? O. No

i. Yes

[10s\$

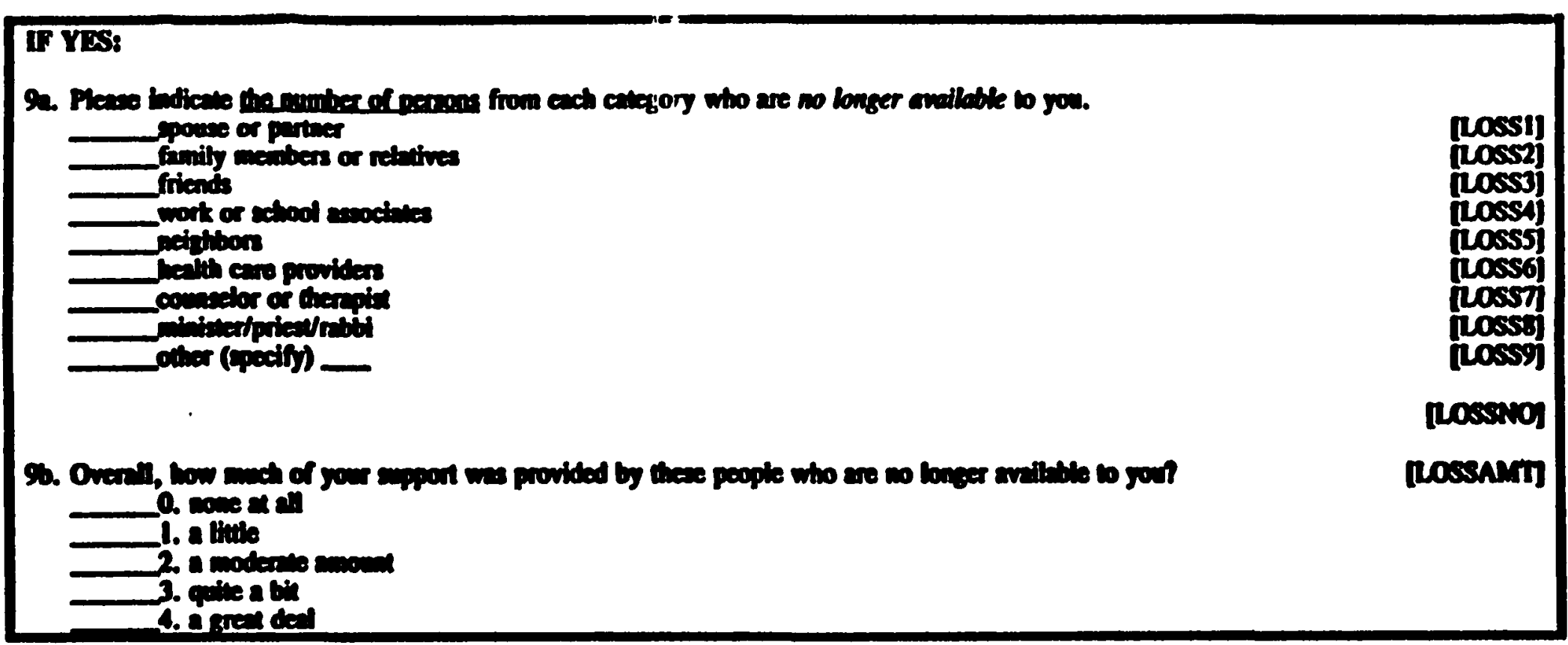


Appendix $\mathbf{F}$

Ferrans and Powers Quality of Life Index - Cancer Version

\author{
Ferrens and Powtes \\ OUALIT OF LITI INDIX \\ CANCXR VIRSTON
}

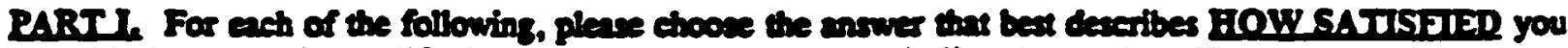
are with thas aree of your life. Plente merk your answer by eireling the aumber. There are so right or wrong answers.

\title{
HOW SATISFIED ARE YOU TODAY WITE:
}
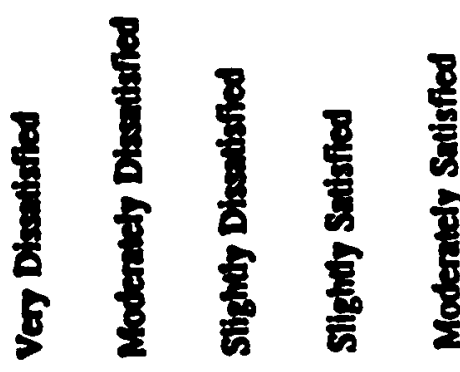

\begin{tabular}{|c|c|c|c|c|c|c|}
\hline 1. Your health? & 1 & 2 & 3 & 4 & $\mathbf{s}$ & 6 \\
\hline 2. The health are you are receiving? & 1 & 2 & 3 & 4 & 5 & 6 \\
\hline 3. The amount of pain that you have? & 1 & 2. & 3 & 4 & 5 & 6 \\
\hline 4. The amount of energy you have for everyday activities? & 1 & 2 & 3 & 4 & $\mathbf{s}$ & 6 \\
\hline 5. Your physieal independence? & 1 & 2 & 3 & 4 & $\mathbf{s}$ & 6 \\
\hline 6. The amount of control you have over your bife? & 1 & 2 & 3 & 4 & $\mathbf{s}$ & 6 \\
\hline 7. Your porential wo live a long time? & 1 & 2 & 3 & 4 & $\mathbf{s}$ & 6 \\
\hline 8. Your family's bealth? & $\mathbf{l}$ & 2 & 3 & 4 & $\mathbf{s}$ & 6 \\
\hline 9. Your childrea? . & 1 & 2 & 3 & 4 & $\mathbf{5}$ & 6 \\
\hline 10. Your fumily's byppineas? & 1 & 2 & 3 & 4 & $\mathbf{s}$ & 6 \\
\hline 11. Your relationship with your epouse/dignificant other? & 1 & 2 & 3 & 4 & $\mathbf{s}$ & 6 \\
\hline 12. Your sex life? & 1 & 2 & 3 & 4 & $\mathbf{s}$ & 6 \\
\hline 13. Your firieadr? & 1 & 2 & 3 & 4 & $\mathbf{s}$ & 6 \\
\hline 14. The emotional appont you ga from chers? & 1 & 2 & 3 & 4 & 5 & 6 \\
\hline 15. Your ability to meer fumily resposstbilities? & 1 & 2 & 3 & 4 & 5 & 6 \\
\hline 16. Your usefulness to othere? & 1 & 2 & 3 & 4 & $\mathbf{s}$ & 6 \\
\hline
\end{tabular}

(Please Go To Next Page)

- Copyright 1984 C. Ferrans and M. Powers (Do not use without permission.) 


\section{HOW SATISFIDD ARE YOU TODAY WITH:}

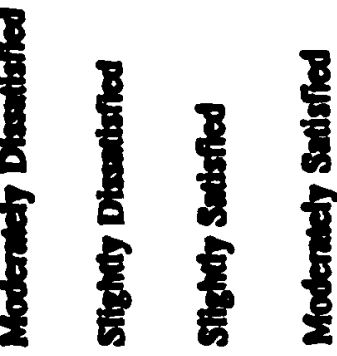

\begin{tabular}{|c|c|c|c|c|c|c|c|}
\hline 17. & The amount of atreas of wavies in your iffe? & $\mathbf{I}$ & 2 & 3 & 4 & $\mathbf{s}$ & 6 \\
\hline 18. & Your boune? & 1 & 2 & 3 & 4 & 5 & 6 \\
\hline 19. & Your neighborthood? & 1 & 2 & 3 & 4 & $\mathbf{s}$ & 6 \\
\hline 20. & Your standurd of living? & 1 & 2 & 3 & 4 & 5 & 6 \\
\hline 21. & Your Job? & 1 & 2 & 3 & 4 & $\mathbf{s}$ & 6 \\
\hline 22. & Not having a job? & 1 & 2 & 3 & 4 & 5 & 6 \\
\hline 23. & Your eduention? & 1 & 2 & 3 & 4 & 5 & 6 \\
\hline 24. & Your financial independence? & 1 & 2 & 3 & 4 & 5 & 6 \\
\hline 25. & Your leisure time ectivities? & 1 & 2 & 3 & 4 & $\mathbf{s}$ & 6 \\
\hline 26. & Your ability to travel on veations? & 1 & 2 & 3 & 4 & 5 & 6 \\
\hline 27. & Your potential for a happy old age/retirement? & 1 & 2 & 3 & 4 & $\mathbf{s}$ & 6 \\
\hline 28. & Your peace of mind? & 1 & 2 & 3 & 4 & 5 & 6 \\
\hline 29. & Your personal frith in God? & 1 & 2 & 3 & 4 & $\mathbf{s}$ & 6 \\
\hline 30. & Your achievement of personal goils? & 1 & 2 & 3 & 4 & $\mathbf{s}$ & 6 \\
\hline 31. & Your happiness in genern? & 1 & 2 & 3 & 4 & 5 & 6 \\
\hline 32. & Your life in general? & 1 & 2 & 3 & 4 & 5 & 6 \\
\hline 33. & Your perrond appearnee? & 1 & 2 & 3 & 4 & $\mathbf{s}$ & 6 \\
\hline 34. & Yourself in general? & 1 & 2 & 3 & 4 & 5 & 6 \\
\hline
\end{tabular}

Piense Co To Next Page)

- Copyright 1984 C. Fernas and M. Powers (Do nox use without parmixtion.) 
RART I. For each of the following. please choose the answer that bes deceribes HOW MMPORTANT that are of your life is to you. Please mark your enswer by cireling the number. There are no tight or wrons answers.

\section{TODAX, HOW IMPORTANT TO YOU IS:}

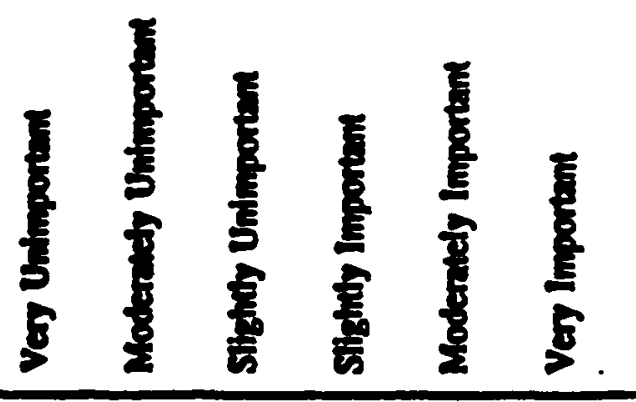

\begin{tabular}{|c|c|c|c|c|c|c|c|}
\hline 1. & Your hesith? & 1 & 2 & 3 & 4 & 5 & 6 \\
\hline 2. & Health eare? & 1 & 2 & 3 & 4 & $\mathbf{s}$ & 6 \\
\hline 3. & Being completely free of pain? & 1 & 2 & 3 & 4 & $s$ & 6 \\
\hline 4. & Having enough energy for everyday activities? & 1 & 2 & 3 & 4 & $\mathbf{s}$ & 6 \\
\hline s. & Your physical independence? & 1 & 2 & 3 & 4 & 5 & 6 \\
\hline 6. & Having control over your life? & 1 & 2 & 3 & 4 & 5 & 6 \\
\hline 7. & Living a long time? & 1 & 2 & 3 & 4 & 5 & 6 \\
\hline 8. & Your family's health? & 1 & 2 & 3 & 4 & 5 & 6 \\
\hline 9. & Your children? & 1 & 2 & 3 & 4 & 5 & 6 \\
\hline 10. & Your fami:y's Majpiness? & 1 & 2 & 3 & 4 & 5 & 6 \\
\hline 11. & Your relationship with your spouse/significant other? & 1 & 2 & 3 & 4 & 5 & 6 \\
\hline 12. & Your sex life? & 1 & 2 & 3 & 4 & 5 & 6 \\
\hline 13. & Your friends? & 1 & 2 & 3 & 4 & 5 & 6 \\
\hline 14. & The emotional support you get from others? & 1 & 2 & 3 & 4 & 5 & 6 \\
\hline 15. & Meeting family responsibilities? & 1 & 2 & 3 & 4 & 5 & 6 \\
\hline 16. & Being usefulnews to otbers? & 1 & 2 & 3 & 4 & 5 & 6 \\
\hline 17. & Having a reasonable amount of strex or worries? & 1 & 2 & 3 & 4 & 5 & 6 \\
\hline 18. & Your home? & 1 & 2 & 3 & 4 & 5 & 6 \\
\hline
\end{tabular}

(Please Go To Next Page)

- Copyright 1984 C. Ferrans and M. Powers (Do not use without permission.) 


\section{TODAY, HOW MPORTANT TO YOU IS:}
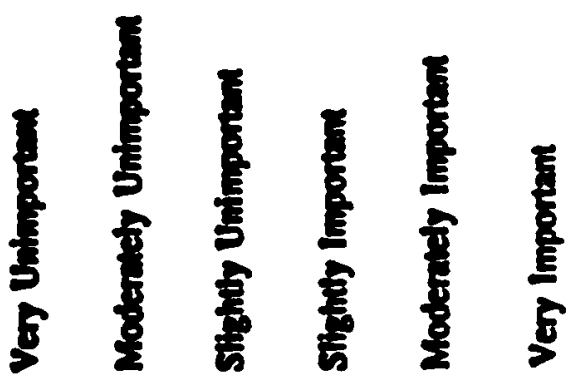

\begin{tabular}{|c|c|c|c|c|c|c|}
\hline 19. Your neiphboutsood? & 1 & 2 & 3 & 4 & $\mathbf{s}$ & 6 \\
\hline 20. A good senderd of living? & 1 & 2 & 3 & 4 & $\mathbf{s}$ & 6 \\
\hline 21. Your Job? & 1 & 2 & 3 & 4 & 5 & 6 \\
\hline 22. To having a job? & 1 & 2 & 3 & 4 & 5 & 6 \\
\hline 23. Your eduation? & 1 & 2 & 3 & 4 & $\mathbf{s}$ & 6 \\
\hline 24. Your financial independence? & 1 & 2 & 3 & 4 & 5 & 6 \\
\hline 25. Leisure time activities? & 1 & 2 & 3 & 4 & $\mathbf{s}$ & 6 \\
\hline 26. The ability to travel on vacations? & 1 & 2 & 3 & 4 & $\mathbf{s}$ & 6 \\
\hline 27. Having a happy old age/retirement? & 1 & 2 & 3 & 4 & $\mathbf{s}$ & 6 \\
\hline 28. Peace of mind? & 1 & 2 & 3 & 4 & $\mathbf{s}$ & 6 \\
\hline 29. Your personal fiith in God? & 1 & 2 & 3 & 4 & 5 & 6 \\
\hline 30. Achieving your? personal goals? & 1 & 2 & 3 & 4 & $\mathbf{s}$ & 6 \\
\hline 31. Your happiness in general? & 1 & 2 & 3 & 4 & $\mathbf{s}$ & 6 \\
\hline 32. Being sutisfied with bife? & 1 & 2 & 3 & 4 & $\mathbf{s}$ & 6 \\
\hline 33. Your persond appearnece? & 1 & 2 & 3 & 4 & $\mathbf{s}$ & 6 \\
\hline 34. Are you to yourseln? & 1 & 2 & 3 & 4 & 5 & 6 \\
\hline
\end{tabular}




\section{Appendix G}

\section{Long-Term Cancer Survivor's Quality of Life Inventory}

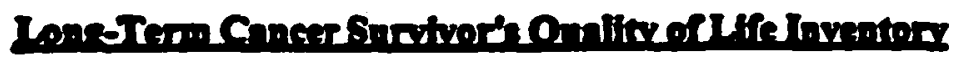

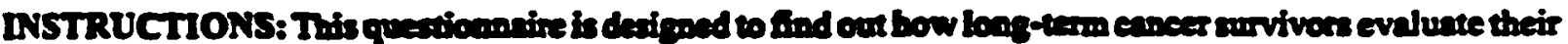

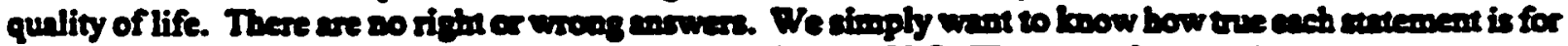

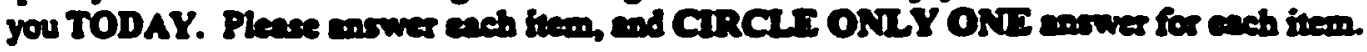

0 - Notine

1. Conculin True

2. Quic Irue

3. Vey True

1. My life is betier when I enereice.

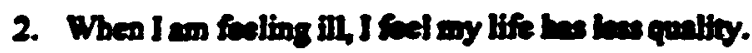

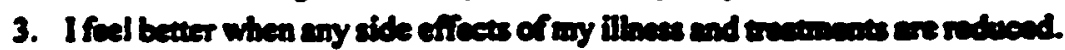

4. Being able to litue a sormal life gives mening wo ny life.

5. Phyrical enersy makes my tifo boure.

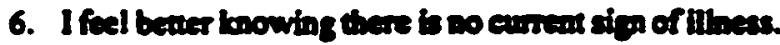

7. The ebility to think elenty anckes my life bouter.

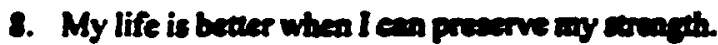

9. Worying about my illweas returing decranes my quality of tife.

10. Physical elowences thereases my quality of life.

11. When I em in pain, I foel my life is nox werth livine.

12. I foel life is worth while over thooph I en sox the enene es I whe.

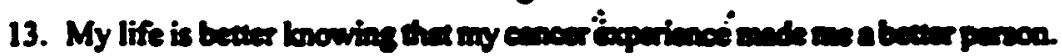

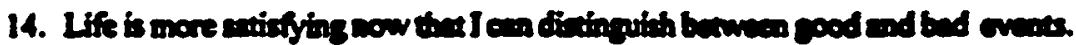

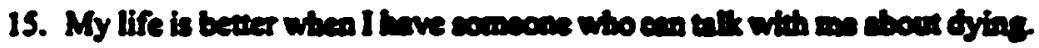

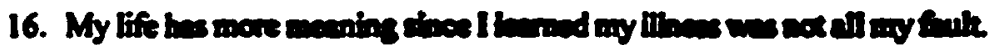

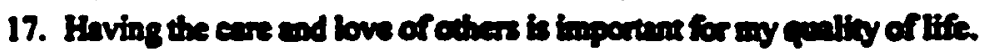

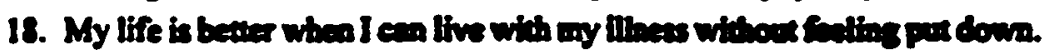

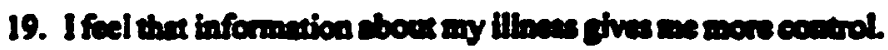

20. If ed more alive sow tha befores any thane.

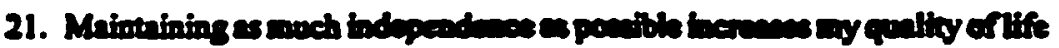

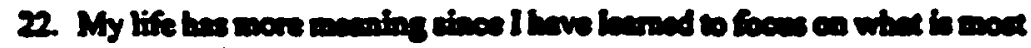
imporime for me.

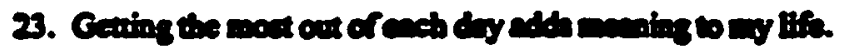

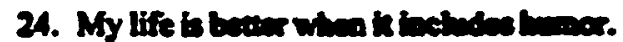

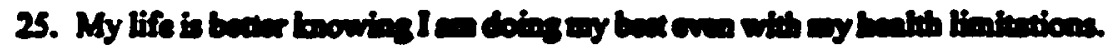

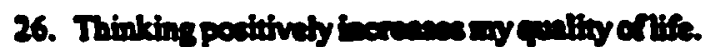

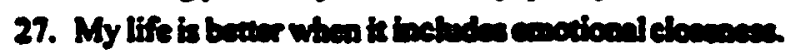

28. Having fin adds to wy priliny of bife.

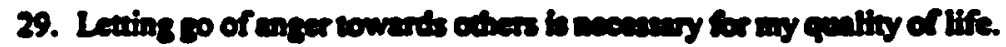

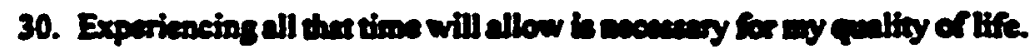

$\begin{array}{llll}0 & 1 & 2 & 3 \\ 0 & 1 & 2 & 3 \\ 0 & 1 & 2 & 3 \\ 0 & 1 & 2 & 3 \\ 0 & 1 & 2 & 3 \\ 0 & 1 & 2 & 3 \\ 0 & 1 & 2 & 3 \\ 0 & 1 & 2 & 3 \\ 0 & 1 & 2 & 3 \\ 0 & 1 & 2 & 3 \\ 0 & 1 & 2 & 3 \\ 0 & 1 & 2 & 3 \\ 0 & 1 & 2 & 3 \\ 0 & 1 & 2 & 3 \\ 0 & 1 & 2 & 3 \\ 0 & 1 & 2 & 3 \\ 0 & 1 & 2 & 3 \\ 0 & 1 & 2 & 3 \\ 0 & 1 & 2 & 3 \\ 0 & 1 & 2 & 3 \\ 0 & 1 & 2 & 3 \\ 0 & 1 & 2 & 3 \\ 0 & 1 & 2 & 3 \\ 0 & 1 & 2 & 3 \\ 0 & 1 & 2 & 3 \\ 0 & 1 & 2 & 3 \\ 0 & 1 & 2 & 3 \\ 0 & 1 & 2 & 3 \\ 0 & 1 & 2 & 3 \\ 0 & 1 & 2 & 3 \\ 0 & & & \\ 0\end{array}$




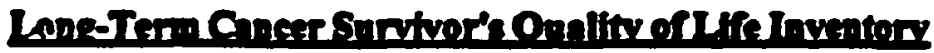

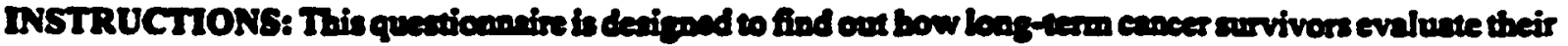
quality of life. There are so sight or wroag enowern. We simply wam to bnow bow true each stremeor is for you TODAY. Please soswer each trem, and CRRCL ONRY ONE anower for each fiem.

$$
\begin{aligned}
& \text { - Nor Tim } \\
& \text { 1. Comench Tre } \\
& \text { 2. Quis Irve } \\
& \text { 3 - Vey Inv }
\end{aligned}
$$

31. Ifeel better when I pray.

32. If feel betur now that I heve pat my trux in a hipher power.

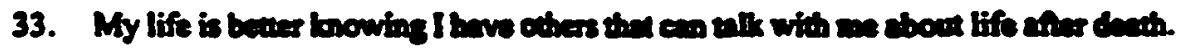

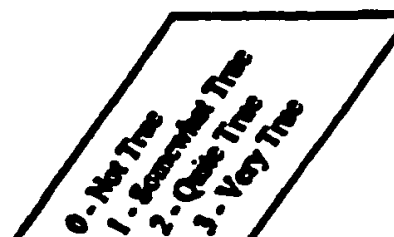

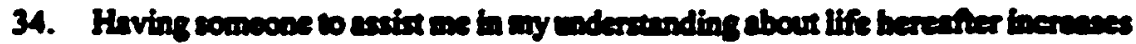
my quality of the.

35. My life is bewor whea I en sble co tilk about my faith.

36. Being involved in formal religion is pecendery for my quality of life.

37. If fecl beter wheo I madiume.

38. Focling forivesess is noceseny for my quality of life.

39. A sense of mening meles any quality of life buter.

40. Precticing spiritinal unditions ineresces my quality of life.

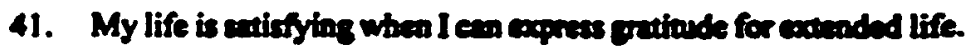

42. Knowing my life hes pupoes increnes my quality of tife.

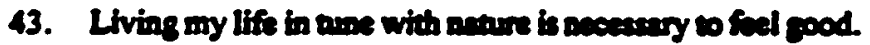

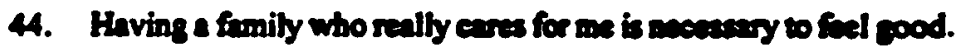

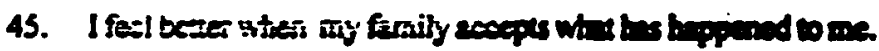

46. My friends make lise worth livine.

47. Being able wo seill do come of the things I love benwes my quality of tife.

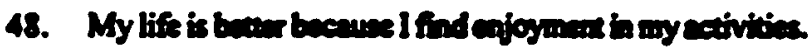

49. Heving profocional ald is nowacery for my quality of tife.

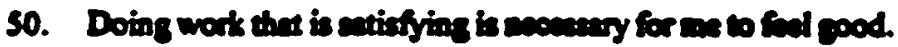

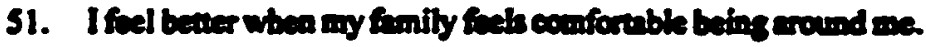

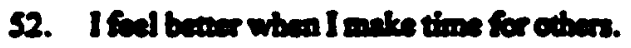

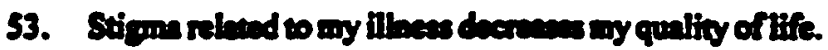

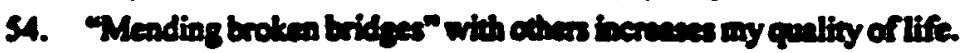

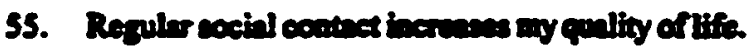

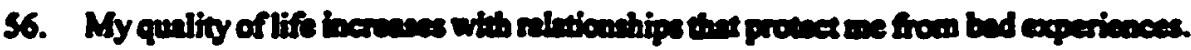

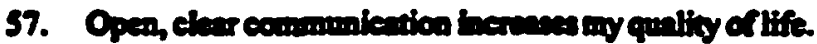

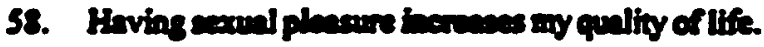

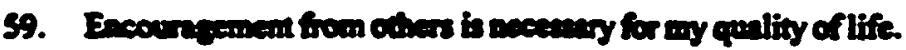

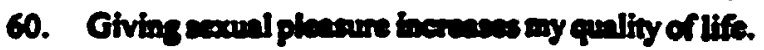

0123

0123

1 123

0123

01123

0123

0123

0123

01123

$0 \begin{array}{llll}0 & 1 & 2 & 3\end{array}$

$0 \begin{array}{lll}0 & 2 & 3\end{array}$

$0 \begin{array}{llll}0 & 2 & 3\end{array}$

$0 \begin{array}{llll}0 & 2 & 3\end{array}$

$0 \begin{array}{llll}0 & 1 & 2 & 3\end{array}$

$0 \begin{array}{llll}0 & 1 & 2 & 3\end{array}$

0123

$\begin{array}{llll}0 & 1 & 2 & 3\end{array}$

01123

0123

$\begin{array}{llll}0 & 1 & 2 & 3\end{array}$

0123

01023

$\begin{array}{llll}0 & 1 & 2 & 3\end{array}$

0123

01123

0123

0123

0123

0123

0123 
Institutional Review Board Approval for Loma Linda University Cancer Institute and Desert Sierra Cancer Surveillance Program (Region5)

\section{MSTIUUTONAL REMEW BOARO

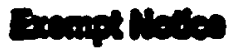

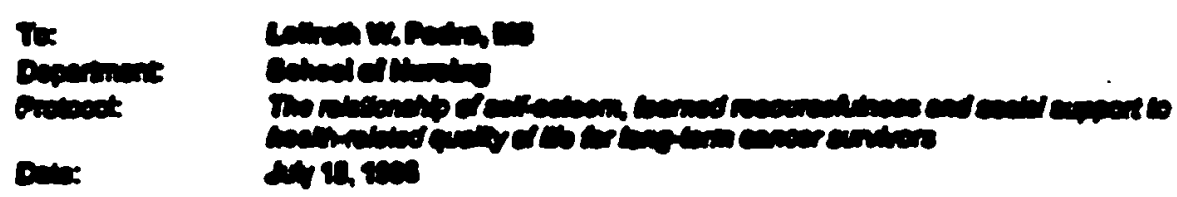

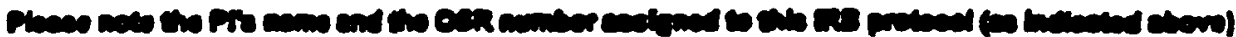

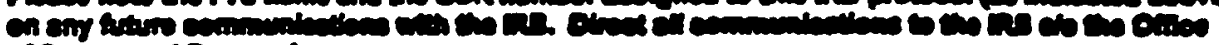

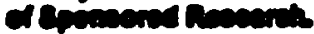

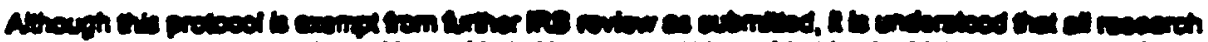

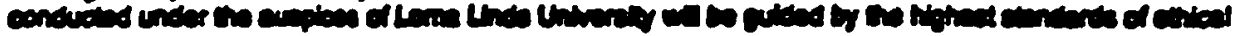
enchet

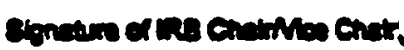
I/es/an

(n)


Appendix J

Letter to Physicians, Loma Linds University Cancer Instrute

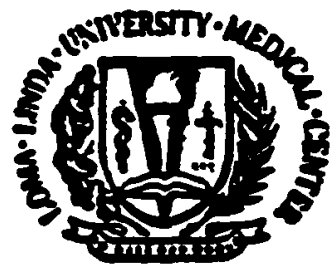

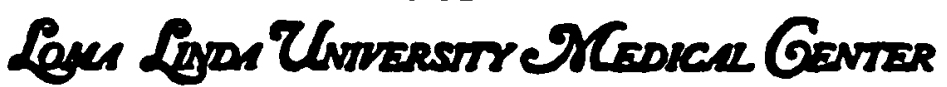

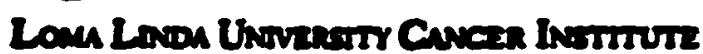

Deta: dest 15. 9000

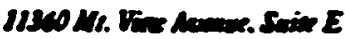

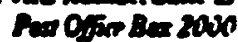

Lon Lind, celifmir 2335

(Bos) resecoss

To:

From: Alan knos Mo

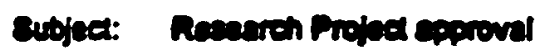

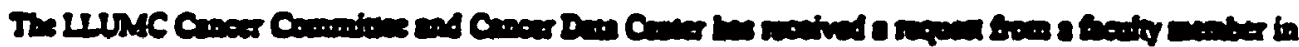

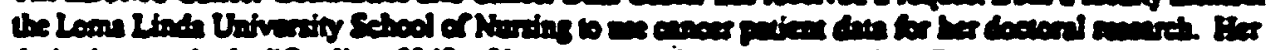

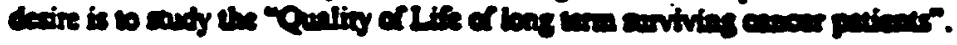

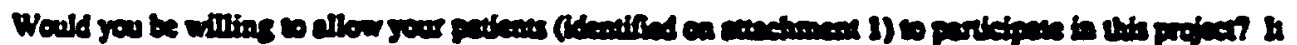

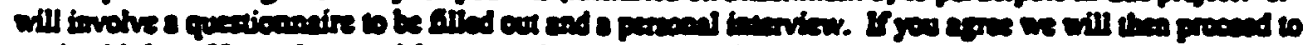

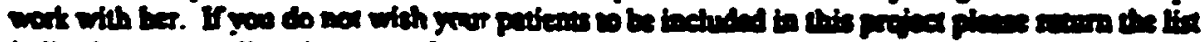

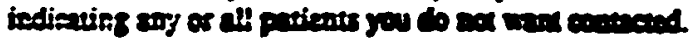

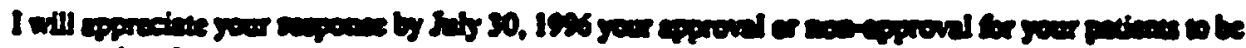
cunced w the:
Croces Din Conter
Herod Bare Ens.
Fit: CS161
Fax: $\cos$

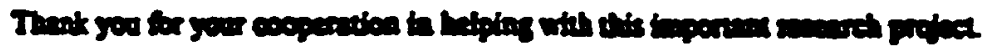
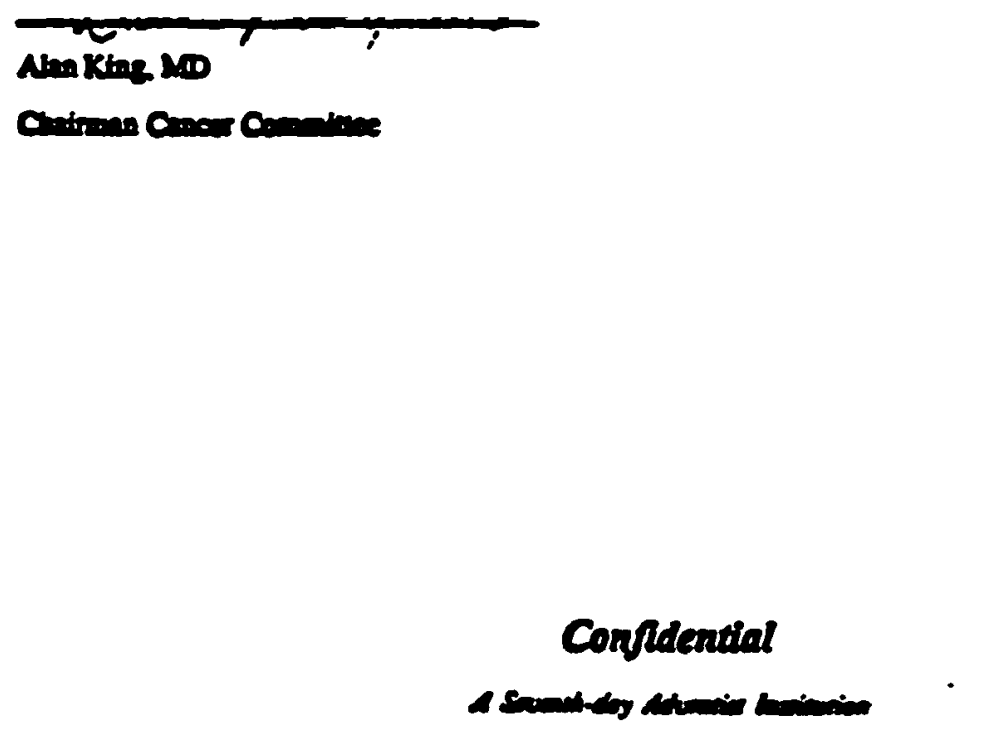


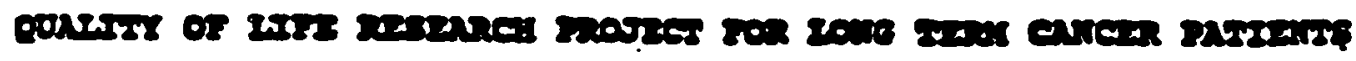

Datsente unas uns

I give persilesion for the abovi mand pationti to be contacted for posibie ontry lnto the resenteh profect 18 thoy afree to do so.

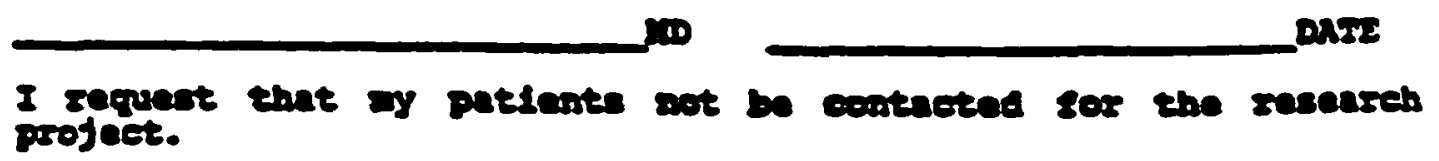

ID

Dare 
Appendix K

Letter to Physicians Desert Sierra Cancer Surveillance Program (Region 5)

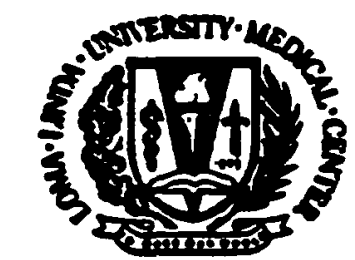

\section{Som Linga Whrvaraty Mearar Ganter

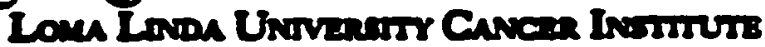

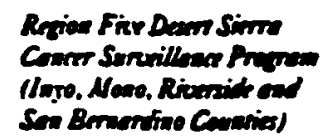

August 29, 1996

Physictan's Name

Street Address

city. State zip

Dear Physiclan's Name:

The Desert S1erra Cancer Surveldlance Program Reglonal Cancer Registry (Region 5). Is collaborating with a certified oncology nurse researcher to describe quality of life for long-term cancer susvivors. Patients included in this study will be breast cancer patients 35 years or more and who have a diagnosis year between 1988 and 1991.

Ihis letzer is written to inform you that we will be consastirg yeur patient (s). who was dignosed with breast eancer at 35 yeass of age or more. The patient (a) can to our attention through the state Cancer Reporting System. We wdll Invite the patient to complete a set of cuestlonnalies that masures their self-esteem, coclal oupport, lenzod resourcefulness and ounlity of life includsng information about thcmelves and theif cancer history. When the petdent consents, the set of questionnaires will be malled to them for their remponse.

The following individual(s) has been sdentifled as your pationt (s):

\section{Patient (8) Name}

If you have any reason to belleve we hould not enthet your

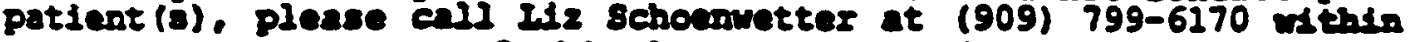

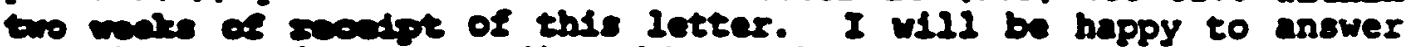
guestions you pave segarding this atudy.

If the patlent do decened, we would appreclate receiving that Information including the date they pasead away.

Sincercly.

Iel1 Pedro, RN
John n. Mozgan, DI. РH

Cancer Rpldemiologst 
Appendix L

Letter to Potential Participants, Loma Linda University Cancer Institute

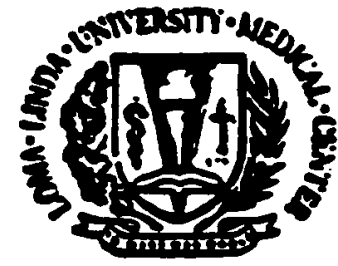

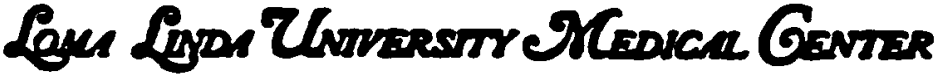

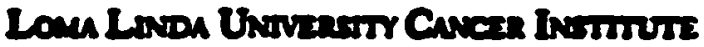

June 27. 2996

Dens Iriona.

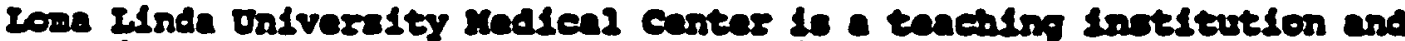

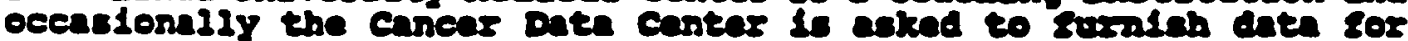

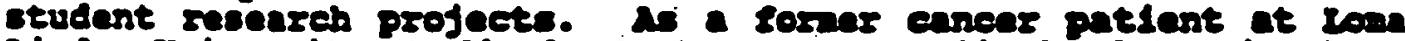
Inda Dafversity rodieal conter your nodeal daten is lopt

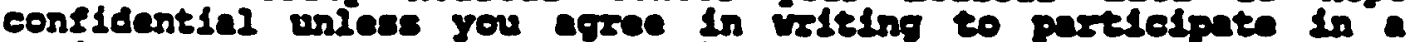

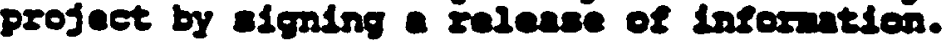

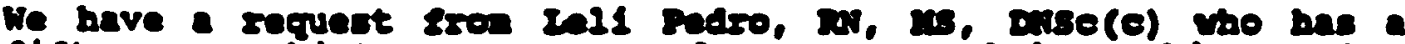

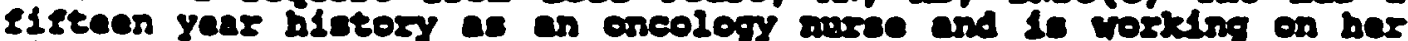
disertation for ber doctoral dofree. oh is lookfng at the

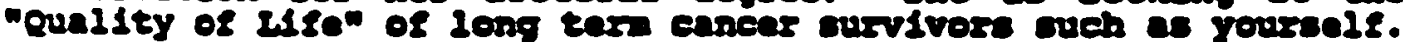
If you arre to aliow us to oive her your whe and addrabe the ulil then contact you and ask you to 2111 out a cot os puostenndres

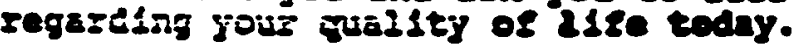

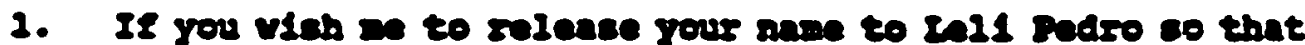
you way be ineluded in this otudy plence indiente by

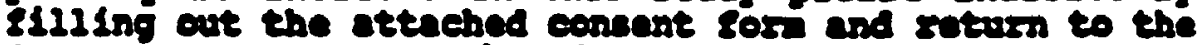
Cancar Date canter in the anclosed anvalope. (bec attachants)

2. If you prefor not to partielpate pleane deatroy this notice and no surther eontact usil be ande to you regarding endo researeh project.

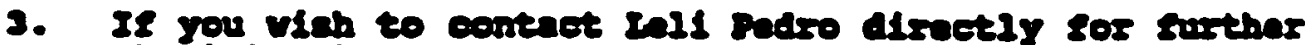
clardeleation of the study before you nake your elnal

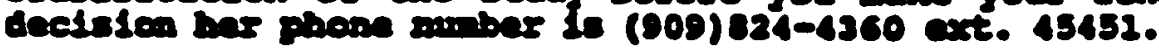

Iour partielpetion vild be inpostant to the struse of other eancer patsante.

sinearaly.

2. Ilminde Loder, Director

Cancer Data Canter

Iome Ifide Oniveraity Canear Institute 
Appendix M

Letter to Potential Participants

Desert Sierra Cancer Surveillance Progrum (Region 5)

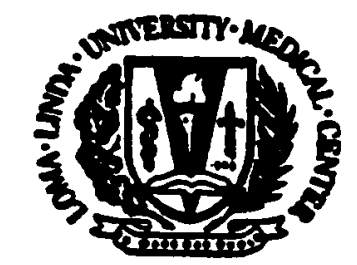

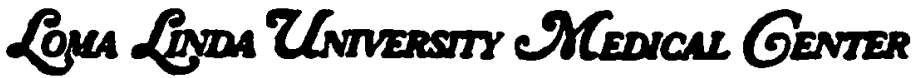

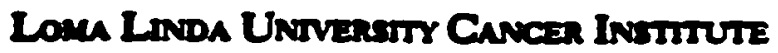

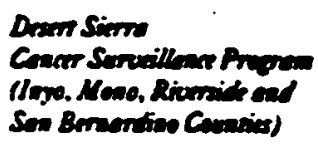

Patient Nome

Street Address

city State Zip

Dear (pariem Name)

Leli Pedro, en oncology mure researeber, in colleborntion with the Desert Siern Cuncer Surveillance Program, is conducting a mudy to begin to deceribe the quality of life for long-term cencer enrvivors. Your physicien, (MD neme) has been contected regarding your potential paricipetion in this atudy.

About four in ten pereons diagnosed with concer will be dive five years after diagnosis. Adtitionally; the diagrosis of cancer can change one's life forever. For many, cancer will be a surviveble disease. Thus it is importan to dencribe and to begin to understand the quality of ife specifically for long-term enseer furvivore?

You are being invited to participate in this sucty becase of your length of arvival. An additiond eriterion for sudy perticipetion is the you ere reamence free today. This meens you are

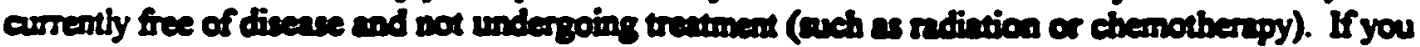
meet this criterion, and wish to participate in this sudy, please rend over the enclosed informed

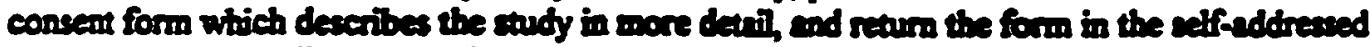
envelope at your eartiex courvience.

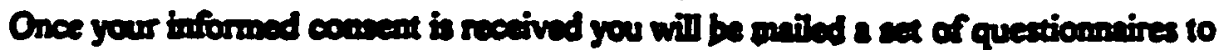
complete and return to ux. Participation in this ctudy is entintly vohumery and will sot aher your arrem care or follow up in exy way. If you have edditiond quextions or concens reording the

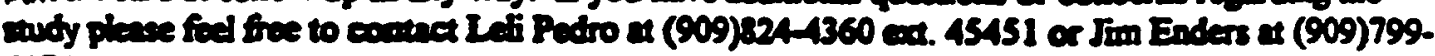
6174.

Thank you very mech for consideries participetion in this importan andy.

Sincerely,

Leli Pedro, RN, DNSc (c) 


\title{
Appendix N
}

\author{
Informed Consent Form
}

(Page 1 of 3)

\author{
Informed Consent \\ The relationship of Self-esteem, Learned Resourcefulness \\ and Social Support to Quality of Life for \\ Long-Term Cancer Survivors
}

I have been invited by Leli Pedro, a registered oncology nurse and a doctoral candidate in the Philip Y. Hahn School of Nursing at the University of San Diego, to participate in a research study. Before I give my consent, I will read the following and ask whatever questions I may have.

\section{Purpose of The Study}

The purpose of this study is to learn more about how long-term cancer survivors feel about themselves, their belief about how effectively they cope with manageable levels of stress, where they get and from whom they get social support, and how this relates to their quality of life.

\section{Procedure}

I understand that if I agree to be in the study, I will complete the set of questionnaires which will take approximately 45-60 minutes. The questionnaires ask about how I feel about myself, my belief about how effectively I cope with manageable levels of stress, where I get and from whom I get social support, and my health-related quality of life. I will also answer some general questions about myself such as age, ethnicity and marital status. Once I complete and mail the set of questionnaires to the investigator I will be finished with my participation in the study.

\section{Risks}

I understand there are no physical risks to me by participating in this study. I understand that in the process of filling out the questionnaires I may be reminded of uncomfortable feelings that have surrounded my cancer experience. 
(Page 2 of 3)

Informed Consent for Participation in a Study on the Relationship of Self-Esteem Learned Resourcefulness and social Support to Health-Related Quality of Life for Long-Term Cancer Survivors

\section{Benefits}

I have been told that I will derive no direct benefit from participating in this study. However, I may feel satisfaction knowing I have contributed to a study that may benefit other survivors life myself. It is hoped that other long-term cancer survivors may benefit from the findings of this study.

\section{Participant's Rights}

I understand my participation in this study is completely voluntary. I am free to refuse my permission to bein this study and may withdraw from the study at any time. I have been told that my decision whether or not to participate or terminate participation in this study will not affect my present or future medical care. I understand that there is no agreement, either written or verbal, beyond that expressed in this consent form.

\section{Confidentiality}

I have been promised anonymity and have been told that any published document that results from this study will not disclose my identity.

\section{Cost}

I understand there is no cost to me for participating in this study.

Reimbursement

I understand there will be no reimbursement to me for participating in this study.

Impartial Third Party Contact

I have been told that if I wish to contact an impartial third party not associated with this study regarding any complaint or concern I may have about the study, I may contack Jean Fankhanel, Patient Representative, Loma Linda University Medical Center, Loma Linda, CA 92354, phone (909) 824-4647 for information and assistance. 
Survivors HRQL 160

(Page 3 of 3)

Informed Consent for Participation in a Study on the Relationship of Self-Esteem. Learned Resourcefulness and social Support to Health-Related Ouality of Life for Long-Term Cancer Survivors

Informed Consent Statement

"I have read the contents of this consent form. My questions concerning this study have been answered to my satisfaction. I hereby give my voluntary consent to participate in this study. Signing this consent form does not waive my rights nor does it release the investigator or sponsors from their responsibilities.

I may call the investigator, Leli Pedro, RN, MS, DNSc (c) during office hours at (909) 8244360 Ext. 45451, or during non-office hours at (909) 796-8232 if I have any additional questions or concerns.

I understand I will be sent a copy of this informed consent form.

I, the undersigned, understand the above explanations and on that basis, I give consent to my voluntary participation in this study."

Signature of Subject

Witness

Printed Name of Subject

Subject's Address (for consent form Mailing)

Signature of Investigator
Phone Number

Date 
Appendix 0

Cover Letter

\section{Dear Cancer Survivor,}

Thank you for agreeing to participate in this important study. The information from this study will assist nursing to understand and enhance quality of life for future cancer survivors like yourself.

Find enclosed the set of questionnaires which will take 45-60 minutes to fill out. Please read the instructions carefully. Please return this set of questionnaires in the large brown envelope provided for you within the next 2 weeks. If you have further questions feel free to contact me at (909) 824-4360 ext. 45451.

Sincerely,

Leli Pedro RN, MS, DNSc (c) 